\title{
Iluminação Baseada em Séries Temporais de Imagens com Aplicações em Realidade Mista
}

\author{
Caio de Freitas Valente
}

DissertaÇÃo APRESENTADA

$\mathrm{AO}$

Instituto De Matemática e Estatística

DA

Universidade DE SÃo PAUlo

PARA

OBTENÇÃO DO TÍTULO

$\mathrm{DE}$

Mestre em CiÊnCIAS

Programa: Ciência da Computação

Orientador: Prof. Dr. Marcel Parolin Jackowski

Durante o desenvolvimento deste trabalho o autor recebeu auxílio financeiro da CAPES 


\section{Iluminação Baseada em Séries Temporais de Imagens com Aplicações em Realidade Mista}

Esta versão da dissertação contém as correções e alterações sugeridas pela Comissão Julgadora durante a defesa da versão original do trabalho, realizada em 06/09/2016. Uma cópia da versão original está disponível no Instituto de Matemática e Estatística da Universidade de São Paulo.

Comissão Julgadora:

- Prof. Dr. Marcel Parolin Jackowski (orientador) - IME-USP

- Prof ${ }^{a}$. Dra ${ }^{a}$. Fátima de Lourdes dos Santos Nunes Marques - EACH-USP

- Prof. Dr. Roberto Hirata Junior - IME-USP 


\section{Agradecimentos}

À minha família e meus pais, Zeo e Cecilia. Ao meu orientador Marcel Jackowski, por todo o apoio e suporte. Ao meu colega Thiago de Gouveia Nunes pela participação nos experimentos preliminares. À Capes pelo apoio financeiro. 


\section{Resumo}

\section{Valente, C. F. Iluminação Baseada em Séries Temporais de Imagens com Aplica- ções em Realidade Mista.}

Dissertação (Mestrado) - Instituto de Matemática e Estatística, Universidade de São Paulo, São Paulo, 2016.

A estimação da iluminação é essencial para aplicações de realidade mista que se propõem a integrar elementos virtuais a cenas reais de maneira harmoniosa e sem a perda do realismo. Um dos métodos mais utilizados para fazer essa estimação é conhecido como iluminação baseada em imagens (Image Based Lighting - IBL), método que utiliza light probes para capturar a intensidade da iluminação incidente em uma cena. Porém, IBL estima a iluminação incidente apenas para um determinado instante e posição. Nesta dissertação, será avaliado um modelo de iluminação que utiliza séries temporais de imagens de light probes, obtidas de maneira esparsa em relação ao tempo, para renderizar cenas em instantes arbitrários. Novas cenas contendo objetos virtuais poderão ser renderizadas utilizando imagens de light probes artificiais, geradas a partir das amostras da iluminação originais. Diferentes funções de interpolação e aproximação são avaliadas para modelar o comportamento luminoso. As imagens finais produzidas pela metodologia também são verificadas por voluntários, de modo a determinar o impacto na qualidade de renderização em aplicações de realidade mista. Além da metodologia, foi desenvolvida uma ferramenta de software em forma de plugin para facilitar o uso de IBL temporalmente variável, permitindo assim a renderização realística de objetos virtuais para instantes arbitrários.

Palavras-chave: iluminação baseada em imagens, light probe, realidade mista. 


\section{Abstract}

Valente, C. F. Time Series Image Based Lighting with Mixed Reality Applications.

Dissertação (Mestrado) - Instituto de Matemática e Estatística, Universidade de São Paulo, São Paulo, 2016.

Lighting estimation is essential for mixed reality applications that strive to integrate virtual elements into real scenes in a seamlessly fashion without sacrificing realism. A widely used method for lighting estimation is known as Image Based Lighting (IBL), which utilizes light probes to determine incident light intensity within a scene. However, IBL estimates light incidence only for a given time and position. In this dissertation, we assess a lighting model based on a time series of light probe images, obtained sparsely, to render scenes at arbitrary times. New scenes containing virtual objects can then be rendered by using artificial light probe images, which are generated from the original light samples. Different types of interpolation and approximation functions were evaluated for modeling lighting behavior. The resulting images were assessed for the impact in rendering quality for mixed reality applications by volunteers. In addition to the methodology, we also developed a software plugin to simplify the use of temporally variable IBL, allowing realistic rendering of virtual objects for arbitrary times.

Keywords: image based lighting, light probe, mixed reality. 


\section{Sumário}

Lista de Abreviaturas $\quad$ vi

Lista de Figuras $\quad$ vii

Lista de Tabelas $\quad$ xiii

1 Introdução 1

1.1 Motivação . . . . . . . . . . . . . . . . . . . 4

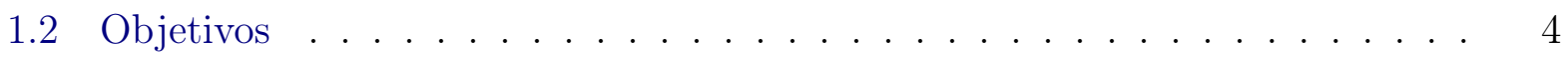

2 Conceitos $\quad 6$

2.1 Realidade Mista . . . . . . . . . . . . . . . . 6

2.2 Iluminação . . . . . . . . . . . . . . . . . . . . . . 7

2.3 Imagens HDR . . . . . . . . . . . . . . . . . . . . . 10

2.4 Iluminação Baseada em Imagens - IBL . . . . . . . . . . . . . . . . 13

2.5 Renderização Diferencial . . . . . . . . . . . . . . . . . . . 17

3 Trabalhos Relacionados $\quad 20$

4 Metodologia $\quad 25$

4.1 Obtenção das Imagens de Light Probes . . . . . . . . . . . . . . . . . . . . 26

4.2 Interpolação das Imagens de Light Probes . . . . . . . . . . . . . . . . . 27

4.3 Comparação entre Light Probes Reais e Artificiais . . . . . . . . . . . . . . . 27 
4.4 Experimento RM . . . . . . . . . . . . . . . . . 28

5 Resultados $\quad 30$

5.1 Experimento Preliminar . . . . . . . . . . . . . . . 30

5.2 Coleta de Dados . . . . . . . . . . . . . . . . . . . 35

5.3 Primeiro Experimento . . . . . . . . . . . . . . . . . . 39

5.4 Segundo Experimento . . . . . . . . . . . . . . . . . 45

6 Conclusões $\quad 54$

$\begin{array}{ll}\text { A Interpolações } & 56\end{array}$

B Aproximações $\quad 64$

$\begin{array}{ll}\text { C Curvas Paramétricas } & 68\end{array}$

$\begin{array}{ll}\text { D Projeção Ortográfica } & 70\end{array}$

$\begin{array}{lll}\text { E Texturas } & 71\end{array}$

$\begin{array}{lll}\text { F } & \text { Implementação } & 73\end{array}$

F.1 Software para Interpolação e Aproximação . . . . . . . . . . . . . . . . 73

F.2 Plugin Maya ${ }^{\circledR} \ldots \ldots \ldots \ldots \ldots \ldots \ldots \ldots$. . . . . . . . . . . . . . . . . . . .

G Dados e Resultados $\quad 83$

Referências Bibliográficas $\quad 1$ 


\section{Lista de Abreviaturas}

BRDF Função de distribuição de refletância bidirecional (Bidirectional Reflectance Distribution Function)

BSDF Função de distribuição de espalhamento bidirecional (Bidirectional Scattering Distribution Function)

BTDF Função de distribuição de transmissão bidirecional (Bidirectional Transmittance Distribution Function)

CG Computação Gráfica

GPS Sistema de posicionamento global (Global Positioning System)

HDR Grande alcance dinâmico (High Dynamic Range)

IBL Iluminação Baseada em Imagens (Image Based Lighting)

LDR Pequeno alcance dinâmico (Low Dynamic Range)

RA Realidade Aumentada

RM Realidade Mista 


\section{Lista de Figuras}

1.1 Esquerda: Um mecânico usando um monitor executa uma tarefa de manutenção em um motor Rolls Royce DART 510. Direita: A visão através do monitor exibe informações usando realidade aumentada para auxiliar o mecânico (Henderson e Feiner, 2007). Além de instruções para cada passo, note o objeto tridimensional inserido na imagem com o propósito de indicar e facilitar o que deve ser feito pelo mecânico. . . . . . . . . . . . . . . 1

1.2 Visão através de óculos de realidade aumentada das estruturas internas do corpo humano. (Christoph Bichlmeier e Navab, 2007) . . . . . . . . . . 2

1.3 Imagem de um piloto equipado com um HMD. (Robertatac, 2011) . . . . . . 2

1.4 Imagem de um light probe. (Bailey, 2007) . . . . . . . . . . . . . . . 3

2.1 Contínuo da virtualidade. (Milgram e Kishino, 1994) . . . . . . . . . . 6

2.2 Representação da função de espalhamento - BSDF. (Jurohi, 2006) . . . . . . 8

2.3 (a) exemplo de iluminação global (Tanski, 2004a), (b) iluminação local (Tanski,

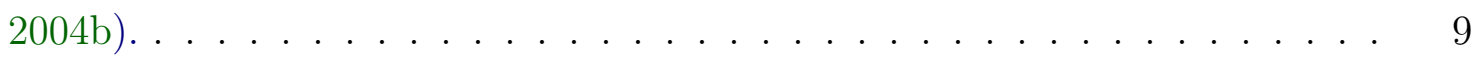

2.4 Componentes do modelo de reflexão Phong. (Smith, 2006) . . . . . . . . . . 9

2.5 Diagrama das variáveis presentes na iluminação de uma superfície usando o modelo Phong. . . . . . . . . . . . . . . . . . . . . 10

2.6 Exemplo de esfera espelhada que pode ser usada como light probe. . . . . . . 13

2.7 Imagem obtida através de uma câmera utilizando uma lente do tipo olho de peixe. (Salgado, 2010) . . . . . . . . . . . . . . . . 14

2.8 Diagrama usado para determinar as coordenadas de textura de um light probe. (Akenine-Möller et al., 2008) . . . . . . . . . . . . . . . 14

2.9 (a) mapa esférico, (b) mapa angular. . . . . . . . . . . . . . . . 16 
2.10 (a) mapa cúbico, (b) mapa latitude longitude. . . . . . . . . . . . . . . 16

2.11 Comportamento dos raios de luz durante renderização, utilizando IBL. (Debevec,

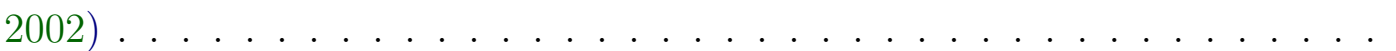

2.12 Da esquerda para direita: (a) $L$ e $L_{o b j}$, (b) $L_{n o o b j}$ e $\alpha$, (c) $(1-\alpha)\left(L_{o b j}-L_{n o o b j}\right)$ e $L_{\text {Final }}$ (Debevec, 1998) . . . . . . . . . . . . . . . . . . . .

3.1 Imagem de um light probe adquirido na catedral Grace em São Francisco e objetos virtuais renderizados utilizando esse light probe. (Debevec, 1998) . .

3.2 Esferas virtuais inseridas em uma cena externa. (Madsen e Lal, 2011) . . . .

3.3 Buddha e luminária virtuais inseridos em cena real. Note que a luminária é capaz de iluminar objetos reais. (Knecht et al., 2012) . . . . . . . . . . . .

4.1 Diagrama representando as etapas existentes para utilizar IBL temporalmente variável e obter de imagens finais realísticas no contexto de RM. Retângulos representam dados, já as elipses representam métodos. As bordas espessas indicam as etapas em que as verificações ocorrem. Além da comparação entre os light probes artificiais e reais, a qualidade das imagens finais, geradas a partir dos mapas de iluminação artificiais, também é avaliada. Note que $L$, $L_{o b j}, L_{n o o b j}$ e $\alpha$ representam respectivamente, o plano de fundo, a cena local com os objetos virtuais, a cena local e a máscara para os objetos virtuais (Seção 2.5) . . . . . . . . . . . . . . . . . . . . . .

4.2 Diagrama que representa o teste baseado na comparação entre imagens de light probes reais e artificiais. . . . . . . . . . . . . . .

4.3 Exemplo de marcador fiducial. . . . . . . . . . . . . . . . . . .

5.1 Série temporal de imagens de light probes obtida em um ambiente externo. A aquisição teve início às 10:45 e término às $20: 00 \ldots . . . . . .$.

5.2 Série temporal de imagens de light probes obtida em um ambiente interno. A aquisição teve início às 11:00 e término às 19:45 . . . . . . . . . . . . . . . .

5.3 (a) Imagem de um light probe na cena externa às 18:05, (b) imagem interpolada por Gauss's Forward, (c) diferença entre a imagem original e interpolada. 32

5.4 (a) Imagem de um light probe na cena externa às 18:05, (b) imagem gerada utilizando interpolação linear, (c) diferença entre a imagem original e interpolada. . . . . . . . . . . . . . . . . . . . . . 
5.5 (a) Imagem de um light probe na cena interna às 18:45, (b) imagem gerada utilizando interpolação linear, (c) diferença entre a imagem original e interpolada. . . . . . . . . . . . . . . . . . . . .

5.6 Paralelepípedo branco usado para realizar as comparações entre as cenas reais e virtuais. . . . . . . . . . . . . . . . . . . . . . . . . .

5.7 (a) cena externa às 18:05, (b) paralelepípedo renderizado utilizando light probe gerado a partir da interpolação linear, (c) diferença. . . . . . . . . . . . . .

5.8 (a) cena interna às 18:45, (b) paralelepípedo renderizado utilizando light probe gerado a partir da interpolação linear, (c) diferença. . . . . . . . . . . . . . .

5.9 Série temporal de imagens de light probes obtida durante a primeira aquisição. Início às 10:52 e término às 20:24 com período de aproximadamente 30 minutos entre cada tomada. . . . . . . . . . . . . . . . . .

5.10 Diagrama que mostra o procedimento adotado durante a segunda aquisição. As elipses representam os passos em que houveram aquisições de imagens. . .

5.11 Série temporal de imagens de light probes obtida durante a segunda aquisição. Início às 15:00 e término às 20:37, com período de aproximadamente 30 minutos entre cada tomada. . . . . . . . . . . . . . . . . . . . . 37

5.12 Planos de fundo utilizados no segundo experimento em diferentes horários. 38

5.13 Plano de fundo utilizado para geração dos keyframes do vídeo em diferentes horários. ........... .

5.14 Imagem utilizada para determinar o coeficiente de reflexão do light probe. (a) intensidade amostrada do objeto, (b) intensidade amostrada da reflexão do objeto. . . . . . . . . . . . . . . . . . . .

5.15 (a) Imagem de um light probe obtida às 12:22, (b) imagem gerada utilizando interpolação linear, (c) diferença. . . . . . . . . . . . . . . . . . . . . . . . . 40

5.16 (a) Imagem de um light probe obtida às 12:22, (b) imagem gerada utilizando aproximação Bézier cúbica, (c) diferença. . . . . . . . . . . . . . . . . . . . . 40

5.17 (a) Imagem de um light probe obtida às 15:53, (b) imagem gerada utilizando interpolação linear, (c) diferença. . . . . . . . . . . . . . . . . . . .

5.18 (a) Imagem de um light probe obtida às 15:38, (b) imagem gerada utilizando interpolação linear, (c) diferença. . . . . . . . . . . . . . . . . . . 
5.19 (a) Imagem de um light probe obtida às 15:38, (b) imagem gerada utilizando aproximação Bézier cúbica, (c) diferença. . . . . . . . . . . . . . . .

5.20 (a) Imagem de um light probe obtida às 17:40, (b) imagem gerada utilizando interpolação linear, (c) diferença. . . . . . . . . . . . . . . . . . .

5.21 Gráfico de intensidades das imagens dos light probes originais e artificiais (Bézier Cúbica) em relação ao tempo, para a primeira série temporal. . . . . .

5.22 Gráfico de intensidades das imagens dos light probes originais e artificiais (Linear) em relação ao tempo, para a primeira série temporal. . . . . . . . .

5.23 Gráfico de intensidades das imagens dos light probes originais e artificiais (Bézier) em relação ao tempo, para a primeira série temporal. . . . . . . . .

5.24 Gráfico de intensidades das imagens dos light probes originais e artificiais (Bézier Cúbica) em relação ao tempo, para a segunda série temporal. . . . . .

5.25 Gráfico de intensidades das imagens dos light probes originais e artificiais (Linear) em relação ao tempo, para a segunda série temporal. . . . . . . . .

5.26 Gráfico de intensidades das imagens dos light probes originais e artificiais (Bézier) em relação ao tempo, para a segunda série temporal. . . . . . . . . . 45

5.27 Uma das imagens $(\# 3)$ sem objetos virtuais utilizada nos testes. . . . . . . .

5.28 Imagem (\#11) com diversos objetos virtuais: lata de Coca-Cola ${ }^{\circledR}$ da esquerda e direita, canetas na parte de cima e bola de basquete. . . . . . . . . . . . . 47

5.29 Imagem $(\# 15)$ com uma lata de Coca-Cola ${ }^{\circledR}$ virtual. . . . . . . . . . . . . 48

5.30 Gráfico que representa a porcentagem de acertos para cada imagem. O eixo superior indica o horário em que foi adquirida a imagem original, não modificada. 49

5.31 Imagem $(\# 10)$ com os objetos virtuais em destaque. . . . . . . . . . . 50

5.32 Imagem $(\# 13)$ com os objetos virtuais em destaque. . . . . . . . . . . 50

5.33 Imagem $(\# 22)$ com os objetos virtuais em destaque. . . . . . . . . . . . 51

5.34 Imagem (\#25). Todos os objetos presentes nessa imagem são virtuais. . . . . 51

5.35 Região de interesse da imagem $(\# 14)$ que teve objetos reais indicados como virtuais. Área em vermelho representa os objetos virtuais. Ao ser questionado a respeito dessa imagem, o voluntário afirmou que continha objetos virtuais, pois a sombra da caneta central estava "errada". . . . . . . . . . . . . . . . . 
5.36 (a) keyframe do vídeo renderizado utilizando a iluminação proveniente de uma imagem de light probe gerada pela aproximação Bézier cúbica, (b) Keyframe do vídeo renderizado utilizando a iluminação proveniente de uma imagem de light probe gerada pela interpolação linear. Note que os objetos virtuais na imagem (a) estão mais claros, em especial a bola de basquete, e sua iluminação não está consistente com a iluminação do plano de fundo. . . . . . . . . . . . . .

A.1 Conjunto de imagens de light probes como amostras de uma função desconhecida. Funções de interpolação podem ser usadas para obter novas imagens de light probes.

A.2 Dois segmentos de curva, $S$ e $R$, com continuidade $C^{0}$. Note que apesar das curvas coincidirem em $S_{3}$ e $R_{0}$, apresentam derivadas diferentes nesse ponto, portanto, a continuidade paramétrica é $C^{0}$. (Oyster, 2014) . . . . . . . . . . 57

A.3 Dois segmentos de curva, $S$ e $R$, com primeiras derivadas iguais no ponto de junção $\left(S_{3}=R_{0}\right)$ e com continuidade paramétrica $C^{1}$. (Fractsofphotos, 2009) 57

A.4 Interpolação linear. . . . . . . . . . . . . . . . . . . . . . . 58

A.5 Interpolação de lagrange. . . . . . . . . . . . . . . . . . . . . 58

A.6 Diferenças centrais para frente. . . . . . . . . . . . . . . . . . . . 59

A.7 Interpolação Gauss's Forward. . . . . . . . . . . . . . . . . . . . . . . . 60

A.8 Diferenças centrais para trás. . . . . . . . . . . . . . . . . . . . . . . . . 60

A.9 Interpolação Gauss's Backward. . . . . . . . . . . . . . . . . . . . . 61

A.10 Interpolação de Stirling. . . . . . . . . . . . . . . . . . . . . . . . . 61

A.11 Interpolação quadrática. . . . . . . . . . . . . . . . . . . . . . . . . . 62

A.12 Interpolação spline cúbica natural. . . . . . . . . . . . . . . . . . . . 63

B.1 Aproximação Bézier quadrática. . . . . . . . . . . . . . . . . . . . 65

B.2 Aproximação Bézier cúbica. . . . . . . . . . . . . . . . . . 65

B.3 Aproximação B-Spline cúbica. . . . . . . . . . . . . . . . . . . . 67

D.1 Projeção ortogonal do objeto em três planos distintos. (Emok, 2008) . . . . . 70 
E.1 Em coordenadas de imagem $I m_{X}$ e $I m_{Y}$ representam a largura e altura, em pixels, da imagem. Já em coordenadas de textura, a largura e a altura da imagem correspondem a valores $(u, v)$ definidos no intervalo $[0.0,1.0]$. . . . 72

F.1 Abrindo o gerenciador de plugins do Maya ${ }^{\circledR} \ldots \ldots . . . . . .78$

F.2 Uso de formato Hora/Minuto para especificação do instante de aquisição das imagens "b2.tif"e "r2.tif". . . . . . . . . . . . . . . . . . . . . . . 79

F.3 Atribuição automática da imagem interpolada. Note que mental-ray ${ }^{\circledR}$ é o renderizador selecionado e existe na cena um objeto do tipo IBL. . . . . . . . 80 


\section{Lista de Tabelas}

2.1 Intensidades de fontes de luminosas. (Wandell, 1995) . . . . . . . . . . . . . 11

2.2 Bits por pixel para imagens em formato HDR. . . . . . . . . . . . . . 11

3.1 Comparação de métodos para estimar a iluminação de uma cena. . . . . . . . 24

5.1 Porcentagem de acertos. . . . . . . . . . . . . . . . . . . . . . 48

F.1 Comparação do custo computacional dos métodos de interpolação e aproximação implementados. . . . . . . . . . . . . . . . . . . . . 77

G.1 Distâncias $L^{2}$ normalizadas resultantes do primeiro experimento, com o conjunto de dados da primeira aquisição. . . . . . . . . . . . . . . . . 83

G.2 Distâncias $L^{2}$ normalizadas resultantes do primeiro experimento, com o conjunto de dados da primeira aquisição. . . . . . . . . . . . . . . . . . . 84

G.3 Distâncias $L^{2}$ normalizadas resultantes do primeiro experimento, com o conjunto de dados da segunda aquisição. . . . . . . . . . . . . . . . . . . . 84

G.4 Distâncias $L^{2}$ normalizadas resultantes do primeiro experimento, com o conjunto de dados da segunda aquisição. . . . . . . . . . . . . . . . . 85

G.5 Respostas dos questionários para o grupo com conhecimentos em CG. . . . . 86

G.6 Respostas dos questionários para o grupo sem conhecimentos em CG. . . . . 87

G.7 Respostas dos questionários sem distinção de grupos por conhecimento em CG. 88 


\section{Capítulo 1}

\section{Introdução}

Realidade Mista (RM) consiste na adição de elementos virtuais a cenas reais por meio de Computação Gráfica (CG). O uso de RM tem como objetivo enriquecer o mundo real com aplicações nas mais diversas áreas, como navegação, medicina, entretenimento e treinamento militar. A Figura 1.1 mostra um exemplo de aplicação de RM com o projeto ARMAR (Henderson e Feiner, 2007), Augmented Reality for Maintenance and Repair, que tem como objetivo auxiliar na execução de tarefas relacionadas a manutenção e reparo.

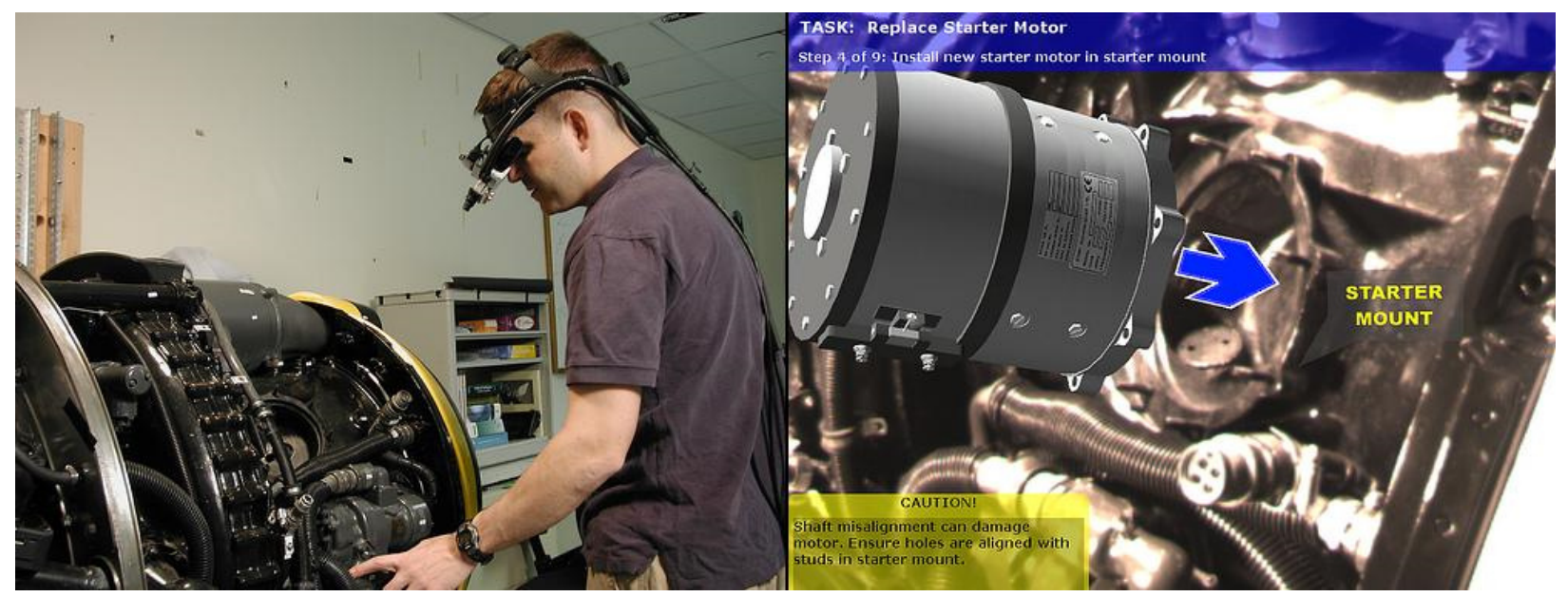

Figura 1.1: Esquerda: Um mecânico usando um monitor executa uma tarefa de manutenção em um motor Rolls Royce DART 510. Direita: A visão através do monitor exibe informações usando realidade aumentada para auxiliar o mecânico (Henderson e Feiner, 2007). Além de instruções para cada passo, note o objeto tridimensional inserido na imagem com o propósito de indicar e facilitar o que deve ser feito pelo mecânico.

Outro exemplo de aplicação de RM é descrito por (Christoph Bichlmeier e Navab, 2007). A aplicação permite a visualização da anatomia interna do corpo humano em tempo real, aumentando a percepção tridimensional do médico e permitindo o desenvolvimento de novas técnicas de treinamento. 


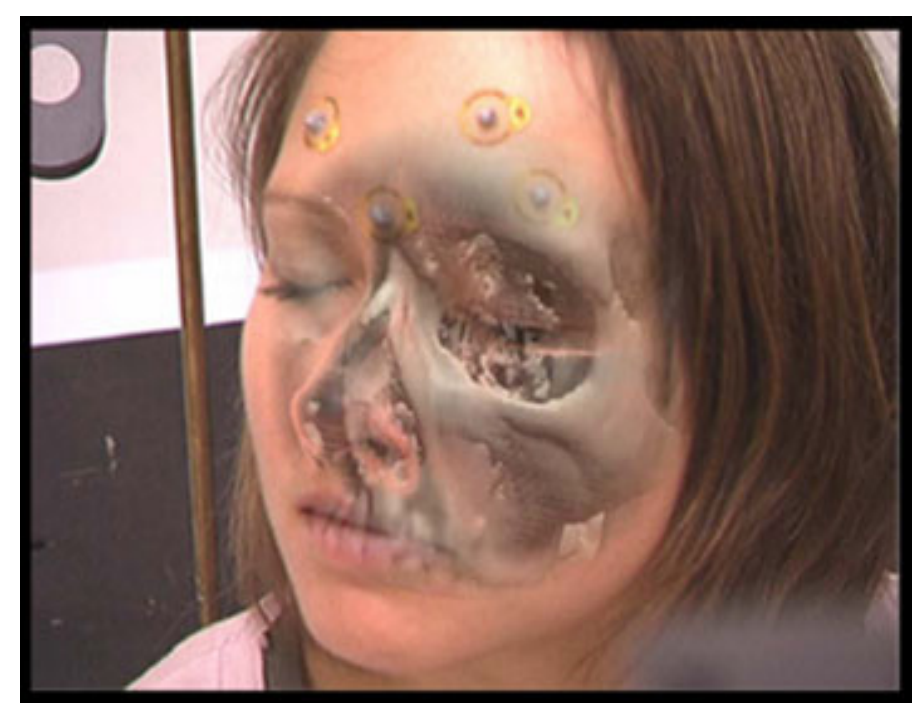

Figura 1.2: Visão através de óculos de realidade aumentada das estruturas internas do corpo humano. (Christoph Bichlmeier e Navab, 2007)

O uso de HMDs (Helmet Mounted Display, Figura 1.3) em aviões militares também pode ser citado entre as aplicações de RM (AFLCMC/WWU, 2015). Esse tipo de sistema combina e fornece ao piloto dados de diversos sensores, informações de navegação e aquisição de alvos. O objetivo desse tipo de sistema é aumentar a percepção espacial do piloto, e com isso melhorar sua eficácia e capacidade de sobrevivência.

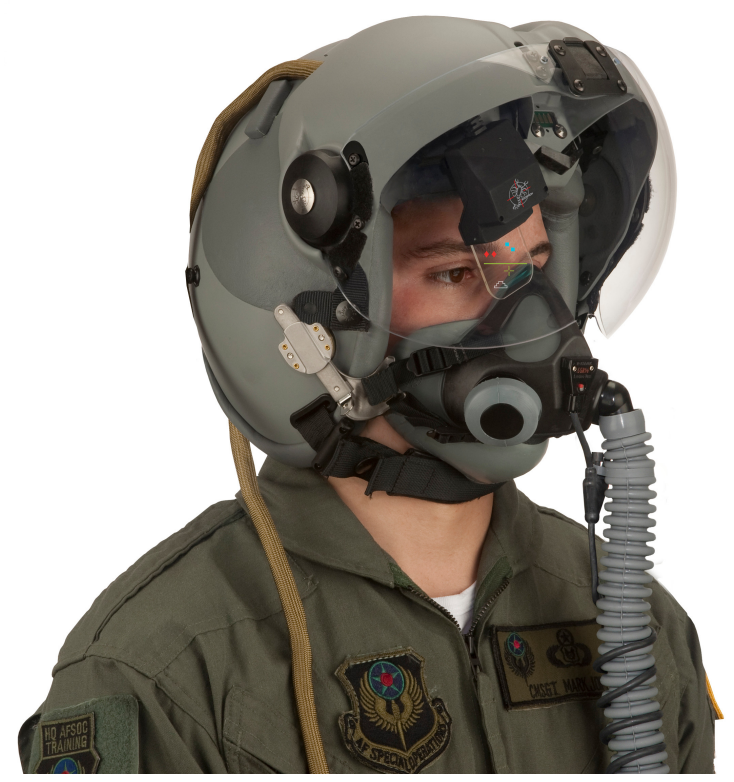

Figura 1.3: Imagem de um piloto equipado com um HMD. (Robertatac, 2011)

Um requisito para algumas aplicações de RM é o realismo. Um exemplo de aplicação não realista pode ser visto na Figura 1.1, com o motor de arranque virtual iluminado de maneira diferente do restante da cena. O realismo é um conceito subjetivo, porém, um sistema de realidade mista pode ser classificado como convincentemente realista (Jacobs e Loscos, 2006) quando não é possível distinguir os objetos virtuais dos reais, para tal algumas das características desejadas (Sato et al., 1999) são: 
- consistência geométrica: objetos inseridos precisam estar posicionados corretamente na cena

- consistência luminosa: tonalização dos objetos virtuais precisa ser equivalente à dos objetos reais. Além disso, sombras consistentes com a dos objetos reais também devem ser geradas

- consistência temporal: movimentos dos objetos virtuais e reais devem ser sincronizados

Um dos mais complexos elementos a serem reproduzidos são aqueles relacionados à consistência luminosa. Sem a correta tonalização, os objetos virtuais destoam do restante da cena eliminando o realismo da imagem gerada. Portanto, a estimação dos parâmetros de iluminação é fundamental para obtenção de cenas sintéticas convincentes.

Uma técnica utilizada para manter a consistência luminosa é conhecida como Iluminação Baseada em Imagens (IBL) (Debevec, 1998). Esta técnica se baseia na obtenção e uso de imagens omnidirecionais para capturar a radiância de ambientes reais. Em geral são utilizadas esferas espelhadas, conhecidas como light probes (Figura 1.4), inseridas nas cenas reais, para obtenção das imagens omnidirecionais. Normalmente são utilizadas imagens HDR (High Dynamic Range), ou seja, imagens com grande alcance dinâmico, e que apresentam a propriedade de codificar as intensidades de cada pixel de maneira linearmente proporcional à radiância incidente, diferentemente das imagens comuns, LDR (Low Dynamic Range), que codificam as intensidades de maneira não linear. Logo, as imagens dos light probes capturam a intensidade luminosa incidente para um dado instante e posição no espaço. Como as imagens de light probes contêm informações sobre a radiância da cena, podem então ser utilizadas como mapas de iluminação para tonalizar objetos, como se esses objetos estivessem inseridos fisicamente na cena onde o light probe foi utilizado.

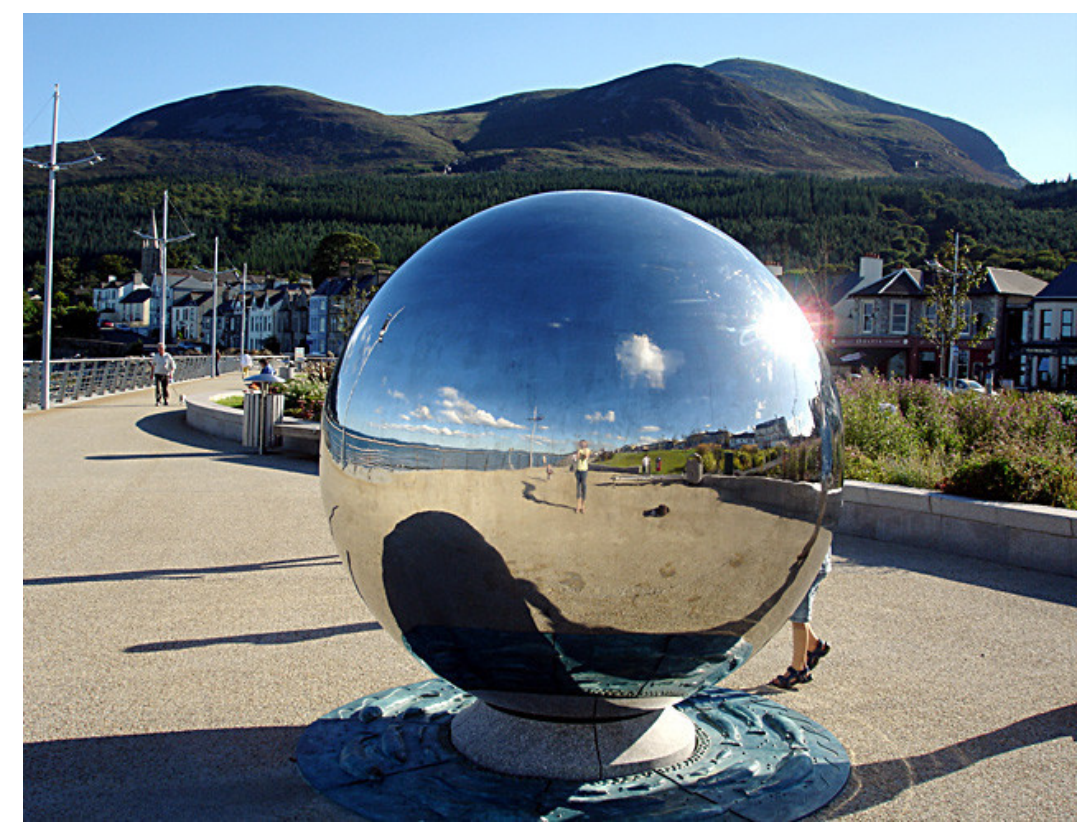

Figura 1.4: Imagem de um light probe. (Bailey, 2007)

A iluminação, no entanto, possui natureza dinâmica. Para aplicações nas quais a reprodução da dinamicidade temporal é desejada, é necessário obter uma imagem de light probe 
da cena real para cada instante de tempo (e.g. horário) correspondente ao da renderização, implicando em muito esforço durante a fase de modelagem da iluminação ou então no uso de equipamentos especiais. Consequentemente, para reproduzir uma cena em um instante de tempo em que dados de iluminação não estão disponíveis, funções de interpolações ou aproximações podem ser empregadas, sintetizando novas radiâncias.

\subsection{Motivação}

A geração de imagens realísticas, contendo objetos virtuais, em que a iluminação é temporalmente variável, demanda a modelagem das mudanças temporais da iluminação. Ou seja, mudanças dinâmicas de iluminação ao longo do dia devem ser consideradas no processo de renderização de uma nova cena.

Neste trabalho, serão utilizadas imagens de light probes para renderizar cenas contendo objetos estáticos e iluminação dinâmica. A iluminação dinâmica será modelada por meio de interpolações e aproximações, que utilizam dados de iluminação capturados de maneira esparsa ao longo do tempo.

\subsection{Objetivos}

Tendo em vista que será utilizado o método de IBL para obtenção de imagens finais realísticas, levando em consideração as mudanças de iluminação que ocorrem ao longo do tempo, os objetivos específicos deste trabalho são:

- adquirir séries temporais esparsas de imagens de light probes;

- avaliar o impacto de diferentes funções de interpolação e aproximação na geração de novos mapas de iluminação;

- avaliar, por meio de voluntários, a qualidade das imagens renderizadas obtidas ao utilizar mapas de iluminação artificiais;

- desenvolver um software capaz de interpolar mapas de iluminação e um plugin que facilite o uso de IBL temporalmente variável em um software de modelagem tridimensional;

O uso de imagens de light probes obtidas de forma esparsa em relação ao tempo, combinadas com funções de interpolação ou aproximação que preservem as características da iluminação ao longo do tempo, possibilitará o uso de IBL temporalmente variável para renderização de imagens realísticas, no contexto de RM. Tal metodologia deve dispensar o uso de equipamentos especiais, como câmeras de vídeo HDR, e reduzir a quantidade de dados de iluminação que devem ser adquiridos ao longo do tempo, sem comprometer o realismo das imagens finais.

Como o objetivo é a geração de imagens realísticas utilizando IBL temporalmente variável, o uso de ray tracing, algoritmo de renderização que produz imagens realísticas, é uma 
escolha natural, mesmo que computacionalmente custoso. Não há, portanto, preocupações com a execução da metodologia em tempo real. Então, de acordo com a classificação de Jacobs e Loscos (2006), a metodologia proposta é uma solução de realidade mista e não de Realidade Aumentada (RA).

O capítulo 2 apresenta conceitos importantes utilizados nesta dissertação, os trabalhos relacionados são apresentados no capítulo 3. O capítulo 4 trata da metodologia adotada para realização dos experimentos. Os resultados dos experimentos estão no capítulo 5 . As conclusões são apresentadas no capítulo 6 . 


\section{Capítulo 2}

\section{Conceitos}

Nesse capítulo serão explorados diversos conceitos utilizados na formulação de uma solução de realidade mista, que permita iluminação temporalmente variável. Os temas abordados serão: definições de RM, conceitos de iluminação, imagens HDR e suas propriedades, modelagem de iluminação por meio de IBL e a inserção de objetos virtuais em cenas reais utilizando de renderização diferencial.

\section{$2.1 \quad$ Realidade Mista}

Milgram (Milgram e Kishino, 1994) define Realidade Mista (RM) como o espectro formado entre cenas reais e virtuais. Dentro de realidade mista (Figura 2.1) há Realidade Aumentada (RA), que consiste em cenas reais com elementos virtuais, inseridos por meio de computação gráfica.

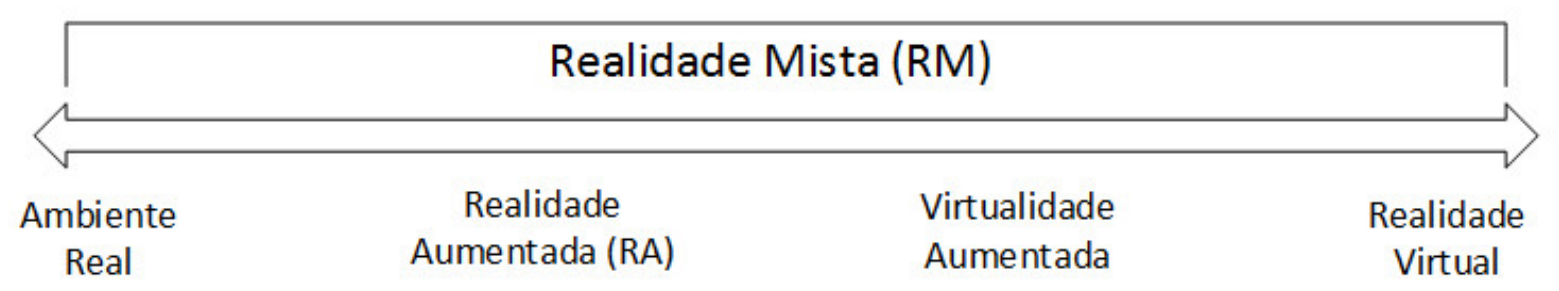

Figura 2.1: Continuo da virtualidade. (Milgram e Kishino, 1994)

De acordo com a definição clássica de Azuma (Azuma, 1997), são necessários três fatores para um sistema de RA:

- combinar elementos reais e virtuais

- interativo e em tempo real

- registro $3 \mathrm{D}$ 
Então, objetos podem ser inseridos ou removidos e a iluminação da cena pode ser alterada. RA e RM são feitos em geral utilizando imagens, porém, podem ser estendidos para sistemas baseado em outros sentidos, como audição ou tato. Note que uma solução de RA é uma solução de RM, porém, o inverso não é necessariamente verdade. Interatividade e tempo real são características de RA, mas não são necessárias em RM (Jacobs e Loscos, 2006).

Há alguns subproblemas que devem ser resolvidos ao trabalhar com RM. Registro, estimação de iluminação, renderização e composição de imagens. O problema de registro, ou seja, o alinhamento entre os objetos virtuais e os objetos reais, é um problema para o qual já existem soluções robustas, um exemplo de solução se baseia no uso de marcadores fiduciais (Kato e Billinghurst, 1999). A técnica, baseada no uso de marcadores fiduciais, será adotada para solucionar o problema de registro nesse trabalho.

\subsection{Iluminação}

A tonalização de um objeto é dependente de algumas variáveis como: iluminação incidente e propriedades do material. Kajiya (Kajiya, 1986) determinou a equação que relaciona essas variáveis e define o comportamento da iluminação em uma cena. Essa equação é conhecida como equação de renderização:

$$
L^{\text {out }}\left(t, P, \boldsymbol{\omega}_{\boldsymbol{o}}, \lambda\right)=L^{e}\left(t, P, \boldsymbol{\omega}_{\boldsymbol{o}}, \lambda\right)+\int_{\boldsymbol{\omega}_{\boldsymbol{i} \in S^{2}}} L^{i n}\left(t, P,-\boldsymbol{\omega}_{\boldsymbol{i}}, \lambda\right) f_{s}\left(P, \boldsymbol{\omega}_{\boldsymbol{i}}, \boldsymbol{\omega}_{\boldsymbol{o}}, \lambda\right)\left|\boldsymbol{\omega}_{\boldsymbol{i}} \cdot \mathbf{n}(P)\right| \mathrm{d} \boldsymbol{\omega}_{\boldsymbol{i}}
$$

- $L^{\text {out }} \rightarrow$ radiância que sai de uma superfície

- $L^{e} \quad \rightarrow \quad$ radiância emitida por uma superfície

- $L^{i n} \rightarrow$ radiância incidente em uma superfície

- $f_{s} \rightarrow \mathrm{BSDF}$

- $\omega_{\boldsymbol{o}} \rightarrow$ direção de saída

- $\omega_{i} \rightarrow$ direção incidente

- $P \rightarrow$ ponto no espaço

- $\mathbf{n}(P) \rightarrow$ normal da superfície no ponto $\mathrm{P}$

- $\lambda \rightarrow$ comprimento de onda

- $t \quad \rightarrow$ instante de tempo

- $S^{2} \rightarrow$ esfera unitária

A equação de renderização é baseada no princípio de conservação de energia, e diz que a radiância que sai de um ponto é igual à radiância emitida mais a radiância espalhada por esse ponto.

A radiância $L(t, P, \boldsymbol{\omega}, \lambda)$ (Hughes et al., 2013), é uma função de tempo, posição, direção e comprimento de onda que captura as características do transporte de luz. Ela dá a potência 
luminosa que sai ou chega em uma superfície por uma dada direção em um comprimento de onda em um certo instante.

O espalhamento ou BSDF (Bidirectional Scattering Distribution Function - função de distribuição de espalhamento bidirecional) é a função que define as características de um material, é composto pelas funções de reflexão (BRDF - Bidirectional Reflectance Distribution Function - função de distribuição de refletância bidirecional) e transmissão (BTDF Bidirectional Transmittance Distribution Function - função de distribuição de transmissão bidirecional). A função modela o comportamento dos materiais (Figura 2.2) levando em consideração a posição, o comprimento de onda, a direção incidente e a direção de saída do raio de luz. É representada por: $f_{s}\left(P, \boldsymbol{\omega}_{\boldsymbol{i}}, \boldsymbol{\omega}_{\boldsymbol{o}}, \lambda\right)$.

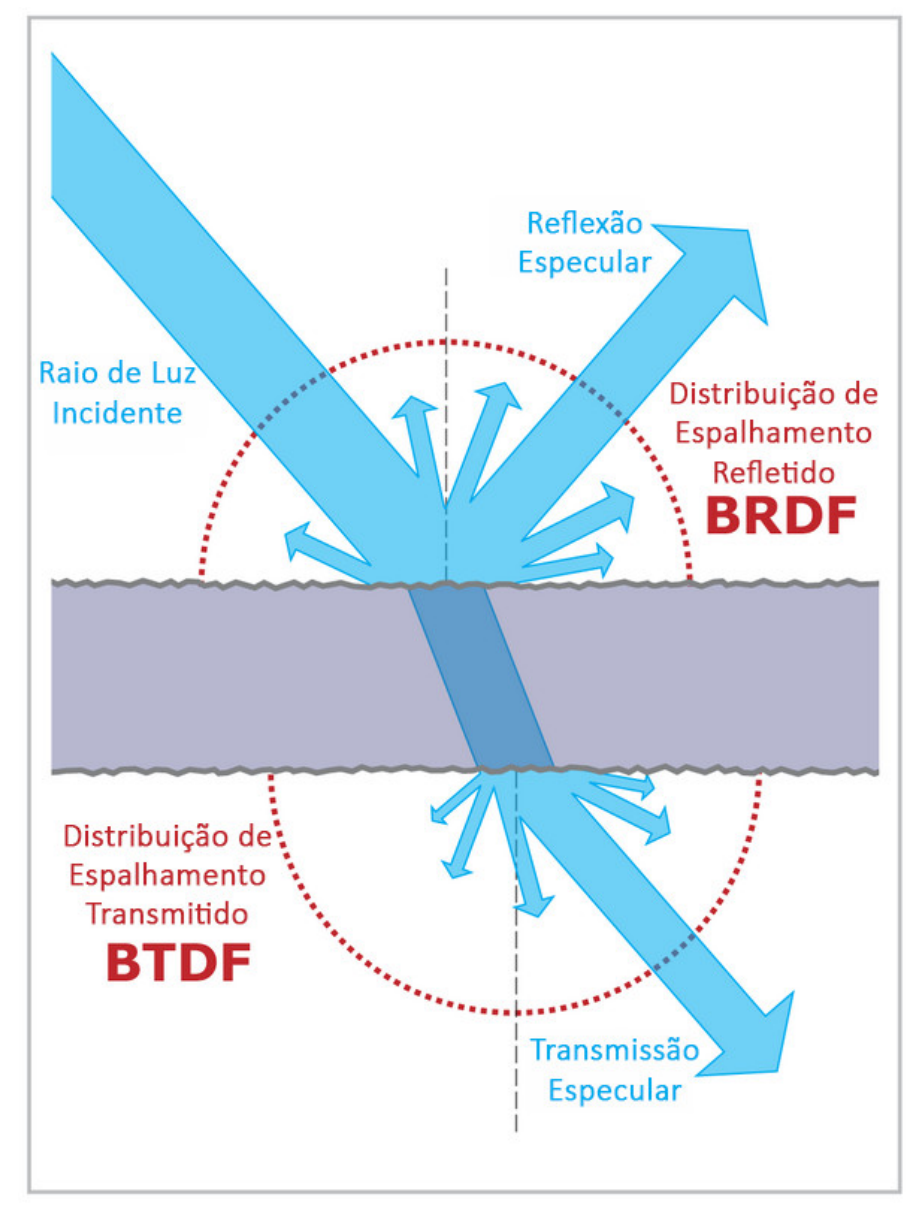

Figura 2.2: Representação da função de espalhamento - BSDF. (Jurohi, 2006)

A avaliação da equação de renderização é o maior desafio para renderização realística. Há soluções que convergem para o resultado da equação (Akenine-Möller et al., 2008), como ray tracing. Há ainda aproximações, como o modelo de iluminação Phong (Phong, 1975), ou o modelo Blinn-Phong (Blinn, 1977).

O funcionamento de ray tracing é simples: raios são disparados a partir da câmera, ao encontrar o primeiro objeto determinam um ponto de intersecção. Nesse ponto disparam mais raios em direção às fontes de iluminação, para determinar se há oclusão, e em outras direções, de modo a computar a radiância incidente vinda de outros objetos. Esse processo se repete de modo recursivo. 
Ray tracing é um algoritmo de iluminação global (Pharr e Humphreys, 2010), ou seja, para calcular a intensidade luminosa de um pixel, considera não apenas as fontes de luz, mas também a geometria e as propriedades de espalhamento de todos os objetos na cena. Esse tipo de algoritmo apresenta resultados muito mais realistas do que algoritmos que não levam iluminação global em consideração (Figura 2.3).

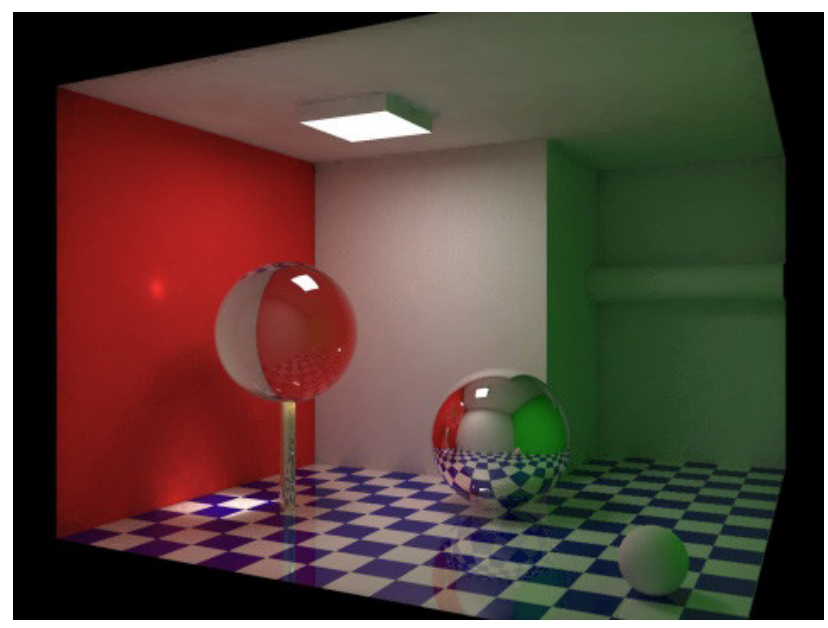

(a)

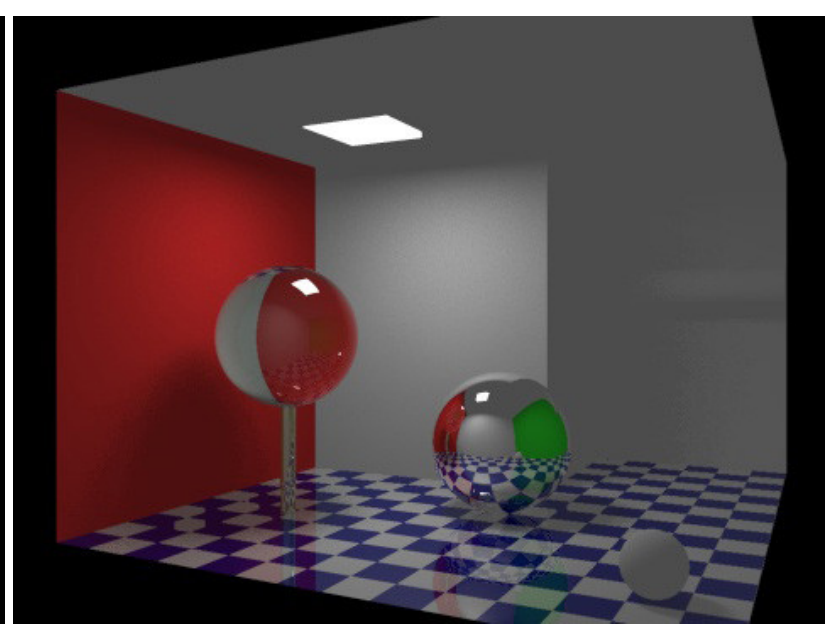

(b)

Figura 2.3: (a) exemplo de iluminação global (Tanski, 2004a), (b) iluminação local (Tanski, 2004b).

O modelo de iluminação Phong é uma simplificação do modelo de iluminação descrito pela equação de renderização. Um dos motivos por ser considerado uma simplificação se da pelo fato de desconsiderar a interação luminosa que deveria ocorrer entre os objetos da cena. No exemplo da Figura 2.3, isso fica claro pela ausência das inter-reflexões difusas nas paredes e a falta de cáustica, causada pela interação entre a esfera de vidro e a fonte de iluminação, que deveria estar projetada no chão. Nesse modelo, a intensidade luminosa de um objeto pode ser descrita pelas seguintes componentes luminosas: ambiente, difusa e especular.

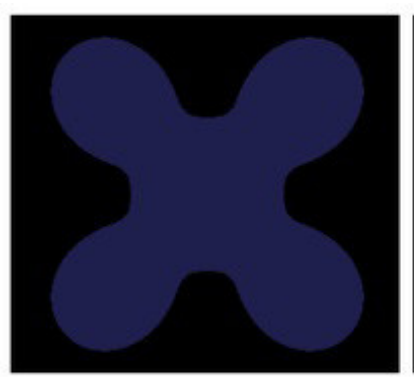

Ambiente

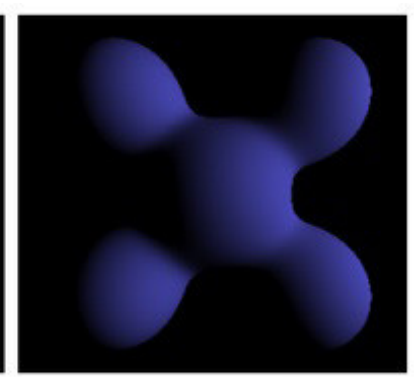

Difuso

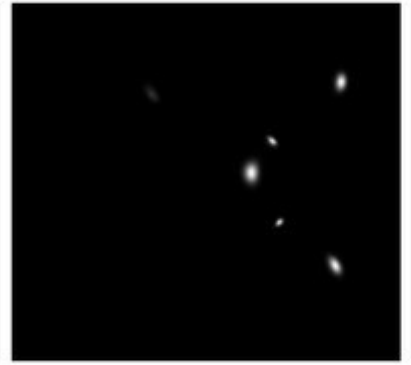

Especular

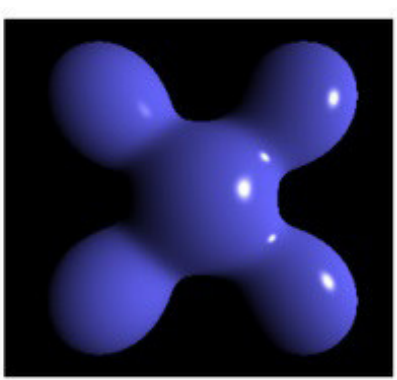

Reflexão Phong

Figura 2.4: Componentes do modelo de reflexão Phong. (Smith, 2006)

Considerando vetores de direção (Figura 2.5) normalizados, a intensidade luminosa de um objeto no modelo Phong é dada por:

$$
I(P)=I_{a} K_{a}+\sum_{l s} I_{l s_{d}} K_{d}(\mathbf{l} \mathbf{. n})+I_{l s_{s}} K_{s}(\mathbf{e . r})^{m}
$$


- $K_{a} \rightarrow$ coeficiente de reflexão ambiente do material

- $K_{d} \rightarrow$ coeficiente de reflexão difusa do material

- $K_{s} \rightarrow$ coeficiente de reflexão especular do material

- $I_{a} \rightarrow$ intensidade luminosa ambiente da cena

- $I_{l s_{d}} \rightarrow$ intensidade difusa da fonte de luminosa $l s$

- $I_{l s_{s}} \rightarrow$ intensidade especular da fonte de luminosa $l s$

- $P \rightarrow$ ponto na superfície

- $\alpha \rightarrow$ coeficiente especular do material

- e $\quad \rightarrow$ direção do observador

- $\mathbf{r} \rightarrow$ direção do raio de luz refletido de maneira perfeita

- $1 \rightarrow$ direção do raio de luz incidente

- $\mathbf{n} \quad \rightarrow$ normal da superfície no ponto $\mathrm{P}$

- $\theta \rightarrow$ ângulo entre o raio de luz e a normal da superfície

- $\delta \quad \rightarrow \quad$ ângulo entre o raio de luz refletido perfeitamente e o observador
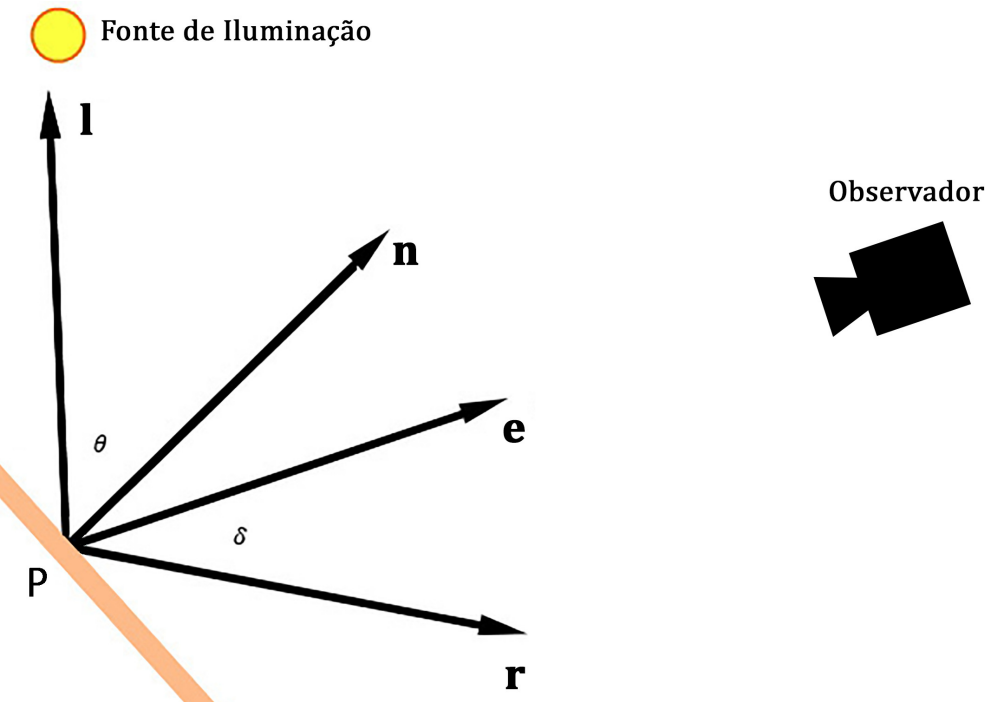

Figura 2.5: Diagrama das variáveis presentes na iluminação de uma superfície usando o modelo Phong.

\subsection{Imagens HDR}

Imagens HDR são imagens com alcance dinâmico expandido. Em uma câmera, o alcance dinâmico é a razão entre a radiância que leva ao ponto de saturação (pixel branco) e o 
que é considerado ruído (pixel preto) (Reinhard et al., 2010). O alcance dinâmico pode ser controlado por meio do tempo de exposição da câmera.

Uma câmera comum é capaz de capturar um alcance dinâmico de ordem de magnitude 2. Isso impede a representação da iluminação de uma cena real por uma imagem comum, afinal, a iluminação em uma cena real não é limitada e, portanto, pode não ser possível capturar todo o alcance dinâmico com uma única imagem. Um exemplo de intensidades para algumas fontes luminosas pode ser visto na Tabela 2.1 .

$\begin{array}{cc}\text { Fonte de luz } & \text { Iluminação }\left(\mathrm{cd} / \mathrm{m}^{2}\right) \\ \text { Luz estelar } & 10^{-3} \\ \text { Luz da lua } & 10^{-1} \\ \text { Iluminação interna } & 10^{2} \\ \text { Luz do Sol } & 10^{5} \\ \text { Monitor CRT } & 10^{2}\end{array}$

Tabela 2.1: Intensidades de fontes de luminosas. (Wandell, 1995)

Em imagens normais, ou LDR, há um mapeamento não linear dos valores de radiância em intensidades de pixel, isso fica claro no ponto de saturação da imagem, já que mesmo que o valor da radiância seja superior ao ponto de saturação, sua intensidade na imagem resultante será a intensidade máxima da imagem. Alguns dos fatores que contribuem para esse mapeamento não linear são: a conversão da voltagem em valores digitais e diferentes mapeamentos que os fabricantes aplicam para simular as características de filme fotográfico (Debevec e Malik, 1997).

O formato de imagens HDR não sofre com o problema de mapeamento não linear, além disso, é capaz de representar um alcance dinâmico muito maior do que o formato LDR. As intensidades em uma imagem HDR são linearmente proporcionais à radiância da cena real, logo, essas imagens podem ser utilizadas como mapas de radiância de cenas reais (Debevec e Malik, 1997). Pontos flutuantes são utilizados para permitir o armazenamento do alcance dinâmico expandido (Reinhard et al., 2010). Há diferentes formatos para armazenamento de imagens HDR, alguns deles são:

$\begin{array}{cc}\text { Formato } & \text { Bits por pixel } \\ \text { RGBE } & 32 \\ \text { Half RGB } & 48 \\ \text { IEEE RGB } & 96\end{array}$

Tabela 2.2: Bits por pixel para imagens em formato HDR.

Já em imagem LDR são utilizados normalmente 24 bits por pixel, em algum formato como sRGB. 
Note que, como a intensidade de um pixel em uma imagem HDR é linearmente proporcional à radiância incidente, então seu valore não é limitado entre 0 e 1 como ocorre em imagens LDR.

Imagens HDR podem ser obtidas a partir de câmeras especiais, como SpheroCam HDR ${ }^{\circledR}$ (SpheronVR, 2016), ou então combinando imagens com exposições diferentes. Nesse caso, o alcance dinâmico expandido cobre todo o alcance dinâmico das imagens originais, sejam:

- $Z \rightarrow$ imagem obtida

- $E \quad \rightarrow$ irradiância no sensor da câmera

- $\Delta t_{k} \rightarrow$ tempo de exposição

- $X \rightarrow$ exposição, igual ao produto da irradiância pelo tempo de exposição

- $L \quad \rightarrow$ radiância

- $w \quad \rightarrow$ função de pesos

- $f \quad \rightarrow$ função que há entre a exposição e a geração da imagem final

- $N \rightarrow$ número de imagens

A imagem final gerada pela câmera pode ser escrita como:

$$
Z=f(X)=f\left(E \Delta t_{k}\right)
$$

Supondo $f$ perfeitamente linear:

$$
Z=E \Delta t_{t}
$$

Sabendo que na maior parte das câmeras modernas existe um mapeamento constante entre a radiância $(L)$ e irradiância $(E)$, então a imagem HDR resultante pode ser obtida por meio de uma média ponderada, pela função $w$, dos valores dos pixels das imagens normalizas, em relação aos seus respectivos tempos de exposição, ou seja:

$$
L_{i j}=\sum_{k=1}^{N} \frac{Z_{i j k} w\left(Z_{i j k}\right)}{\Delta t_{k}} / \sum_{k=1}^{N} w\left(Z_{i j k}\right)
$$

Para dar maior robustez ao algoritmo, é utilizada uma função, $w(Z)$, de peso para cada pixel, que prioriza valores próximos a média do alcance dinâmico e descarta valores saturados ou insaturados, ou seja, pontos brancos ou pretos.

Porém, em câmeras reais $f(X)$ não é uma função perfeitamente linear, $Z$ sofre manipulações e outros processos não lineares. Nesse caso:

$$
L_{i j}=\sum_{k=1}^{N} \frac{f^{-1}\left(Z_{i j k}\right) w\left(Z_{i j k}\right)}{\Delta t_{k}} / \sum_{k=1}^{N} w\left(Z_{i j k}\right)
$$

É preciso então determinar a função de resposta da câmera. Mais informações a respeito da determinação dessa função podem ser encontradas nos trabalhos de Debevec (Debevec e Malik, 
1997) e Mitsunaga (Mitsunaga e Nayar, 1999). Dentre os softwares capazes de determinar as funções de resposta e combinar imagens com exposições diferentes, para gerar imagens HDR, podem ser citados os softwares Photoshop ${ }^{\circledR}$ (Adobe Systems, Inc., 2015) e HDRShop ${ }^{\circledR}$ (HDR Shop, 2001).

O processo de conversão de uma imagem HDR em uma imagem com um número menor de bits por canal, ou seja, uma imagem "comum" (LDR), é conhecido como tone mapping. Apesar de não ser usado no processo de renderização, é útil por permitir a exibição de imagens HDR em monitores convencionais.

\subsection{Iluminação Baseada em Imagens - IBL}

Os conceitos de iluminação e imagens HDR uma vez combinados, permitem a tonalização realística de objetos. Para tal uma técnica baseada na substituição do modelo de iluminação convencional (luzes pontuais, direcionais, etc.) por um modelo baseado em buscas em texturas é utilizada.

Iluminação Baseada em Imagens, técnica proposta por Debevec (Debevec, 1998), consiste na obtenção e uso de imagens HDR omnidirecionais para tonalização de objetos virtuais com a iluminação de uma cena real. São utilizadas imagens HDR omnidirecionais por permitirem a captura da radiância de toda uma cena real.

Imagens omnidirecionais podem ser obtidas por meio de esferas espelhadas, conhecidas como light probes (Figura 2.6), inseridas na cena real. É possível utilizar outros tipos de imagens omnidirecionais, como por exemplo imagens obtidas por meio de lentes do tipo olho de peixe (Figura 2.7).

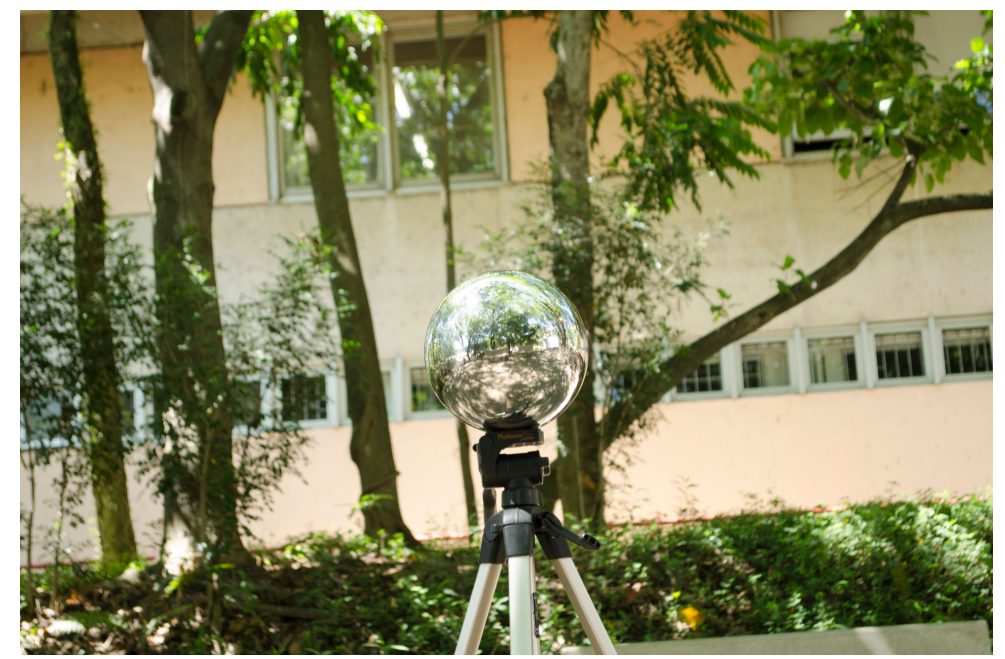

Figura 2.6: Exemplo de esfera espelhada que pode ser usada como light probe. 


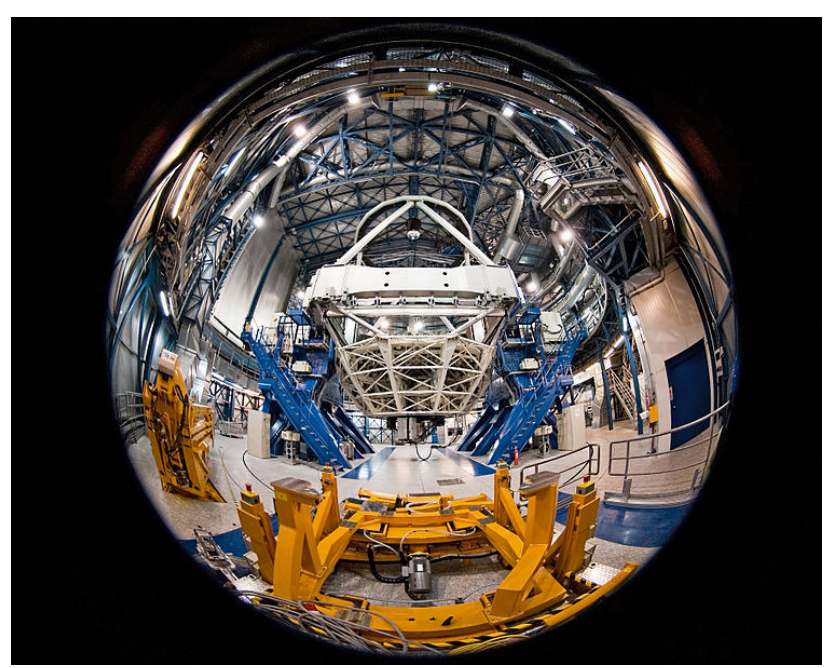

Figura 2.7: Imagem obtida através de uma câmera utilizando uma lente do tipo olho de peixe. (Salgado, 2010)

Caso seja utilizada uma esfera para obter uma imagem omnidirecional, essa imagem estará em um formato conhecido como mapeamento esférico. Nesse caso, a parte imediatamente atrás da esfera $(\mathbf{v}=(0,0,-1))$ não é amostrada, além disso, as direções próximas são mal amostradas, porém, de acordo com Debevec (1998), os efeitos causados por esse tipo de artefato podem ser minimizados com o posicionamento cuidadoso da esfera espelhada na cena real, e nesse caso serão insignificantes no processo de renderização.

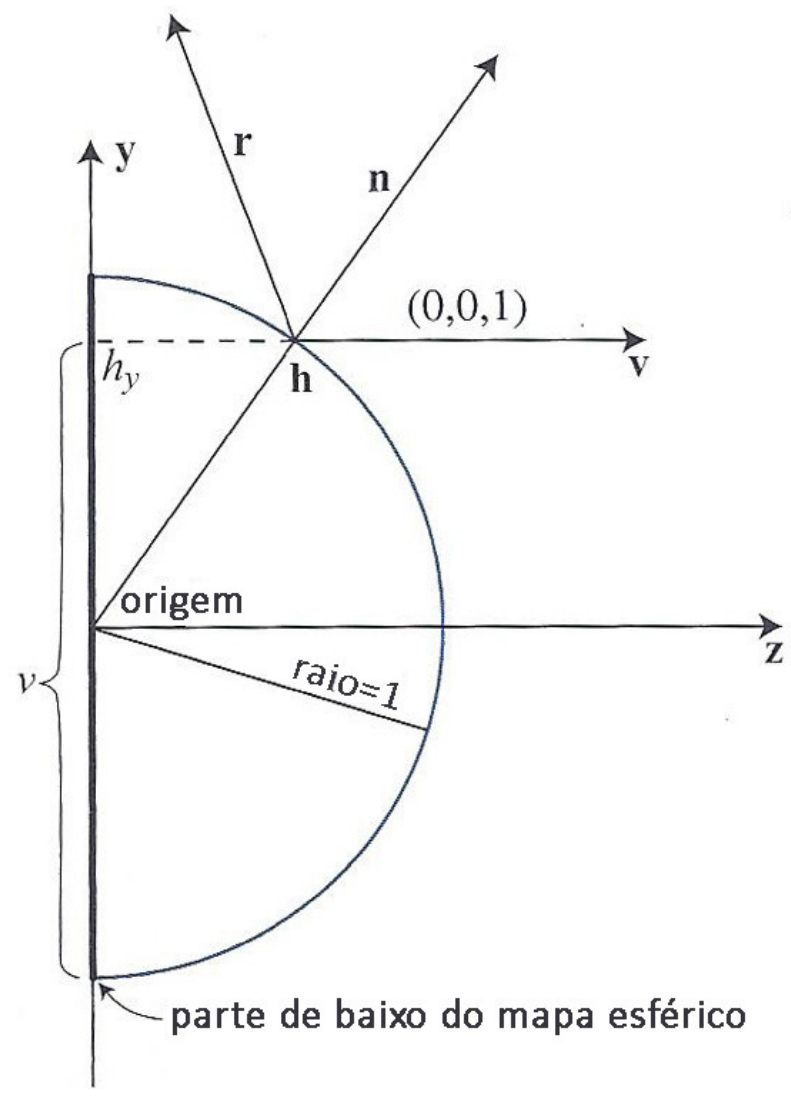

Figura 2.8: Diagrama usado para determinar as coordenadas de textura de um light probe. (Akenine-Möller et al., 2008) 
- $\mathbf{v} \rightarrow$ vetor de visão

- $\mathbf{h} \rightarrow$ ponto na superfície da esfera

- $\mathbf{n} \rightarrow$ normal na superfície da esfera

- $\mathbf{r} \rightarrow$ vetor de reflexão usado para tonalizar um objeto

Considere uma imagem de um light probe obtida por meio de uma câmera ortográfica (Apêndice D), logo o vetor de visão $\mathbf{v}$ é constante e igual à $(0,0,1)$. Para encontrar as coordenadas de textura (Apêndice E) é necessário determinar o mapeamento que ocorre entre o vetor refletido, (r), e a superfície do light probe. Sabe-se que a posição na superfície (h) da esfera coincide (2.8) com a normal (n) da esfera unitária (Akenine-Möller et al., 2008), que por sua vez é dada por:

$$
\mathbf{n}=\frac{(\mathbf{v}+\mathbf{r})}{|\mathbf{v}+\mathbf{r}|}
$$

Sejam $n_{x}$ e $n_{y}$ as projeções de $\mathbf{n}$ no eixo $X$ e $Y$ respectivamente. Essas variáveis podem assumir valores entre $[-1,1]$, então, não podem ser utilizadas diretamente como coordenadas de texturas $(u, v)$, é necessário normalizá-las para que seus valores fiquem entre $[0,1]$ :

$$
\begin{aligned}
& u=\frac{n_{x}}{2}+0.5 \\
& v=\frac{n_{y}}{2}+0.5
\end{aligned}
$$

Ao tonalizar um objeto, o vetor de reflexão $\mathbf{r}$ é conhecido, além disso, o vetor de visão v para o light probe também é conhecido, afinal é constante e igual à $(0,0,1)$, já que essa imagem foi obtida de frente e por uma câmera ortográfica. Com isso é possível determinar as coordenadas de textura, $(u, v)$, que são necessárias para obter a intensidade luminosa corresponde à direção $\mathbf{r}$, na imagem do light probe. Note que, quase todo o ambiente está mapeado na textura, a única exceção é a direção imediatamente atrás do light probe, para o qual $\mathbf{r}=(0,0,-1)$, portanto, $|\mathbf{v}+\mathbf{r}|=0$. A normal $\mathbf{n}$ é indefinida para essa direção.

De acordo com Reinhard (Reinhard et al., 2010), o mapeamento de esferas reais é similar ao de esferas perfeitas, desde que as esferas sejam pequenas em relação à sua distância para a câmera. Porém, mesmo aproximando uma esfera perfeita, esse formato não é livre de problemas. Um dos problemas do uso de mapas esféricos, é a grande variação nas bordas da imagem, o que pode levar a problemas de amostragem. Para minimizar esse problema é comum substituir o mapeamento esférico por outros tipos de mapeamento, como o mapeamento angular ou cúbico (Reinhard et al., 2010). 


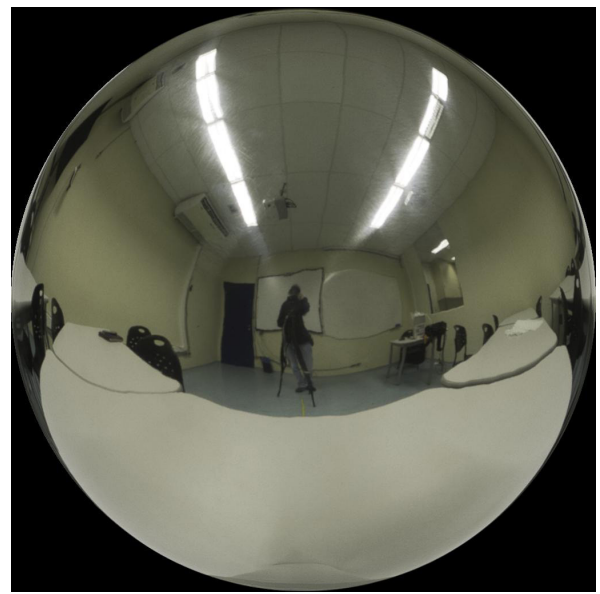

(a)

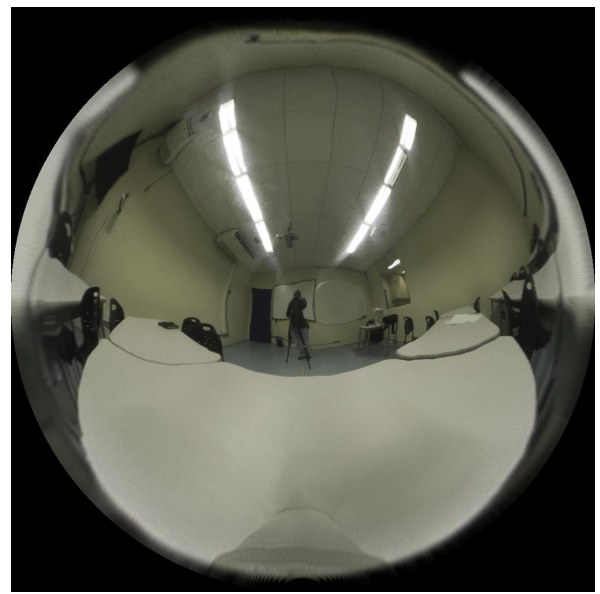

(b)

Figura 2.9: (a) mapa esférico, (b) mapa angular.

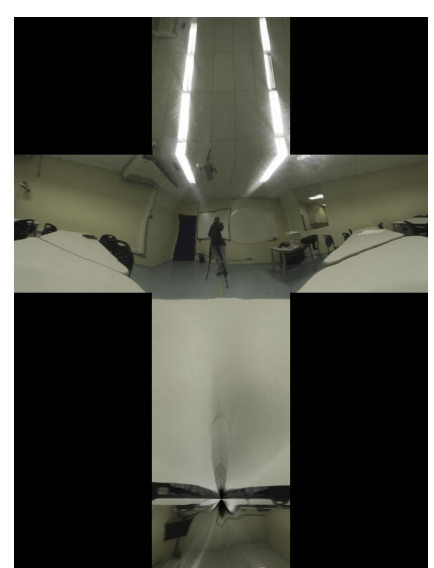

(a)

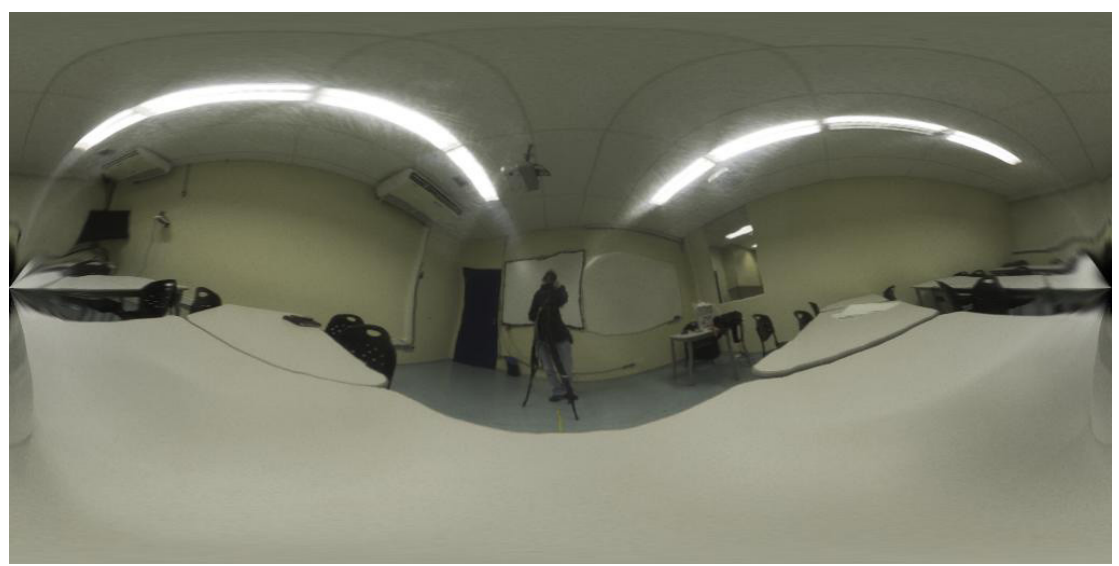

(b)

Figura 2.10: (a) mapa cúbico, (b) mapa latitude longitude.

Mapas angulares são similares aos mapas esféricos, a diferença está no fato de que a distância de algum ponto para o centro da imagem é proporcional ao ângulo formado entre o vetor de direção correspondente a esse ponto e o vetor de visão v (Reinhard et al., 2010). Conforme mais próxima à borda, mais esticada se torna a imagem. O mapeamento nesse formato é dado pelas seguintes expressões:

$$
\begin{gathered}
m=\frac{\cos ^{-1}\left(-r_{z}\right)}{2 \pi \sqrt{r_{x}^{2}+r_{y}^{2}}} \\
u=\frac{r_{x} m}{2}+0.5 \\
v=\frac{r_{y} m}{2}+0.5
\end{gathered}
$$

A imagem do light probe funciona como se tivesse sido mapeada em uma esfera infinita, que encobre o restante da cena. Com ray tracing, um raio, ao atingir um ponto, gera novos raios para amostrar a radiância incidente, dependendo de sua direção esses raios ou inter- 
ceptam a esfera infinita que contêm as informações de iluminação do light probe, ou então outros objetos, o que causa uma recursão (Figura 2.11).

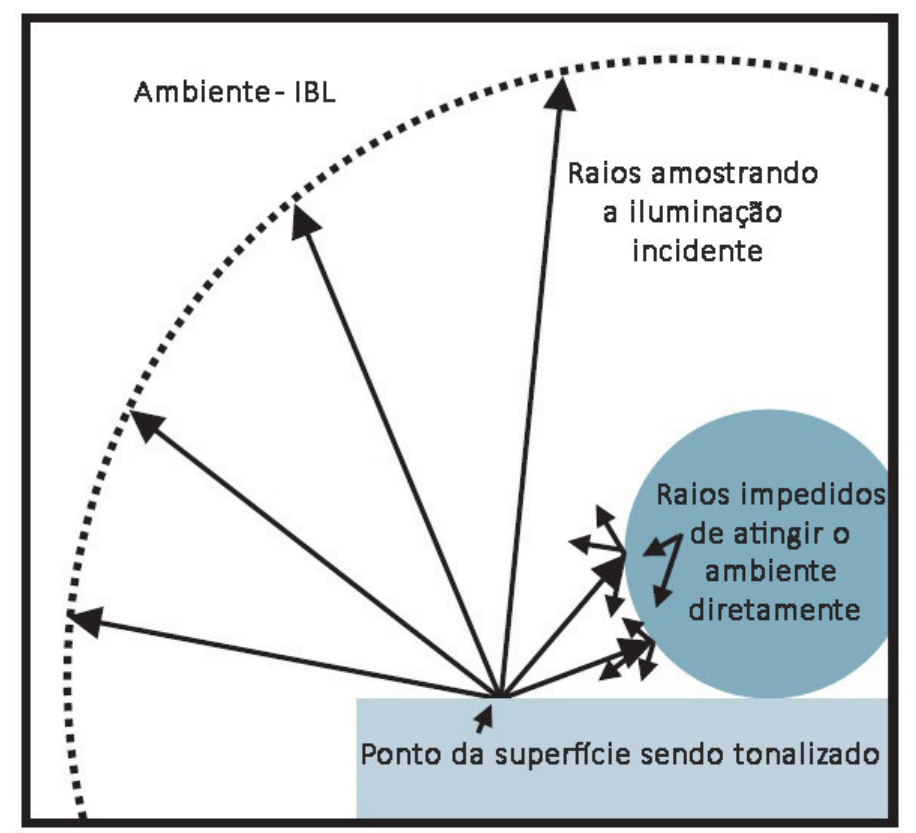

Figura 2.11: Comportamento dos raios de luz durante renderização, utilizando IBL. (Debevec, 2002)

A equação de renderização para IBL pode ser escrita como:

$$
L^{o u t}\left(t, P, \boldsymbol{\omega}_{\boldsymbol{o}}, \lambda\right)=L^{e}\left(t, P, \boldsymbol{\omega}_{\boldsymbol{o}}, \lambda\right)+\int_{\boldsymbol{\omega}_{\boldsymbol{i} \in S^{\boldsymbol{2}}}} L^{I B L}\left(t, P,-\boldsymbol{\omega}_{\boldsymbol{i}}, \lambda\right) f_{s}\left(P, \boldsymbol{\omega}_{\boldsymbol{i}}, \boldsymbol{\omega}_{\boldsymbol{o}}, \lambda\right)\left|\boldsymbol{\omega}_{\boldsymbol{i}} \cdot \mathbf{n}(P)\right| \mathrm{d} \boldsymbol{\omega}_{\boldsymbol{i}}
$$

A função $L^{I B L}\left(t, P,-\boldsymbol{\omega}_{\boldsymbol{i}}, \lambda\right)$ é similar à função $L^{i n}\left(t, P,-\boldsymbol{\omega}_{\boldsymbol{i}}, \lambda\right)$. A diferença ocorre caso não haja uma intersecção com algum objeto na direção $\boldsymbol{\omega}_{\boldsymbol{i}}$, e sob essa condição a função assume o valor contido na imagem do light probe.

Caso seja usada uma esfera como forma de estimação de iluminação há ainda outro passo necessário para modelagem correta da iluminação. É preciso obter o coeficiente de reflexão da esfera, isso pois a esfera não reflete a luz de maneira perfeita. Esse coeficiente é determinado pela razão entre a intensidade de algum ponto na cena real e a intensidade de sua reflexão na esfera. Durante a renderização esse coeficiente é utilizado para aumentar a intensidade luminosa emitida pela imagem do light probe, compensando o fato da esfera não ser uma refletora perfeita.

\subsection{Renderização Diferencial}

Além de renderizar os objetos virtuais de maneira realística, respeitando a estimativa de iluminação obtida, ainda é preciso combinar os objetos virtuais (modelos tridimensionais) com o plano de fundo real (imagem), inserindo na imagem final as interações luminosas, como 
sombras e inter-reflexões difusas. Isso pode ser feito por meio de renderização diferencial, uma técnica proposta por Debevec (Debevec, 1998) e utilizada no contexto de RM para inserir, de maneira realística, objetos virtuais em cenas reais. Nesse método uma cena é subdividida da seguinte maneira:

- objetos virtuais - apresentam geometria e BSDF (Seção 2.2) conhecidos

- cena local - área, em geral próxima aos objetos virtuais. É uma região em que ocorre interação luminosa entre a cena real e os objetos virtuais. Sombras e outros efeitos de iluminação, como cáustica, podem ocorrer nessa região. O modelo geométrico e pelo menos uma aproximação da BRDF (Seção 2.2) dessa região são necessários

- cena distante - região que não sofre influência luminosa da adição dos objetos virtuais. É o modelo luminoso da cena, a imagem do light probe

Para que essa metodologia produza sombras ou interações luminosas adequadas entre as partes reais e virtuais a geometria da cena local deve ser conhecida e deve haver pelo menos uma aproximação para BRDF da cena local. Há técnicas para obter uma estimativa da BRDF de maneira automática, mas tanto a modelagem da cena local e sua BRDF podem ser definidos de forma manual.

A imagem final pode ser obtida pela composição de diferentes imagens, essas imagens são:

- $L_{o b j} \rightarrow$ renderização dos objetos virtuais e da cena local

- $L_{n o o b j} \rightarrow$ renderização da cena local sem os objetos virtuais

- $L \quad \rightarrow$ plano de fundo

- $\alpha \quad \rightarrow \quad$ máscara criada para $L_{o b j}$ com informações de transparência para diferenciar os objetos virtuais da cena local em $L_{o b j}$

A expressão que define a composição de imagens, para geração da imagem final, pode ser escrita como:

$$
L_{f i n a l}=\alpha L_{o b j}+(1-\alpha)\left(L+L_{o b j}-L_{n o o b j}\right)
$$




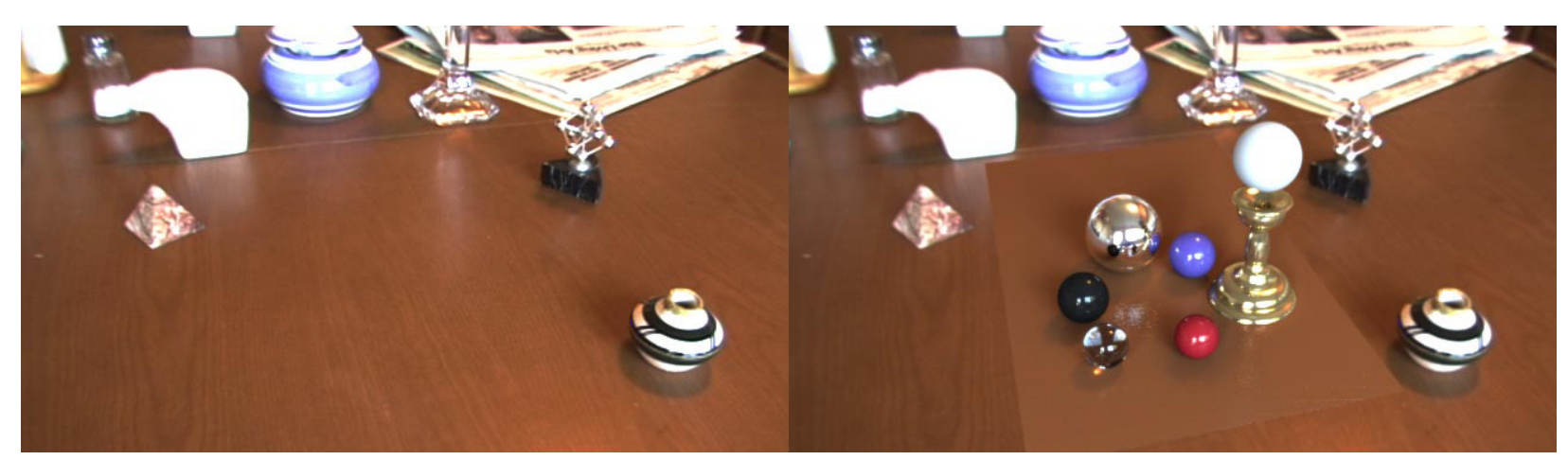

(a)

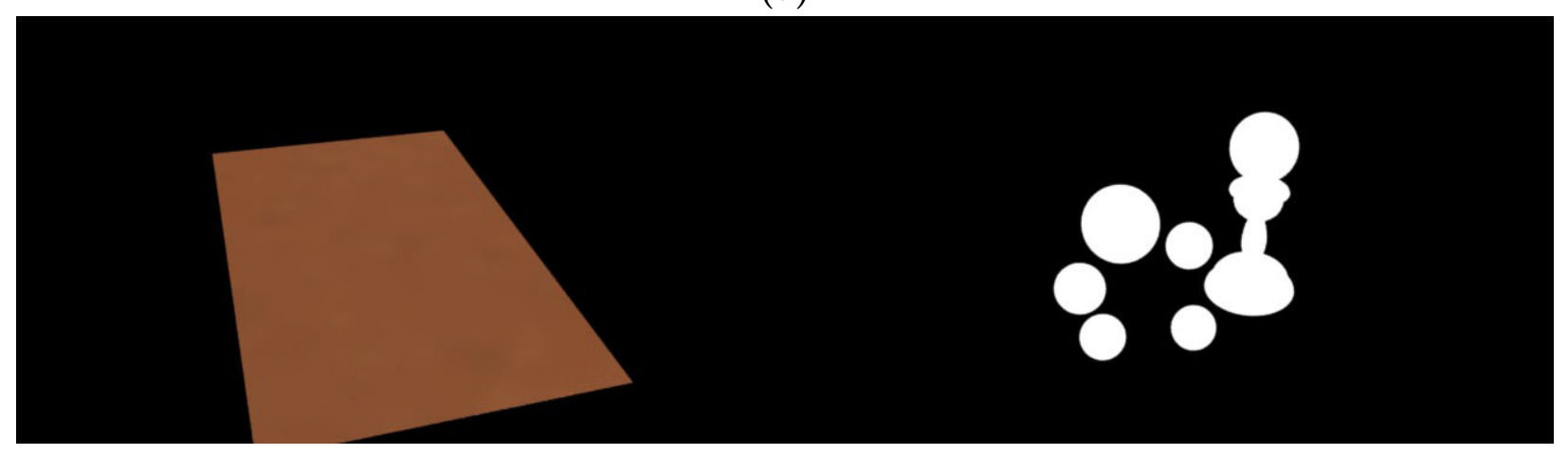

(b)

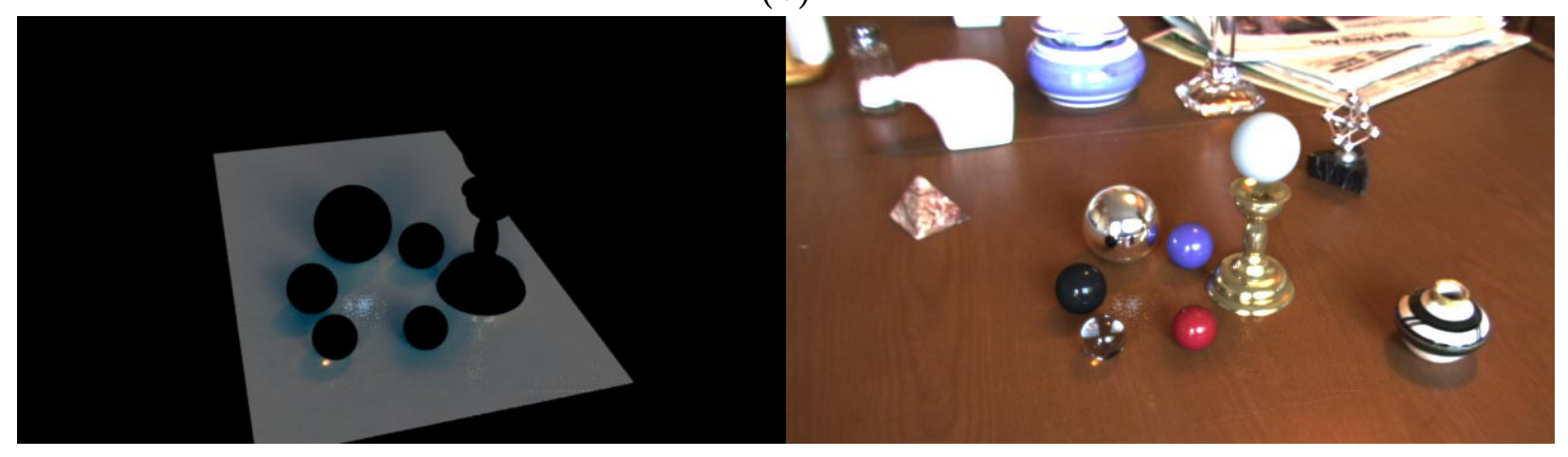

(c)

Figura 2.12: Da esquerda para direita: (a) $L$ e $L_{o b j}$, (b) $L_{n o o b j}$ e $\alpha$, (c) $(1-\alpha)\left(L_{o b j}-L_{n o o b j}\right)$ e $L_{\text {Final. }}$ (Debevec, 1998) 


\section{Capítulo 3}

\section{Trabalhos Relacionados}

A preocupação com o realismo e a correta estimação de iluminação, no contexto de RM, é uma área relativamente recente. Inicialmente poucos se importavam com o realismo, afinal haviam outros problemas mais urgentes a serem resolvidos, como o problema de registro e o alinhamento entre os objetos virtuais e reais (Azuma, 1997). Conforme esses problemas foram resolvidos, um número crescente de trabalhos na área de estimação de iluminação e realismo foi publicado.

Um dos precursores da tonalização realística, na área de RM, foi Nakamae (Nakamae et al., 1986), inserindo construções virtuais em imagens reais. Havia preocupação em saber como a iluminação e as sombras iriam se comportar caso novos edifícios fossem construídos. Uma estimativa para a intensidade da iluminação é obtida a partir de uma relação entre o valor dos pixels em áreas sombreadas e áreas iluminadas. Já a direção do Sol é obtida a partir do horário e de dados de geolocalização.

Fournier (Fournier et al., 1993), aplica radiosidade progressiva (Cohen et al., 1988) a um modelo tridimensional simplificado da cena, e com as imagens originais da cena real, consegue obter uma estimativa para a iluminação. Esse método exige a modelagem e o alinhamento do modelo tridimensional da cena. Drettakis (Drettakis et al., 1997) estende o trabalho de Fournier utilizando radiosidade hierárquica (Hanrahan et al., 1991), e fazendo a reconstrução do modelo da cena por métodos semiautomáticos baseados em visão computacional.

Um método simples que utiliza câmeras convencionais para obtenção de imagens HDR foi proposto por Debevec (Debevec e Malik, 1997), que já menciona uma possível utilização em renderização, apesar de ainda não haver nenhuma aplicação. No ano seguinte Debevec (Debevec, 1998) mostrou como utilizar imagens HDR omnidirecionais (light probes) para estimar a radiância de uma cena real, e inserir objetos virtuais em cenas reais com tonalização realística 3.1. O método necessita do modelo tridimensional dos objetos reais que estão próximos aos objetos virtuais. Utiliza ray tracing como técnica de renderização e obtém imagens finais realísticas. 

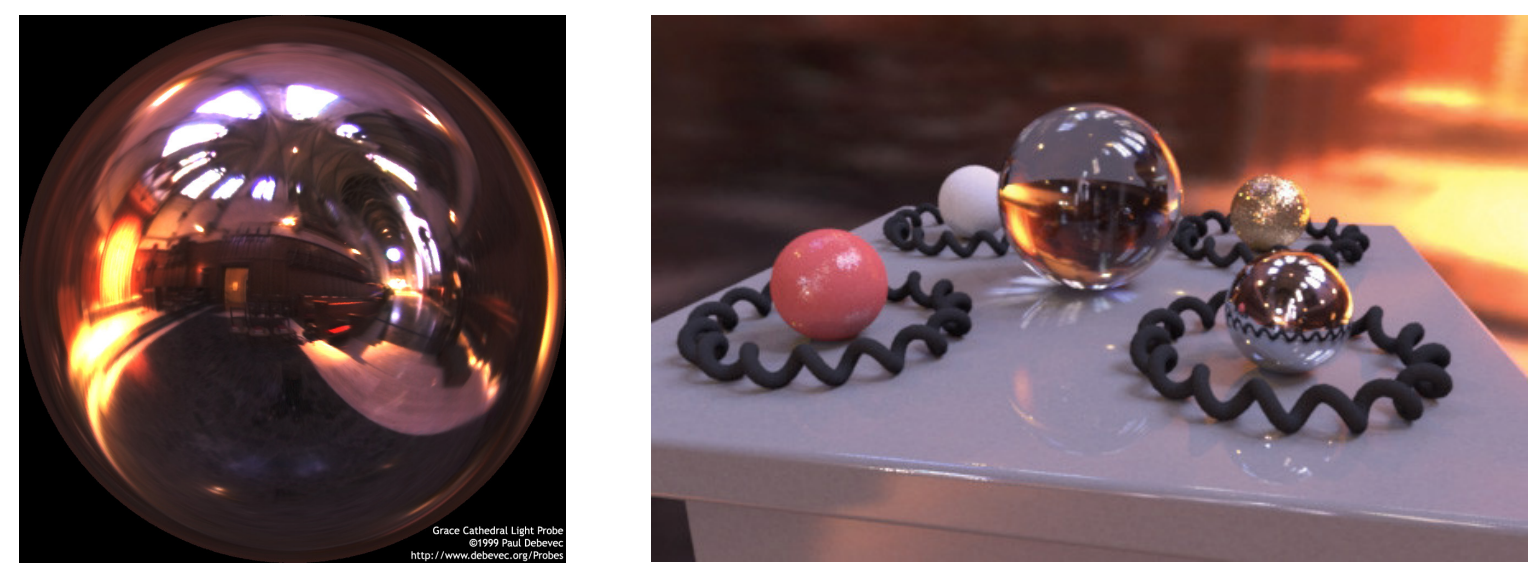

Figura 3.1: Imagem de um light probe adquirido na catedral Grace em São Francisco e objetos virtuais renderizados utilizando esse light probe. (Debevec, 1998)

A solução proposta por Sato (Sato et al., 1999) utiliza um sistema de câmeras, com lentes olho peixe, para obter imagens omnidirecionais a partir de dois pontos distintos da cena, e com isso gerar o modelo geométrico da cena. Utiliza também uma câmera com olho de peixe para obter uma imagem HDR omnidirecional, que é então mapeada no modelo geométrico, criando um "mapa de radiâncias". Esse mapa é usado tanto para amostrar a radiância dos objetos virtuais que são inseridos na cena, quanto para gerar sombras. Utiliza ray casting para renderização.

Kanbara (Kanbara e Yokoya, 2002) propõe uma solução combinando light probes e marcadores de realidade aumentada, eliminando a necessidade de informações geométricas a priori para calibração do sistema. Utiliza áreas brilhantes na imagem do light probe como luzes direcionais, a posição na imagem indica a direção, e a intensidade do pixel indica a intensidade da fonte de luz. Utiliza imagens LDR para aquisição de informações de iluminação.

Agusanto (Agusanto et al., 2003) decompõe a imagem do light probe em um mapa difuso e especular, permitindo a utilização de técnicas baseadas em hardware para renderização (environment map). Apesar do longo pré-processamento para decompor a imagem do light probe, a renderização é feita em tempo real.

Sombras são parte essencial das soluções de RM que geram imagens realísticas e convincentes. Dentre os trabalhos que utilizam imagens de light probes no formato LDR e que focam em sombras, podem ser citados: Supan (Supan et al., 2006), que utiliza a localização de áreas brilhantes no light probe para determinar a direção das fontes de luz, e também decompõe a imagem do light probe em um environment map, obtendo uma solução que é capaz de tonalizar os objetos virtuais e gerar sombras em tempo real, sem pré-processamento. Castro (Castro et al., 2012) trabalha com plataformas móveis na geração de sombras realísticas.

Um método, válido apenas para cenas ao ar livre, é descrito por Madsen (Madsen e Lal, 2010) (Madsen e Lal, 2011). Este método consiste em detectar dinamicamente sombras e determinar a relação entre a radiância proveniente do Sol e do céu. O método utiliza informações de geolocalização e uma versão parcial da malha tridimensional da cena, que pode 
ser adquirida por um sistema de câmeras estéreo.

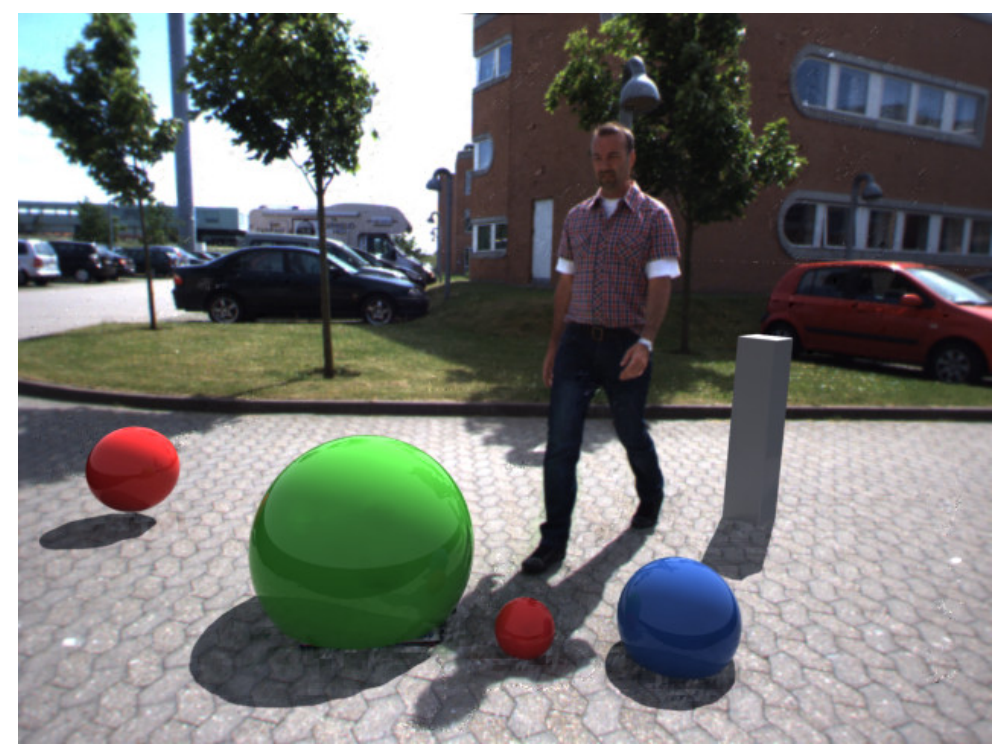

Figura 3.2: Esferas virtuais inseridas em uma cena externa. (Madsen e Lal, 2011)

Também para cenas externas, Kolivand (Kolivand e Sunar, 2014) utiliza o modelo de Perez (Perez et al., 1993) para obter uma aproximação mais precisa do céu. Propõe melhorias em relação às sombras e leva em consideração efeitos como nevoa com o aumento da distância entre a câmera e os objetos virtuais. O método não precisa do modelo da cena. Um domo é mapeado com as intensidades do céu, e a renderização é feita utilizando radiosidade (Kolivand e Sunar, 2013).

Há ainda soluções que vão além da estimação de iluminação e são capazes também de estimar os materiais da cena, permitindo inclusive a inserção de novas fontes de iluminação na cena. Entre esses métodos pode ser citado Gibson (Gibson et al., 2001), em que luzes virtuais são posicionadas em regiões em que não há primitivas geométricas ou informações radiométricas, em seguida os materiais da cena e as intensidades do conjunto de luzes virtuais são otimizados iterativamente, de modo a obter iluminação similar à real. Imagens HDR e o modelo tridimensional parcial da cena são necessários. Neverova (Neverova et al., 2012) estima os parâmetros de iluminação ao minimizar o erro entre as imagens reais e renderizadas. A imagem original é decomposta (Shen e Cai, 2009) (Land e McCann, 1971) em partes difusa e especular, e a minimização do erro ocorre para ambas as partes, de modo a obter resultados mais precisos. O método não utiliza imagens HDR para capturar informações de iluminação, porém, necessita de um sensor de profundidade para capturar o modelo tridimensional parcial da cena.

Knecht (Knecht et al., 2012) reconstrói a cena usando um sensor de profundidade, e estima a iluminação por meio de pontos de luz virtuais. Os pontos de luz são gerados para as áreas de maior intensidade de uma imagem da cena, que é obtida por uma câmera com lente olho de peixe. Apesar de não estimar os parâmetros de reflexão dos materiais (utiliza a cor da imagem adquirida como constante difusa e desconsidera a parte especular), o algoritmo é suficientemente robusto, permitindo inclusive a inserção de novas fontes de iluminação na cena. A renderização é feita utilizando radiosidade instantânea diferencial (Knecht et al., 2010).

Unger (Unger et al., 2013) propõem uma maneira para utilizar IBL temporalmente variá- 


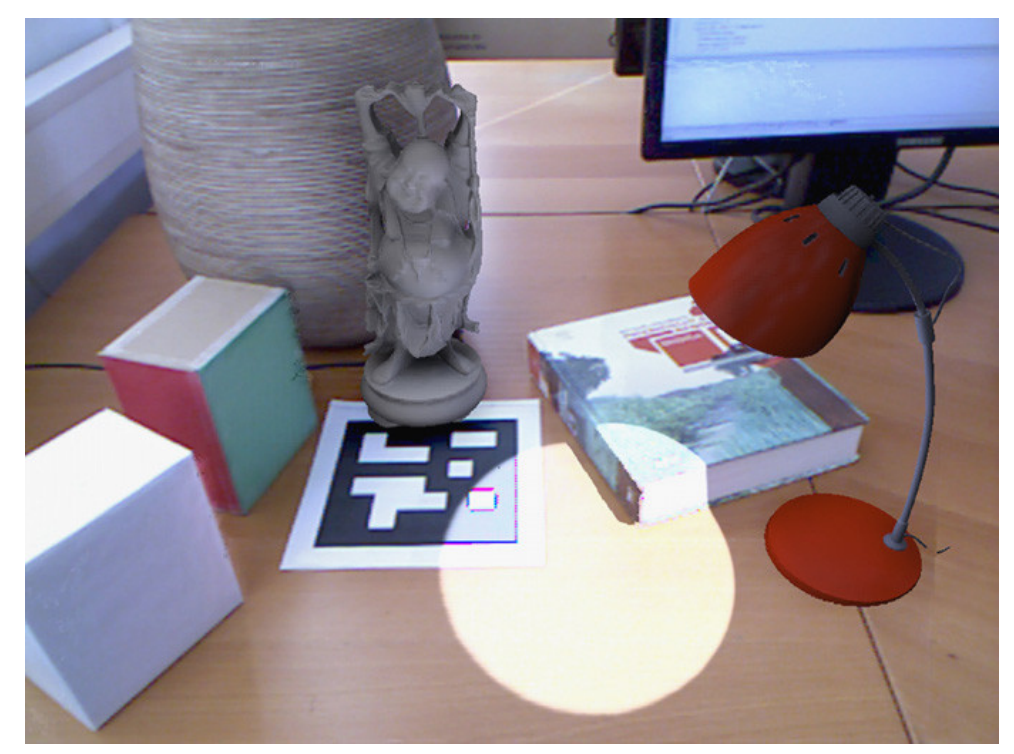

Figura 3.3: Buddha e luminária virtuais inseridos em cena real. Note que a luminária é capaz de iluminar objetos reais. (Knecht et al., 2012)

vel, mas utiliza vídeos HDR para isso, escolhendo o frame do vídeo corresponde ao instante da renderização como base para a iluminação. Para que a transição de iluminação entre frames seja suave, um frame novo é gerado a partir de um filtro Gaussiano. A renderização é feita projetando a imagem do light probe em harmônicos esféricos (Ramamoorthi e Hanrahan, 2001) (harmônicos esféricos formam uma base ortonormal para funções definidas na superfície de uma esfera) e utilizando uma implementação (Hajisharif et al., 2012) de pre-computed radiance transfer (Kautz et al., 2002).

Os métodos descritos de uma maneira ou outra são limitados, precisam de muitos dados, demandam equipamentos especiais, ou assumem coisas e fazem simplificações (Ver Tabela 3.1). Uma classificação e discussão mais profunda dos métodos de estimação de iluminação pode ser encontrada em Jacobs e Loscos (2006).

Como a maior preocupação é o realismo, e sem preocupações em relação à velocidade de execução, a técnica de IBL proposta por Debevec se destaca. Esse destaque se dá por quatro motivos: oferece o maior realismo, pode ser usado para cenas internas e externas, não exige equipamentos especiais e demanda apenas modelo local da cena. 


\begin{tabular}{|c|c|c|c|c|c|c|}
\hline & Ambiente & HDR & Equipamentos & Renderização & $\begin{array}{l}\text { Tempo } \\
\text { Real }\end{array}$ & $\begin{array}{l}\text { Informações } \\
\text { Adicionais }\end{array}$ \\
\hline Nakamae & Externo & Não & & $\begin{array}{l}\text { Phong (sem } \\
\text { componente } \\
\text { especular) }\end{array}$ & Não & $\begin{array}{c}\text { Latitude e } \\
\text { longitude do local }\end{array}$ \\
\hline Fournier & Interno & Não & & Radiosidade & Não & $\begin{array}{c}\text { Modelo } \\
\text { tridimensional } \\
\text { simplificado }\end{array}$ \\
\hline Drettakis & Interno & Não & & Radiosidade & Não & $\begin{array}{c}\text { Imagens } \\
\text { Omnidirecionais }\end{array}$ \\
\hline Debevec & Ambos & Sim & Light probe & Ray Tracing & Não & $\begin{array}{l}\text { Modelo da cena } \\
\text { local }\end{array}$ \\
\hline Sato & Ambos & Sim & $\begin{array}{l}\text { Câmeras com } \\
\text { lente olho de } \\
\text { peixe }\end{array}$ & Ray Tracing & Não & $\begin{array}{c}\text { Imagens } \\
\text { Omnidirecionais } \\
\text { obtidas de } \\
\text { diferentes posições }\end{array}$ \\
\hline Kanbara & Ambos & Não & Light probe & $\mathrm{N} / \mathrm{D}$ & Sim & $\begin{array}{l}\text { Light probe e } \\
\text { marcador fiducial } \\
\text { calibrados }\end{array}$ \\
\hline Agusanto & Ambos & Sim & Light probe & $\begin{array}{l}\text { Environment } \\
\text { Mapping }\end{array}$ & $\operatorname{Sim}$ & \\
\hline Supan & Ambos & $\operatorname{Sim}$ & Light probe & $\begin{array}{l}\text { Environment } \\
\text { Mapping }\end{array}$ & Sim & $\begin{array}{l}\text { Light probe e } \\
\text { marcador fiducial } \\
\text { calibrados }\end{array}$ \\
\hline Castro & Ambos & Não & $\begin{array}{c}\text { Light } \\
\text { probe(Cenas } \\
\text { internas), GPS } \\
\text { (Cenas } \\
\text { externas) }\end{array}$ & $\mathrm{N} / \mathrm{D}$ & Sim & $\begin{array}{l}\text { Light probe e } \\
\text { marcador fiducial } \\
\text { calibrados }\end{array}$ \\
\hline Madsen & Externo & Sim & $\begin{array}{l}\text { Sensor de } \\
\text { profundidade, } \\
\text { GPS }\end{array}$ & Ray Tracing & Não & $\begin{array}{l}\text { Estimação ocorre } \\
\text { em quase tempo } \\
\text { real, porém, a } \\
\text { renderização não }\end{array}$ \\
\hline Kolivand & Externo & Não & GPS & Radiosidade & Sim & $\begin{array}{c}\text { Céu baseado no } \\
\text { modelo de Perez } \\
\text { (Perez et al., 1993) }\end{array}$ \\
\hline Gibson & Ambos & $\operatorname{Sim}$ & & Ray Tracing & Não & $\begin{array}{c}\text { Modelo } \\
\text { tridimensional } \\
\text { parcial }\end{array}$ \\
\hline Neverova & Interno & Não & $\begin{array}{l}\text { Sensor de } \\
\text { profundidade }\end{array}$ & Phong & Não & $\begin{array}{c}\text { Decomposição da } \\
\text { cena em partes } \\
\text { difusa e especular }\end{array}$ \\
\hline Knecht & Ambos & Não & $\begin{array}{c}\text { Sensor de } \\
\text { profundidade, } \\
\text { câmera com } \\
\text { lente olho de } \\
\text { peixe }\end{array}$ & $\begin{array}{l}\text { Radiosidade } \\
\text { instantânea }\end{array}$ & Sim & $\begin{array}{l}\text { Os materiais da } \\
\text { cena não são } \\
\text { estimados }\end{array}$ \\
\hline Unger & Ambos & Sim & $\begin{array}{c}\text { Light probe, } \\
\text { câmera de vídeo } \\
\text { HDR }\end{array}$ & PRT & Sim & $\begin{array}{l}\text { Pré-processamento } \\
\text { por causa de PRT }\end{array}$ \\
\hline
\end{tabular}

Tabela 3.1: Comparação de métodos para estimar a iluminação de uma cena. 


\section{Capítulo 4}

\section{Metodologia}

O objetivo deste trabalho é renderizar, de maneira realística, cenas com iluminação temporalmente variável. A técnica escolhida para atingir o objeto se baseia em IBL, e utiliza imagens artificiais de light probes geradas por meio de interpolações ou aproximações. Para permitir a geração dos dados interpolados é preciso primeiro adquirir imagens de light probes em diversos horários, ou seja, uma série temporal de imagens de light probes, possibilitando assim a amostragem da iluminação da cena ao longo do tempo.

A avaliação de desempenho das diferentes funções de interpolação e aproximação foi feita comparando dados interpolados com os dados reais. Em seguida a técnica que obteve destaque durante esse primeiro teste foi utilizada para gerar dados de iluminação para os experimentos de realidade mista.

Os testes de realidade mista foram realizados comparando imagens reais e modificadas. Essas comparações foram feitas por meio de questionários distribuídos para voluntários. Esse teste foi realizado para verificar se as imagens modificadas poderiam ser diferenciadas das imagens reais, comprovando assim a eficácia da metodologia proposta.

Também foram gerados vídeos no contexto de RM. Esses vídeos foram gerados com o propósito de permitir a observação de possíveis discrepâncias na tonalização entre os objetos virtuais e reais conforme as mudanças de iluminação que ocorrem ao longo do tempo. 


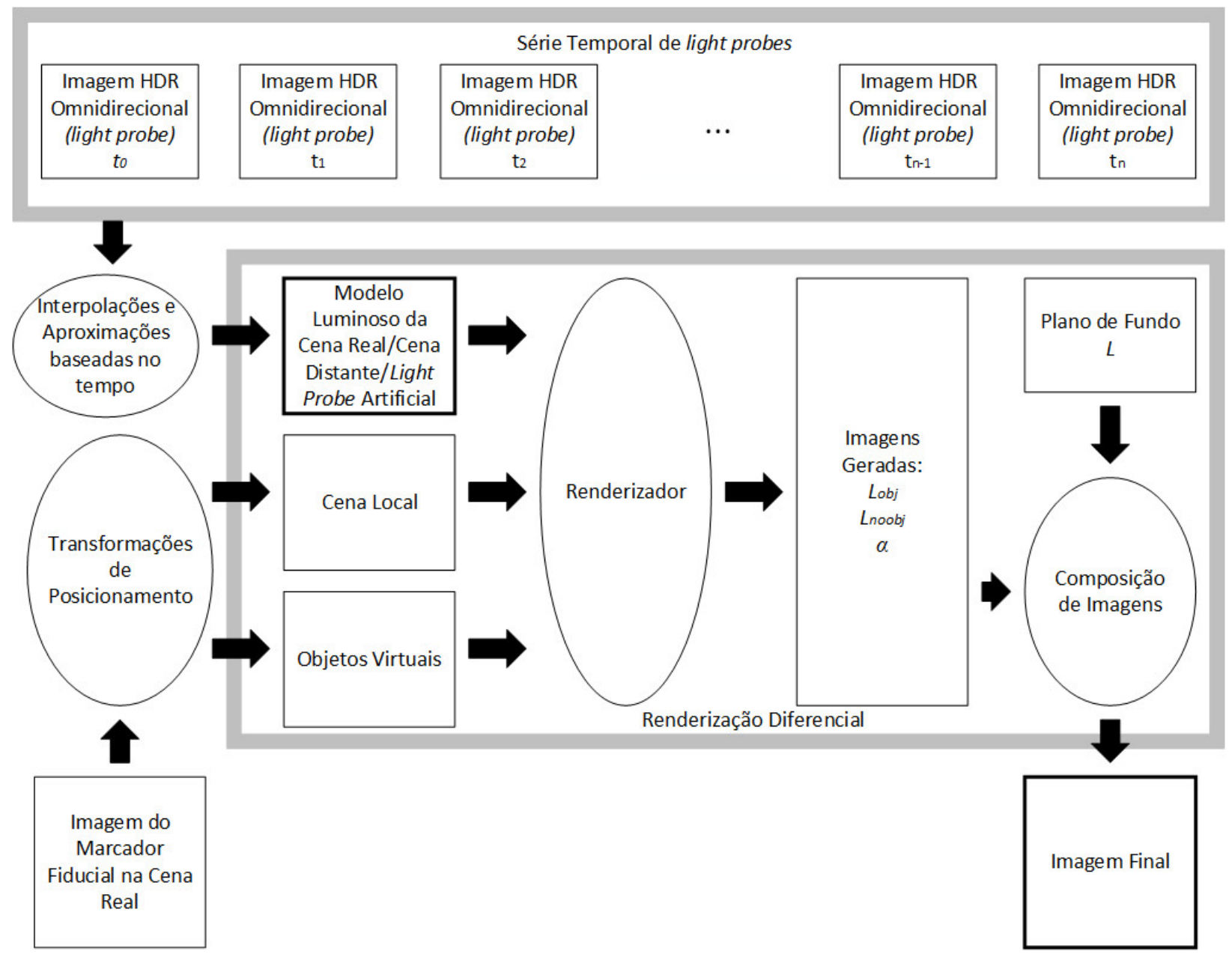

Figura 4.1: Diagrama representando as etapas existentes para utilizar IBL temporalmente variável e obter de imagens finais realísticas no contexto de RM. Retângulos representam dados, já as elipses representam métodos. As bordas espessas indicam as etapas em que as verificações ocorrem. Além da comparação entre os light probes artificiais e reais, a qualidade das imagens finais, geradas a partir dos mapas de iluminação artificiais, também é avaliada. Note que $L, L_{o b j}, L_{n o o b j}$ e a representam respectivamente, o plano de fundo, a cena local com os objetos virtuais, a cena local e a máscara para os objetos virtuais (Seção 2.5).

\subsection{Obtenção das Imagens de Light Probes}

Uma câmera convencional foi utilizada para obter imagens da cena e do light probe. Para gerar as imagens dos light probes no formato HDR foi utilizado o método descrito na Seção 2.3, ou seja, a combinação de diversas imagens com tempos de exposição diferentes. O software Photoshop ${ }^{\circledR}$ foi utilizado para realizar a combinação de exposições.

Como pretende-se estudar o comportamento das imagens dos light probes em relação ao tempo, foram realizadas aquisições em diversos horários. Foram realizadas duas aquisições em dias diferentes, uma começou no final da manhã e outra no início da tarde, ambas se estenderam até o pôr do Sol, de modo a capturar boa parte das mudanças luminosas que ocorrem ao longo do dia.

Apesar da técnica base (IBL) ser suficientemente robusta, tanto para cenas internas 
quanto externas, os experimentos foram realizados apenas em cenas internas de modo a ter um pouco mais de controle sobre a cena, diminuindo a movimentação e também eliminando a possibilidade de variações, como passagem de pessoas e objetos estranhos na cena, além, é claro, de facilitar as aquisições. As aquisições foram feitas sem iluminação artificial.

\subsection{Interpolação das Imagens de Light Probes}

Imagens de light probes artificiais foram geradas utilizando as séries temporais de imagens já adquiridas, interpolando as intensidades de cada pixel em relação ao tempo. Ou seja, cada posição na imagem foi considerada de maneira independente do resto, a interpolação foi feita levando em conta apenas as variações de intensidade dos pixels em relação ao tempo. Logo, para gerar uma imagem artificial, esse processo de interpolação é repetido para todos os pixels.

Para todos os métodos de interpolação e aproximação apresentados (Apêndices A e B) as imagens dos light probes, do conjunto de dados, podem ser representadas por $\left(y_{0}, y_{1}, y_{2}, \ldots\right)$, já os tempos de aquisição são dados pelo conjunto $\left(x_{0}, x_{1}, x_{2}, \ldots\right)$. Com exceção das interpolações de Gauss, Stirling e Lagrange, todas as outras formas de interpolação e aproximação são amplamente utilizadas na área de CG, mas essas interpolações também foram incluídas, pois apresentam características que diferem dos outros métodos. Foram utilizadas tanto as interpolações quanto as aproximações para derivar novas informações de iluminação a partir das amostras já coletadas.

\subsection{Comparação entre Light Probes Reais e Artificiais}

O primeiro experimento se baseia na comparação entre imagens reais de light probes, fotografados na cena, e imagens artificiais, produzidas por meio de interpolações ou aproximações. Nesse teste uma imagem de light probe é removida do conjunto de dados, e uma imagem artificial é gerada para o instante referente à remoção (Figura 4.2). Desse modo é possível comparar os dados reais com os dados artificiais.

Para comparação das imagens no formato HDR, foi adotada a mesma metodologia utilizada por $\mathrm{Ng}$ et al., ou seja, a distância $L^{2}$. Sejam $I 1$ e $I 2$ duas imagens, sendo que: $r 1$ e $r 2$ representam o canal vermelho; $g 1$ e $g 2$ o canal verde; $b 1$ e $b 2$ o canal azul. Então a distância $L^{2}$ entre as duas imagens é:

$$
L^{2}=\sqrt{\sum_{i}^{n} \sum_{j}^{m}\left(r 1_{i j}-r 2_{i j}\right)^{2}+\left(g 1_{i j}-g 2_{i j}\right)^{2}+\left(b 1_{i j}-b 2_{i j}\right)^{2}}
$$




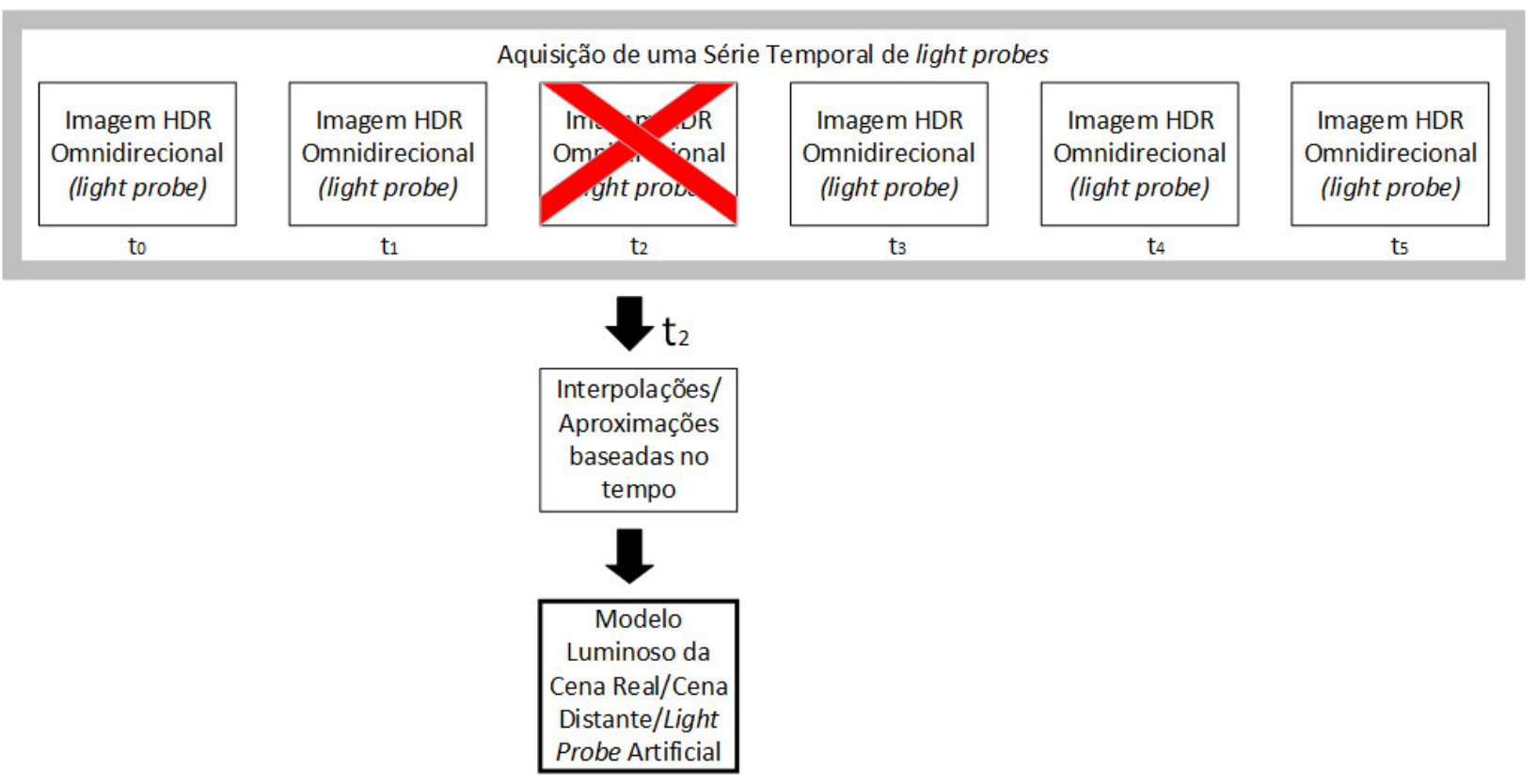

Figura 4.2: Diagrama que representa o teste baseado na comparação entre imagens de light probes reais e artificiais.

\subsection{Experimento RM}

Ao trabalhar com RM, um dos primeiros problemas que surge é o problema de registro, ou seja, o correto posicionamento dos objetos virtuais em relação à cena real. As transformações que levam ao posicionamento correto podem ser obtidas a partir de uma imagem com um marcador fiducial (Figura 4.3) inserido na cena. Como não há movimentação, então uma única imagem com o marcador, obtida em qualquer horário, é suficiente para obtenção dos parâmetros de posicionamento, independente do instante de tempo da renderização.

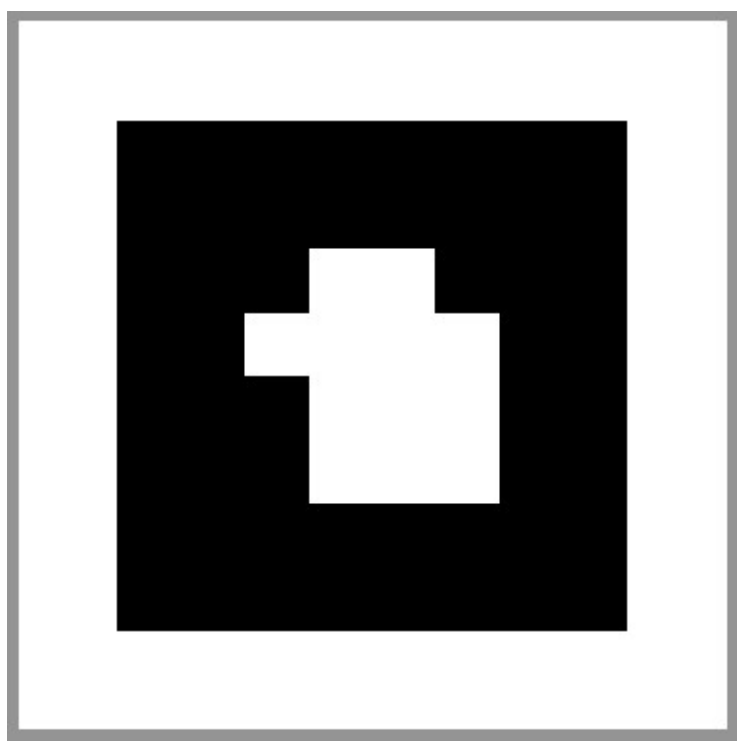

Figura 4.3: Exemplo de marcador fiducial.

Como uma implementação de uma nova solução para resolver esse problema está fora do 
escopo desta dissertação, foi utilizada a biblioteca ArUco (Garrido-Jurado et al., 2014) para detecção e obtenção das transformações dos objetos virtuais. Essa biblioteca foi escolhida por dois motivos: é de fácil configuração e independente de soluções de renderização.

Ao utilizar renderização diferencial é necessário fornecer os modelos tridimensionais tanto dos objetos virtuais quanto da cena local. Não foi utilizado nenhum método automatizado para gerar o modelo tridimensional dos objetos que compõe a cena local, esses objetos, assim como os objetos virtuais, foram modelados ou modificados de forma manual, utilizando o software de modelagem tridimensional Maya ${ }^{\circledR}$ (Autodesk Inc., 2015).

Ray tracing foi a técnica de renderização escolhida, como o foco do trabalho não é a execução em tempo real e sim o realismo, essa é uma escolha natural, afinal permite a geração de imagens muitas vezes indistinguíveis de imagens reais. É um método de renderização robusto que permite a utilização dos mais diversos tipos de materiais. Além disso, ray tracing também leva em consideração efeitos de iluminação global durante a renderização. mentalray ${ }^{\circledR}$ (Nvidia, 2015) foi a implementação de ray tracing escolhida por permitir renderização fisicamente correta e já estar integrada com o software de modelagem utilizado.

Com as imagens renderizadas (objetos virtuais, cena local e da máscara dos objetos virtuais) disponíveis, é então aplicado o método de renderização diferencial para inserção dos objetos virtuais dentro da cena real, gerando assim as imagens finais.

De acordo com Jacobs e Loscos (2006), um sistema de realidade mista é convincente quando não é possível distinguir os objetos virtuais dos reais. Os testes para essa etapa foram baseados nesse princípio. Esse experimento se baseia na inserção de objetos virtuais em cenas reais e verificação, por meio de questionários aplicados à voluntários, se é possível distinguir os objetos virtuais dos objetos reais. Para formulação de cada questionário foram utilizadas imagens com objetos virtuais e sem objetos virtuais, no caso das cenas com objetos virtuais, a iluminação foi proveniente exclusivamente de imagens de light probes artificiais.

\section{Geração de Vídeos}

Outra forma de comprovar o funcionamento da metodologia de interpolação se dá pela criação de vídeos, no contexto de realidade aumentada, mostrando as mudanças que ocorrem com a iluminação e a tonalização ao longo do dia. Esses vídeos foram gerados com renderização diferencial utilizando imagens de light probes artificiais como fontes de iluminação.

Os vídeos foram gerados pela interpolação linear de keyframes. Os keyframes por sua vez foram gerados pela mesma metodologia usada para obter imagens com objetos virtuais em cenas reais descrita na Seção 4.4. As duas melhores interpolações/aproximações (que melhor minimizam o erro, $L^{2}$, em relação aos dados originais) foram utilizadas para geração dos keyframes, ou seja, há dois vídeos diferentes. 


\section{Capítulo 5}

\section{Resultados}

Os experimentos foram divididos em três partes: Experimento Preliminar, em que foram adquiridos os primeiros conjuntos de imagens de light probes e realizadas as primeiras comparações com os mapas de iluminação artificiais; no Primeiro Experimento também foram realizadas comparações entre imagens de light probes, porém, de maneira mais sistemática, com mais métodos de interpolação, mais instantes de testes e em cenas mais controladas; já o Segundo Experimento se baseou na percepção de usuários para determinar se imagens produzidas pela metodologia proposta, no contexto de RM, poderiam ser diferenciadas de imagens sem modificações.

\subsection{Experimento Preliminar}

Antes da realização dos experimentos finais foram efetuados alguns experimentos preliminares. Esses experimentos foram feitos em cenas internas e externas. Foram adotadas duas metodologias para para validação dos resultados:

- comparação entre imagens de light probes obtidas de maneira normal, combinando imagens com diferentes exposições, com imagens obtidas a partir de interpolações

- comparação entre um objeto simples, cubo branco difuso, inserido na cena real com sua versão virtual, renderizada utilizando um mapa de iluminação interpolado

Para realizar os experimentos foram adquiridos dois conjuntos de imagens de light probes: um conjunto para uma cena interna (Figura 5.2) e outro para uma cena externa (Figura 5.1). Os light probes foram adquiridos tentando mantê-los sempre na mesma posição, em cada um dos conjuntos adquiridos. Imagens do paralelepípedo branco também foram adquiridas ao final de cada tomada, de modo a permitir as comparações com o paralelepípedo renderizado. As duas aquisições, ambiente interno e externo, foram realizadas no mesmo dia. 


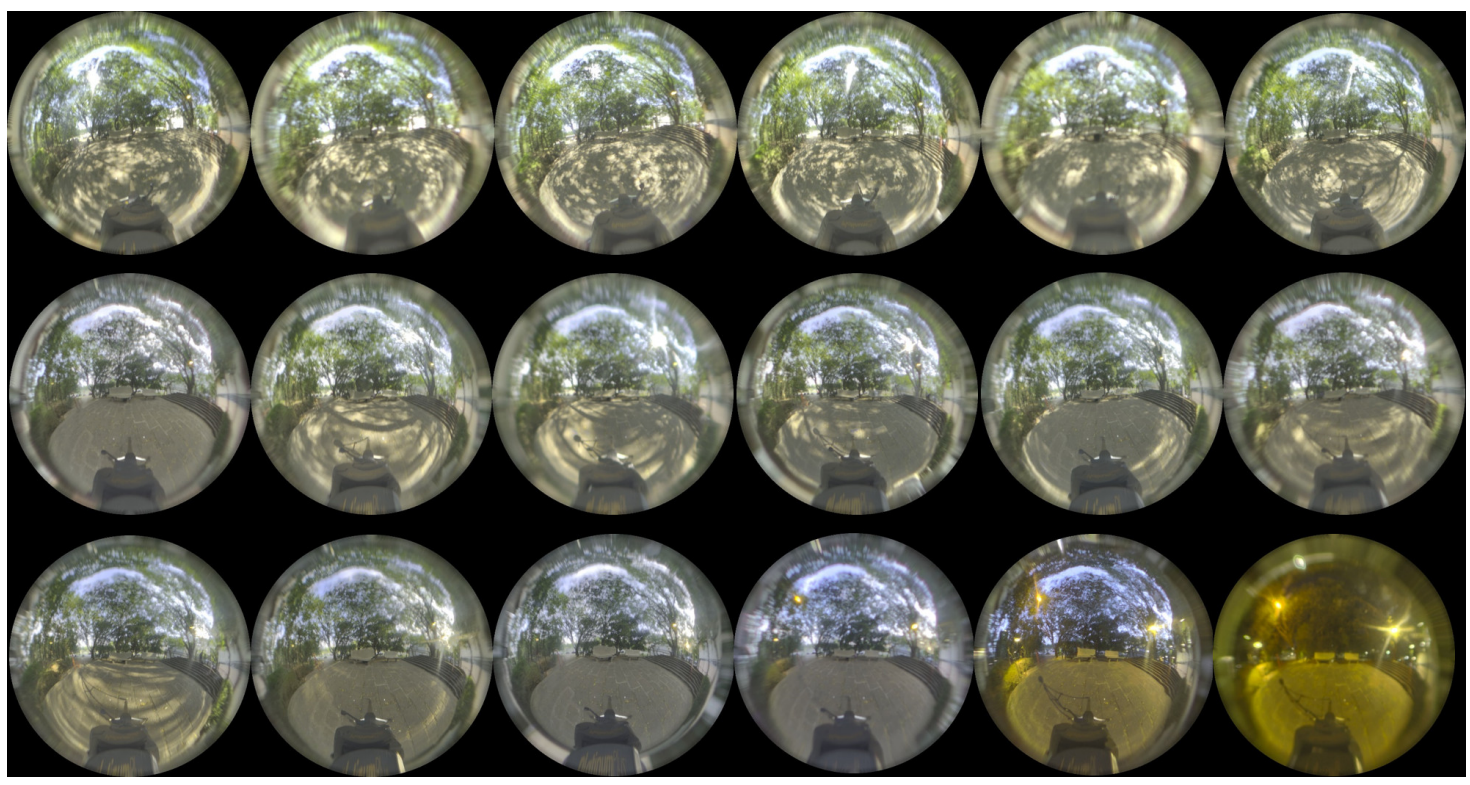

Figura 5.1: Série temporal de imagens de light probes obtida em um ambiente externo. A aquisição teve início às 10:45 e término às 20:00.

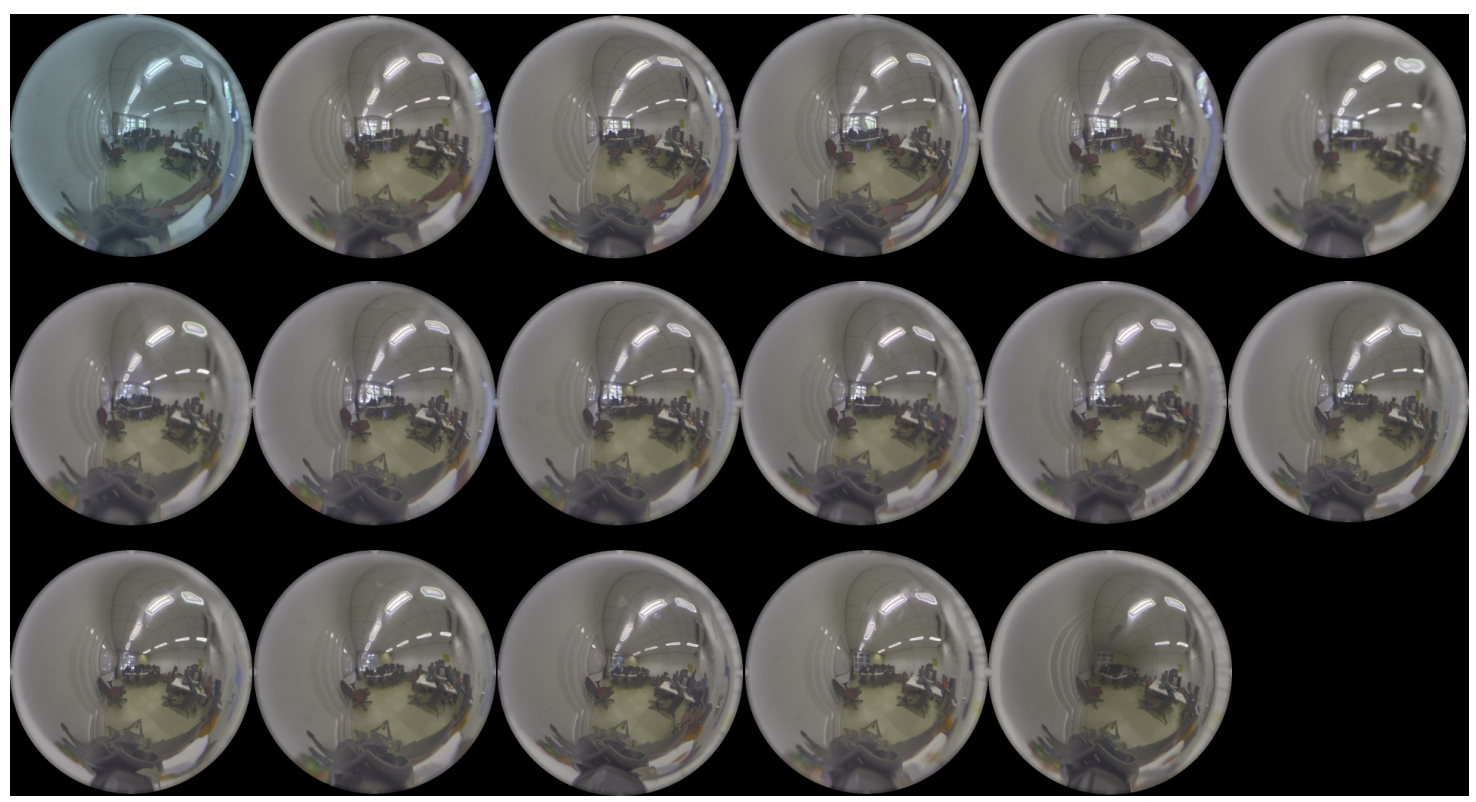

Figura 5.2: Série temporal de imagens de light probes obtida em um ambiente interno. A aquisição teve início às 11:00 e término às 19:45.

Para a realização dos testes foi desenvolvido um software capaz de gerar os dados interpolados e calcular as distâncias entre imagens HDR (Apêndice F). Nesse teste preliminar foram utilizadas as seguintes interpolações:

- Lagrange

- Linear

- Gauss's Forward 
- Gauss's Backward

- Stirling

Para a interpolação linear e de Lagrange todo o conjunto de dados disponível foi utilizado na geração de novos dados, mas no caso da interpolação de Gauss e Stirling foi utilizado apenas um subconjunto. Essas interpolações demandam dados uniformemente espaçados, como um ponto do conjunto de dados é removido para o instante de teste, então o espaçamento se torna uma hora, o que implica na remoção de outros dados da série temporal de imagens. Note que, para realizar as interpolações foi utilizada uma diferença de tempo aproximada de 30 minutos entre cada uma das aquisições.

Os horários de testes foram escolhidos de modo a apresentarem grandes variações de iluminação em relação às amostras próximas. A seguir há exemplos de imagens de light probes originais, interpoladas e suas diferenças. Note que, como as intensidades de imagens HDR não são limitadas entre 0 e 1, suas diferenças também não são.

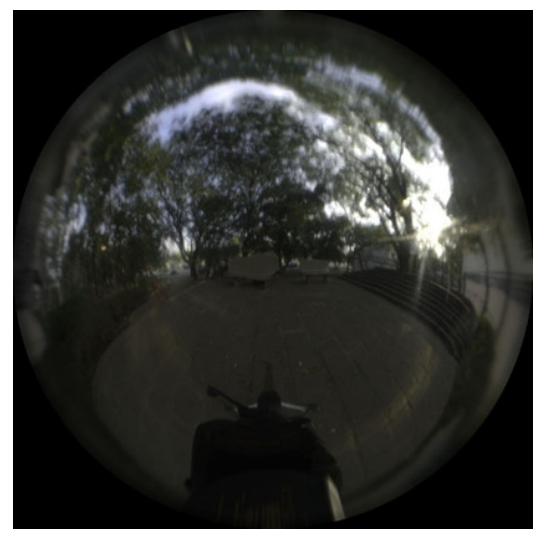

(a)

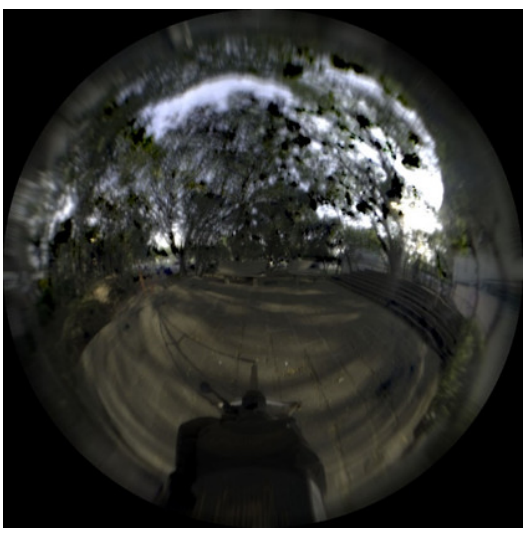

(b)

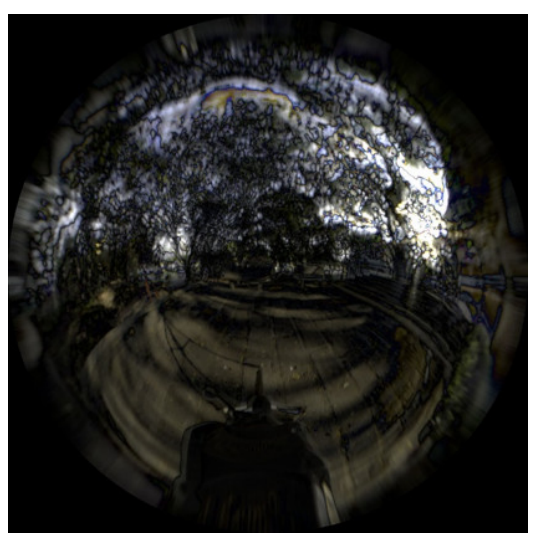

(c)

Figura 5.3: (a) Imagem de um light probe na cena externa às 18:05, (b) imagem interpolada por Gauss's Forward, (c) diferença entre a imagem original e interpolada.

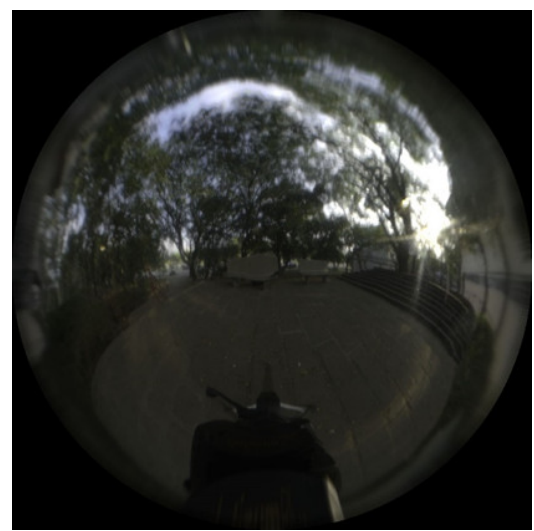

(a)

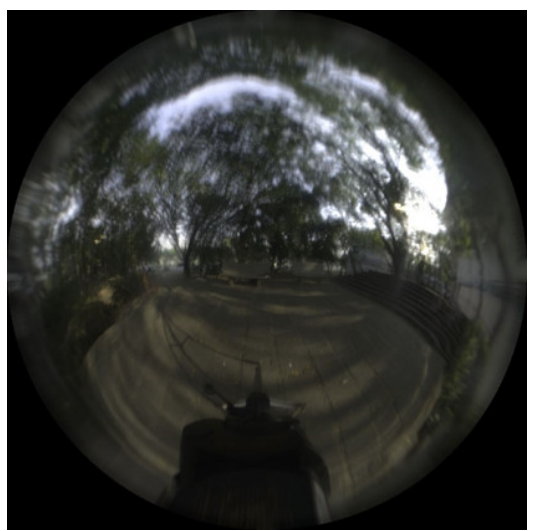

(b)

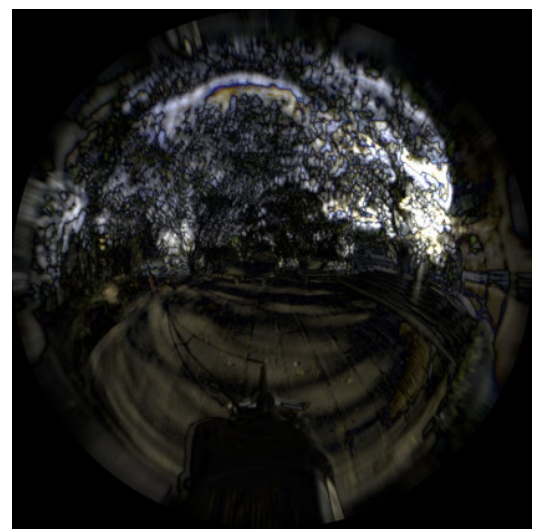

(c)

Figura 5.4: (a) Imagem de um light probe na cena externa às 18:05, (b) imagem gerada utilizando interpolação linear, (c) diferença entre a imagem original e interpolada. 


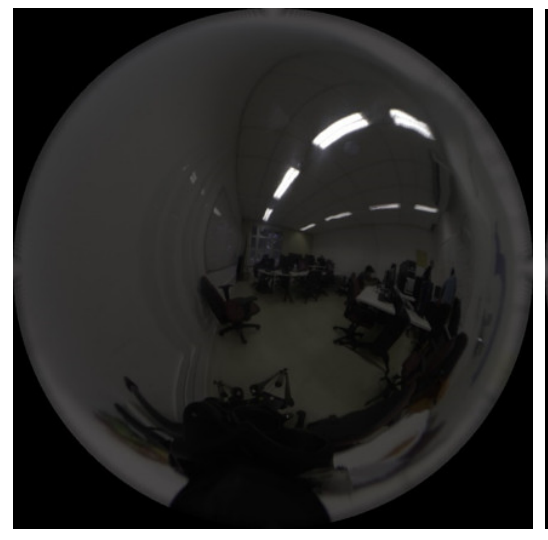

(a)

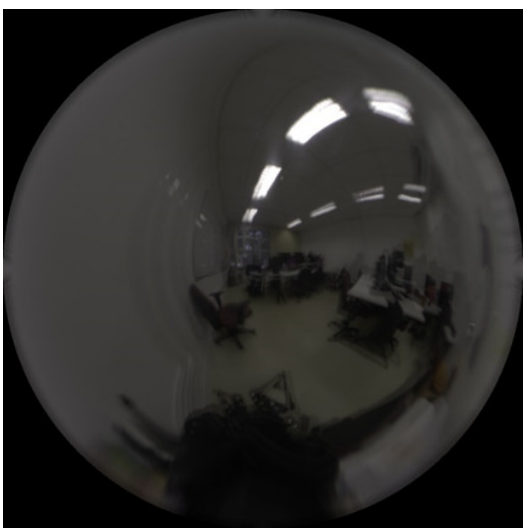

(b)

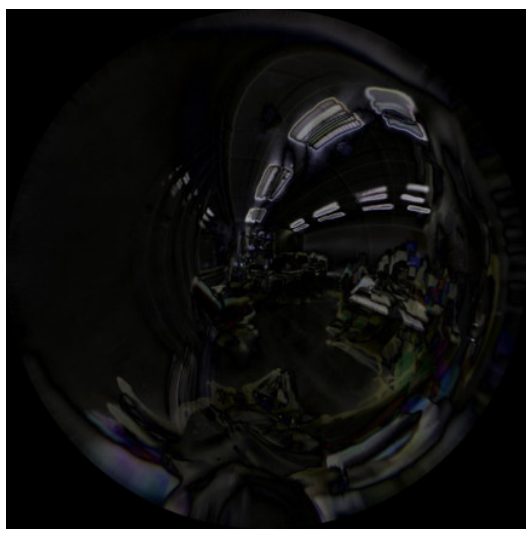

(c)

Figura 5.5: (a) Imagem de um light probe na cena interna às 18:45, (b) imagem gerada utilizando interpolação linear, (c) diferença entre a imagem original e interpolada.

Um ponto a ser destacado em relação às imagens de light probes geradas a partir de interpolações polinomiais de alto grau, como Gauss e Lagrange, são algumas regiões totalmente pretas. Isso se deve ao fato de que essas interpolações podem gerar intensidades negativas, que são posteriormente alteradas para 0.0, afinal intensidades negativas não fazem sentido.

Durante esse experimento, $L^{1}$ foi a métrica de distância adotada entre imagens HDR. A interpolação linear produziu o melhor ou segundo melhor resultado em todos os casos de teste. Além disso, por ser de grau baixo, esse método de interpolação não gerou áreas pretas, como ocorreu em todos os outros métodos de interpolação testados.

Para o segundo teste utilizou-se um objeto simples como base para renderização, no caso, um paralelepípedo feito de papelão, coberto por papel branco (Figura 5.6).

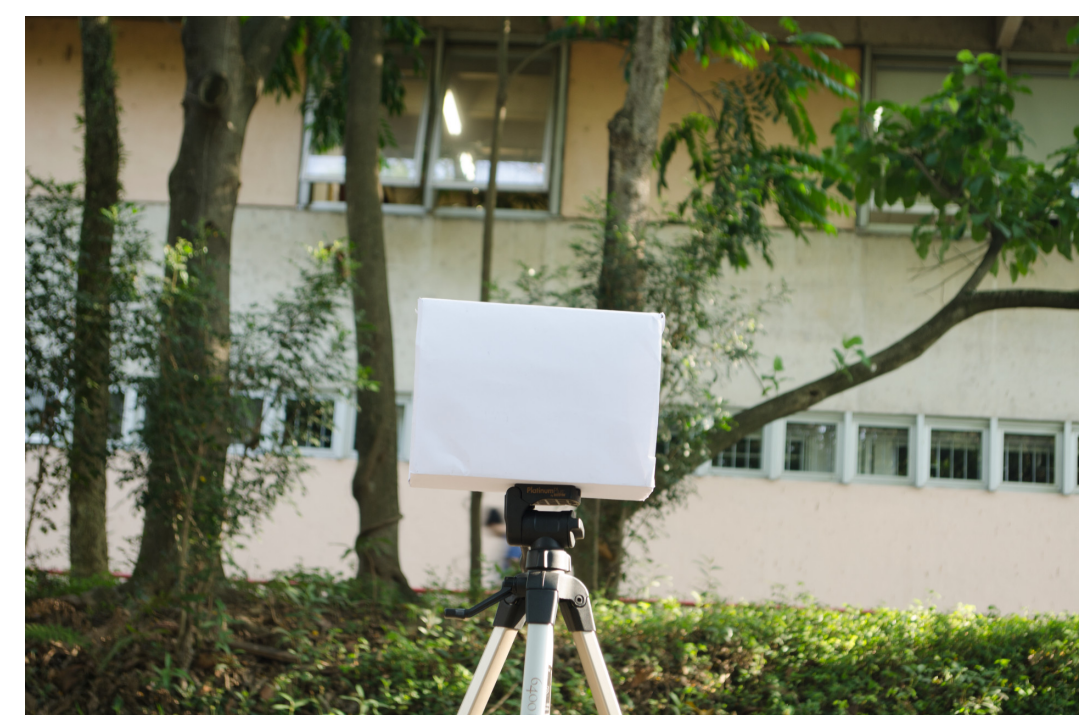

Figura 5.6: Paralelepípedo branco usado para realizar as comparações entre as cenas reais e virtuais.

Para cada instante de teste, foi removida uma imagem de light probe da série temporal de dados, e gerada, por meio de interpolações, uma imagem de light probe artificial. Em seguida foram determinadas as duas imagens artificiais com menor distância em relação à original, essas imagens foram então utilizadas na renderização do paralelepípedo virtual. 
Durante esse experimento não foram utilizados marcadores fiduciais para determinar as transformações de posicionamento do objeto virtual. A imagem original do paralelepípedo foi usada como plano de fundo e o paralelepípedo virtual foi inserido manualmente, de modo a tentar manter a proporção e a perspectiva corretas. Um branco difuso foi utilizado como material do paralelepípedo virtual.

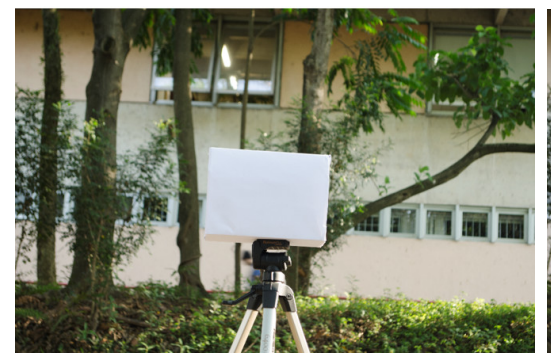

(a)

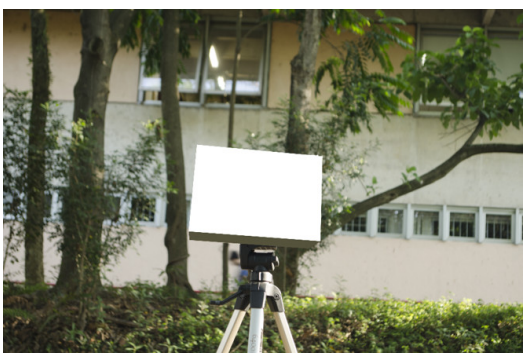

(b)

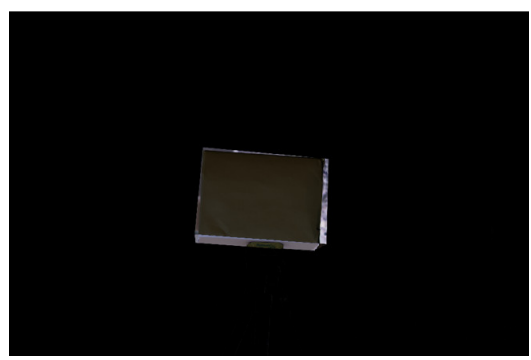

(c)

Figura 5.7: (a) cena externa às 18:05, (b) paralelepípedo renderizado utilizando light probe gerado a partir da interpolação linear, (c) diferença.

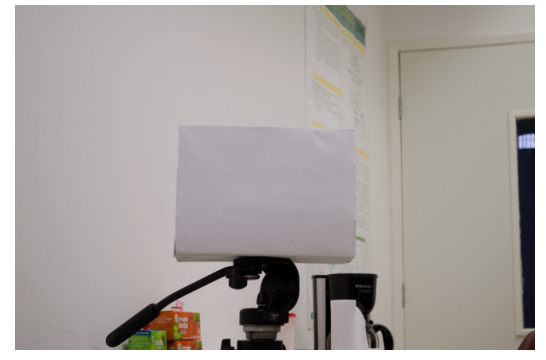

(a)

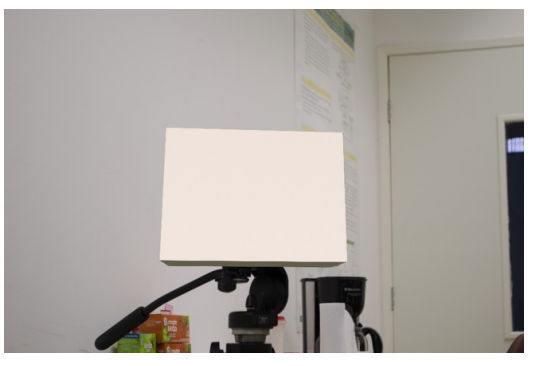

(b)

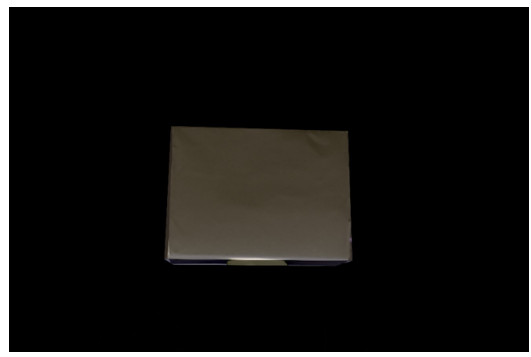

(c)

Figura 5.8: (a) cena interna às 18:45, (b) paralelepípedo renderizado utilizando light probe gerado a partir da interpolação linear, (c) diferença.

Houveram pelo menos dois problemas na geração desses dados: em algumas das imagens o light probe ficou fora de foco, pequenos deslocamentos também foram detectados. Isso ocorreu, pois tanto o light probe quanto a câmera tiveram que ser reposicionados entre cada tomada, o que implicou nas movimentações e nas diferenças de foco.

A comparação entre o paralelepípedo real e o renderizado não foi bem-sucedida. Para que esse teste funcionasse corretamente o paralelepípedo virtual precisaria ser modelado (geometria e materiais) e posicionado de maneira idêntica ao real. Como a modelagem de objetos virtuais não é uma tarefa trivial, decidiu-se abandonar esse formato de teste, em favor do uso de questionários e voluntários, como descrito na seção 4.4.

Um ponto importante que ficou claro ao realizar esses experimentos preliminares é o fato de que um ambiente controlado é fundamental. Pequenas movimentações não necessariamente precisam ser eliminadas, mas certamente minimizadas, e apesar de não haver nenhum impedimento para o funcionamento em cenas externas, a aquisição de dados nesse tipo de cena se torna muito mais complexa, pois há variáveis que fogem de controle, como a movimentação de pessoas e objetos, além disso, caso haja a necessidade de remover o equipamento entre cada tomada há um aumento na movimentação, rotação e diferenças no foco. 


\subsection{Coleta de Dados}

Para os testes finais foram realizadas duas aquisições. Ambas em ambientes internos, sem o uso de iluminação artificial, porém, com propósitos diferentes: a primeira foi feita para comparação entre imagens de light probes originais e interpoladas, já a segunda foi feita tanto para comparar as imagens de light probes quanto para inserir objetos virtuais no plano de fundo, permitindo a realização dos experimentos de realidade mista e a criação dos vídeos. As aquisições foram realizadas em dias diferentes.

\section{Primeira Aquisição}

A primeira aquisição foi relativamente simples, tanto a câmera quanto o light probe foram mantidos fixos. A câmera foi posicionada no mesmo nível e direcionada para o centro do light probe. Essa aquisição teve início às 10:58 e término às 20:29, foram realizadas 20 tomadas com período de aquisição de aproximadamente 30 minutos (Figura 5.9).

Em cada tomada foram obtidas no mínimo 17 imagens com exposições diferentes, e no máximo 19, dependendo da iluminação da cena no instante da aquisição, os tempos de exposição utilizados variaram então de $1 / 4000 s$ até $\{15 s, 20 s, 30 s\}$. A câmera utilizada na primeira aquisição foi uma Nikon D5100 com as seguintes configurações: balanço de branco "Nublado", ISO-100, distância focal $55 \mathrm{~mm}$ F-Stop $f / 7.1$ e focagem manual.

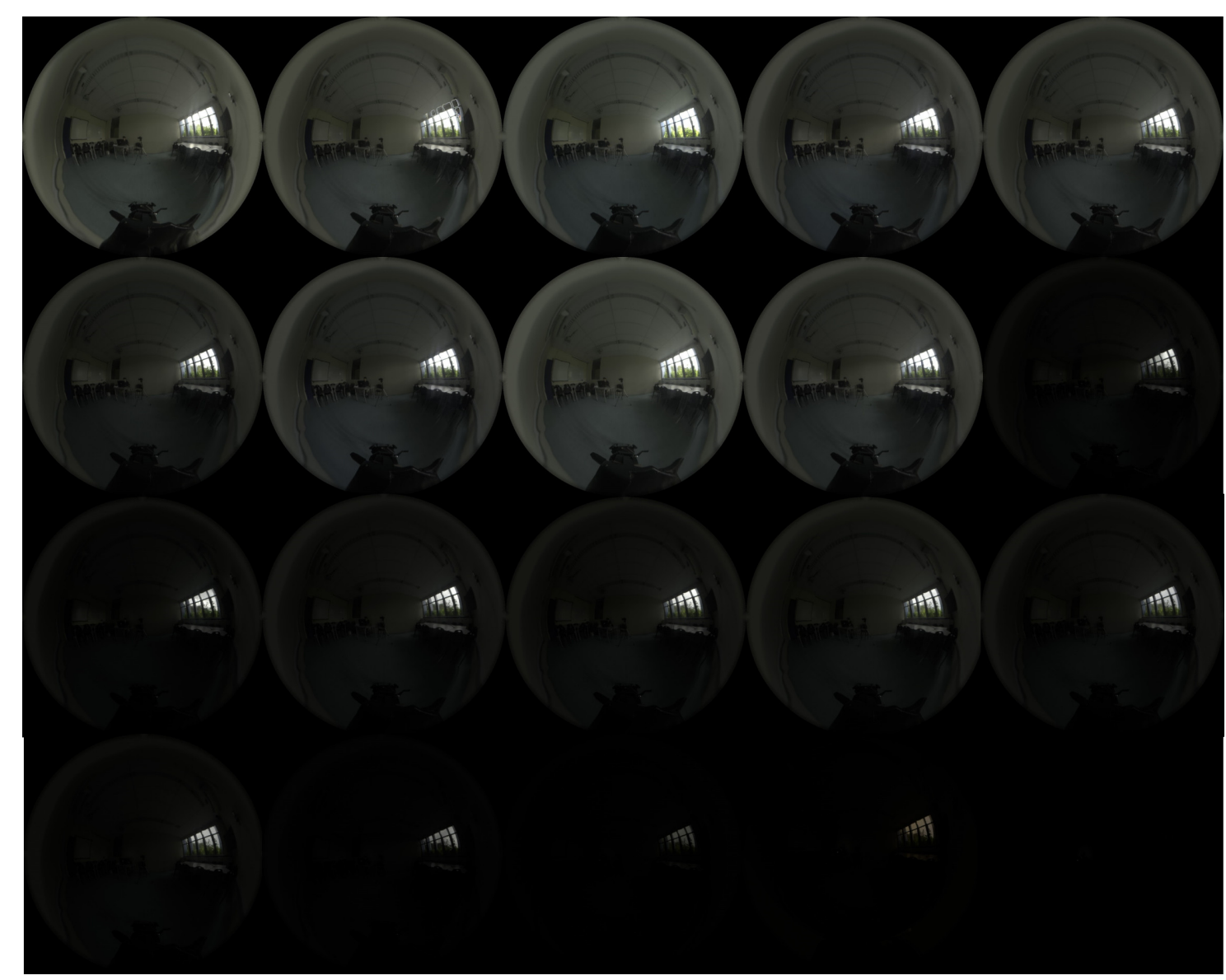

Figura 5.9: Série temporal de imagens de light probes obtida durante a primeira aquisição. Início às 10:52 e término às 20:24 com período de aproximadamente 30 minutos entre cada tomada. 


\section{Segunda Aquisição}

Durante a segunda aquisição, além de imagens do light probe, também foram adquiridas imagens do plano de fundo. Duas versões do plano de fundo foram adquiridas: uma sempre igual e outra diferente para cada tomada. A versão com plano de fundo igual em todas as tomadas foi adquirida para criação dos vídeos, já a versão com plano de fundo diferente foi adquirida para o experimento de realidade mista. Além disso, nessa segunda aquisição foi inserido um marcador fiducial em uma das tomadas, de modo a estimar as transformações de posicionamento para os objetos virtuais. O procedimento adotado nessa aquisição pode ser visto na Figura 5.10.

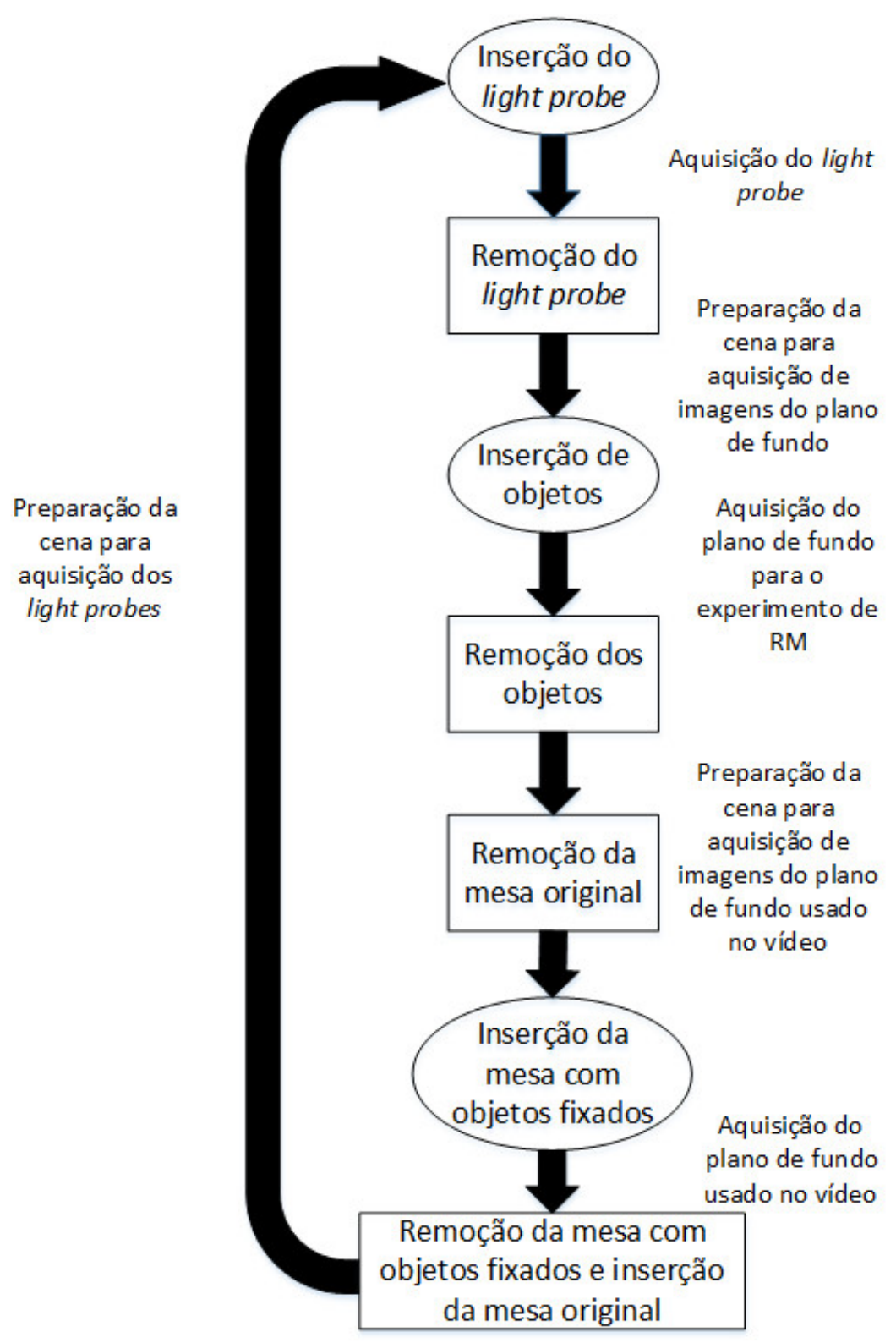

Figura 5.10: Diagrama que mostra o procedimento adotado durante a segunda aquisição. As elipses representam os passos em que houveram aquisições de imagens.

Foram utilizadas duas câmeras como forma de minimizar movimentações, as câmeras utilizadas foram: Nikon D5100 e Nikon D3200. A Nikon 3200 foi utilizada para capturar 
imagens do light probe, a câmera foi posicionada no mesmo nível e direcionada para o centro do light probe. A Nikon D5100 por sua vez foi utilizada para capturar o plano de fundo, e estava deslocada para cima e levemente inclinada para baixo. As duas câmeras estavam configuradas da mesma maneira: balanço de branco "Nublado", ISO-100, distância focal 35mm F-Stop $f / 8$ e focagem manual. Em cada tomada foram utilizadas 18 exposições diferentes, com tempo de exposição variando entre $1 / 4000 s$ e $30 s$.

Essa aquisição teve início às 15:06 e término às 20:37. Foram adquiridas: uma série temporal com 12 imagens de light probes (Figura 5.11), 12 imagens do plano de fundo com objetos distintos (Figura 5.12) e 23 imagens do plano de fundo com os mesmos objetos (Figura 5.13), para uso na geração dos keyframes do vídeo.

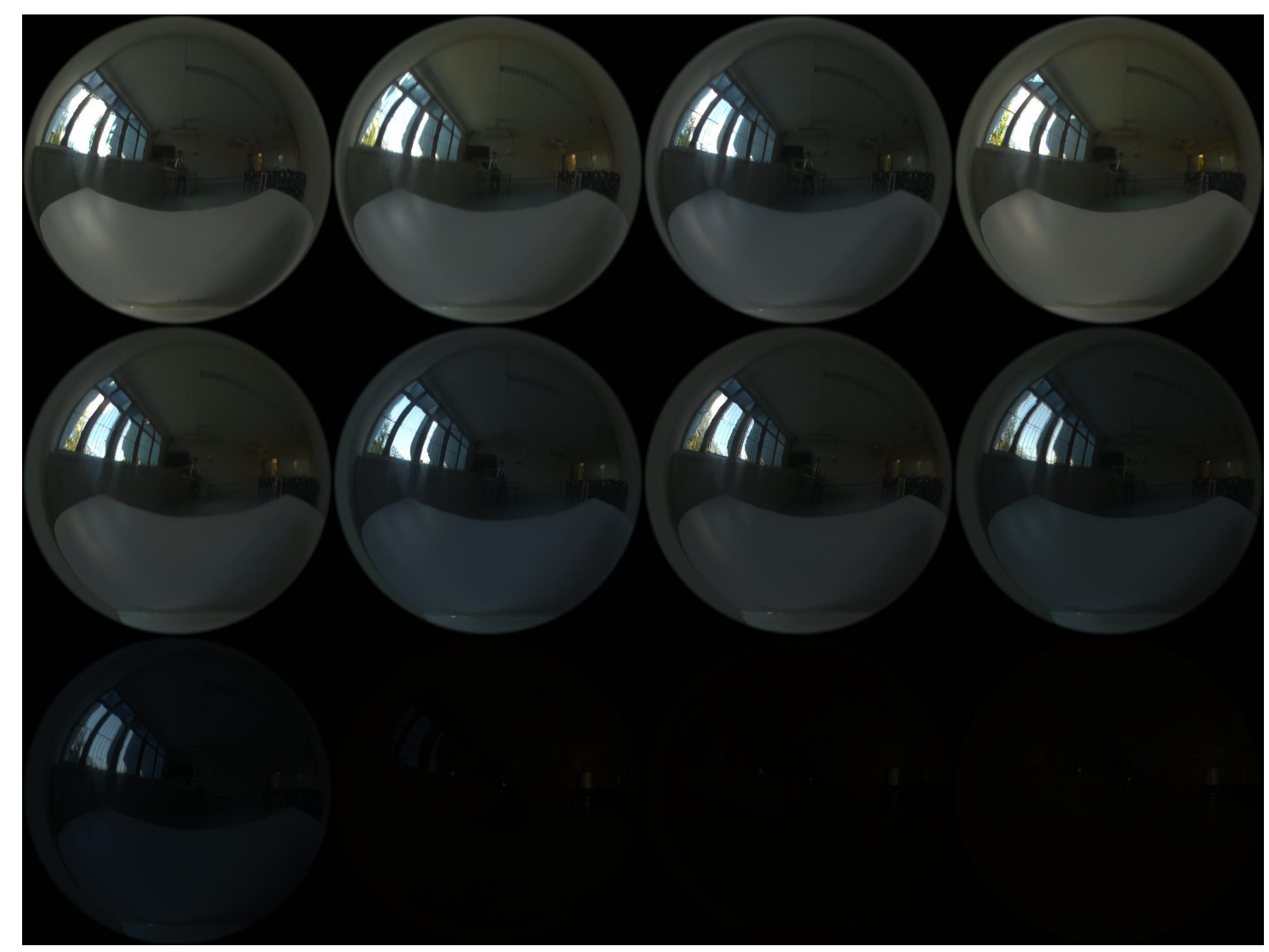

Figura 5.11: Série temporal de imagens de light probes obtida durante a segunda aquisição. Início às 15:00 e término às 20:37, com período de aproximadamente 30 minutos entre cada tomada. 


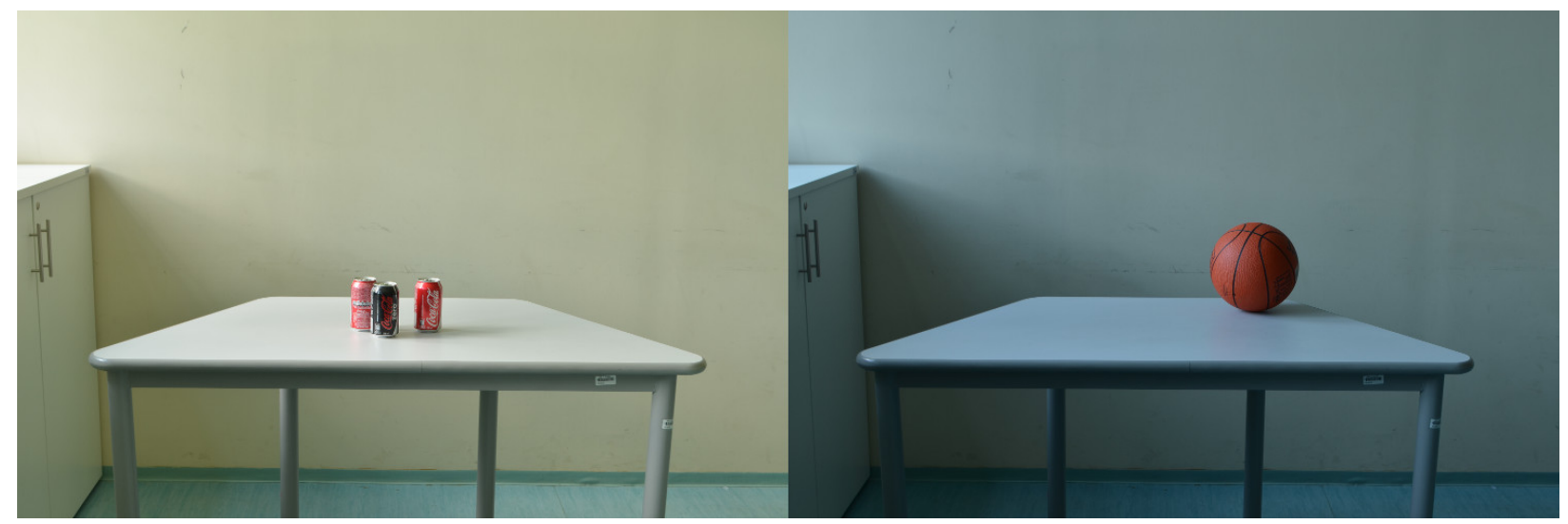

Figura 5.12: Planos de fundo utilizados no segundo experimento em diferentes horários.

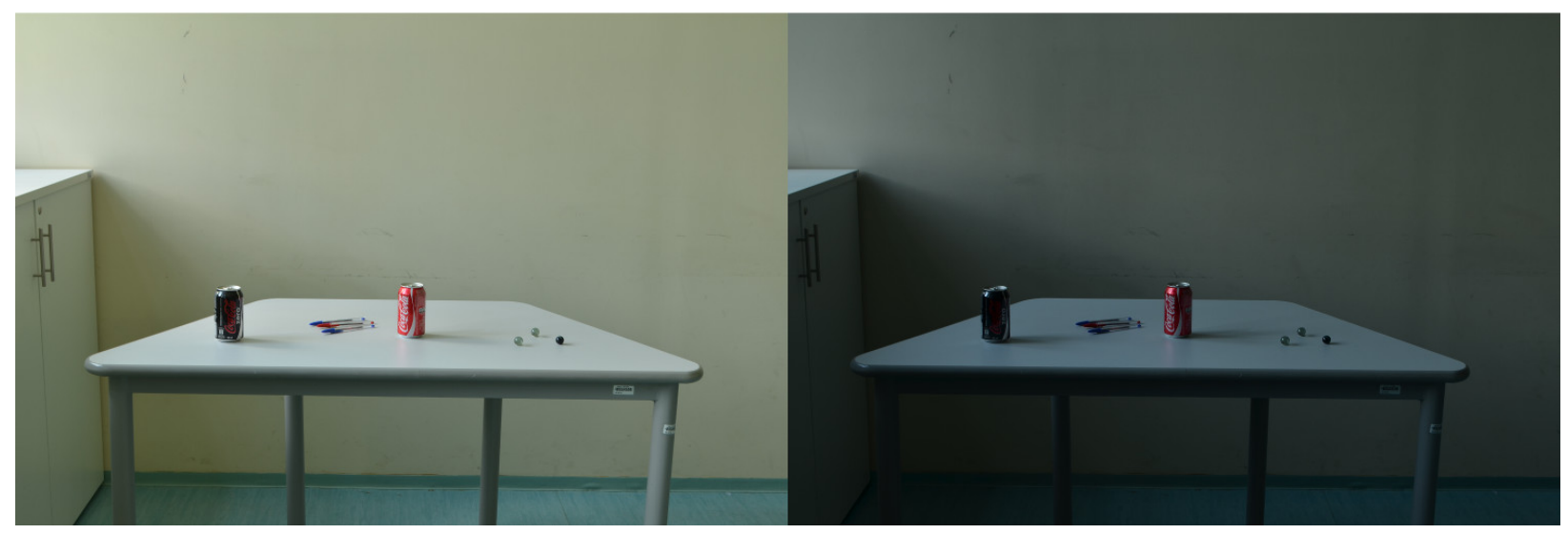

Figura 5.13: Plano de fundo utilizado para geração dos keyframes do vídeo em diferentes horários.

Devido a necessidade de alterar o plano de fundo para realização dos experimentos de realidade mista, houve a necessidade de alterar a cena entre cada tomada, e devido a essas alterações houveram pequenas movimentações entre cada tomada. Pequenos deslocamentos no posicionamento da esfera de metal foram corrigidos utilizando Photoshop ${ }^{\circledR}$.

\section{Calibragem do Light Probe}

Como mencionado na Seção 2.4, um passo importante ao se trabalhar com light probes é a determinação do coeficiente de reflexão, afinal, o light probe não é um refletor perfeito e ajustes precisam ser feitos durante a renderização, como forma de compensação. O coeficiente, por sua vez, é dado pela razão entre o valor dos pixels de um objeto e de sua reflexão pelo light probe. $\mathrm{O}$ coeficiente foi determinado de forma independente para cada canal:

- $R=1.74$

- $G=1.75$

- $B=1.85$ 


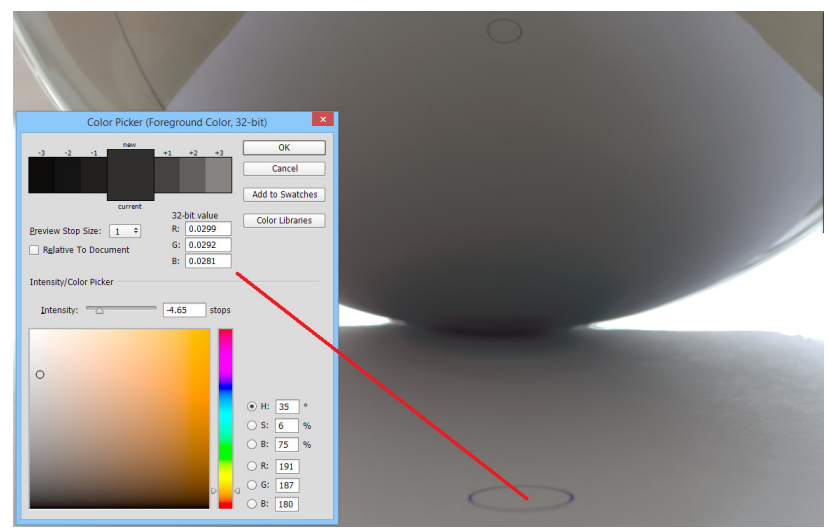

(a)

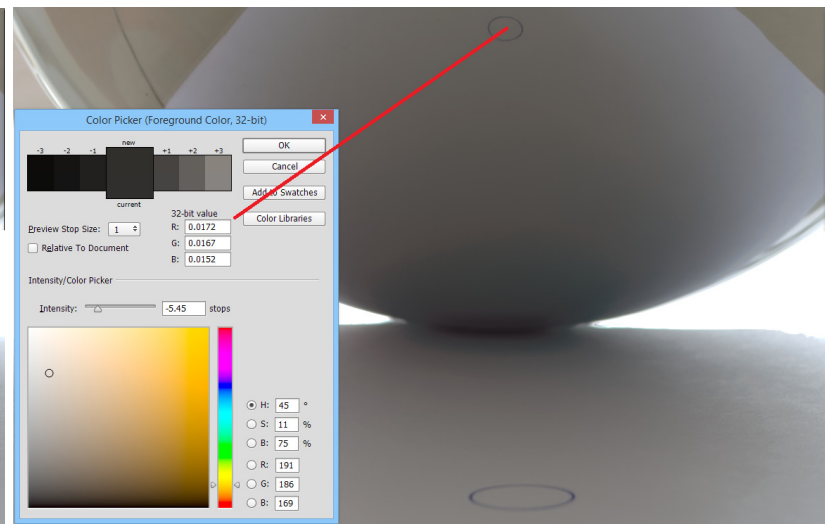

(b)

Figura 5.14: Imagem utilizada para determinar o coeficiente de reflexão do light probe. (a) intensidade amostrada do objeto, (b) intensidade amostrada da reflexão do objeto.

\subsection{Primeiro Experimento}

O procedimento adotado nesse experimento foi similar ao adotado durante o experimento preliminar. Uma imagem de light probe foi removida do conjunto de dados, em seguida uma versão artificial dessa imagem foi gerada para comparação. Porém, há algumas diferenças notáveis, os testes foram realizados para todos os instantes possíveis e não apenas em alguns horários selecionados, além disso, foram utilizadas todas as interpolações e aproximações descritas nos Apêndices A e B, ou seja:

- Lagrange

- Linear

- Quadrática

- Gauss's Forward

- Gauss's Backward

- Stirling

- Spline cúbica natural

- Bézier

- Bézier quadrática

- Bézier cúbica

- B-Spline cúbica
$(\mathrm{SCN})$

(BÉZ QUAD)

(BÉZ CÚB)

$(\mathrm{BSC})$

Para os testes com as interpolações de Gauss e Stirling, que necessitam de dados uniformemente espaçados, além de remover a imagem do light probe que estava sendo testada, também foram removidas outras imagens da série temporal, de modo que o intervalo de tempo entre elas se tornasse aproximadamente uma hora. Para os demais casos, foram considerados todos os outros instantes de aquisição para geração das interpolações ou aproximações. 
A métrica adotada para as comparações foi a distância $L^{2}$. Os testes foram realizados com as imagens dos light probes no formato de mapa esférico.

Esse primeiro teste foi feito utilizando os dois conjuntos de dados que foram adquiridos. As tabelas com os resultados obtidos para cada instante e tipo de interpolação podem ser vistas no Apêndice G. De acordo com a métrica utilizada, dentre as interpolações, a que mais se aproxima dos resultados esperados é a interpolação linear, já para as aproximações os destaques foram a Bézier e Bézier cúbica. A Bézier obteve bons resultados em um dos conjuntos de dados, porém, os resultados foram ruins para o outro conjunto, já a Bézier cúbica obteve bons resultados nos dois conjuntos de dados. Algumas imagens resultantes dos experimentos com o primeiro conjunto de dados podem ser vistas nas Figuras 5.15, 5.16 e 5.17 .

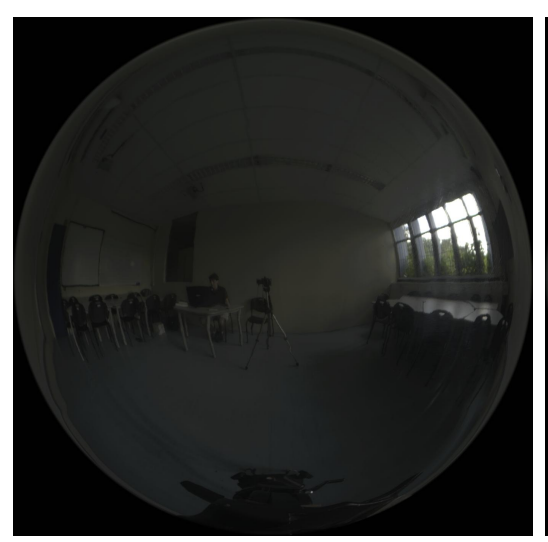

(a)

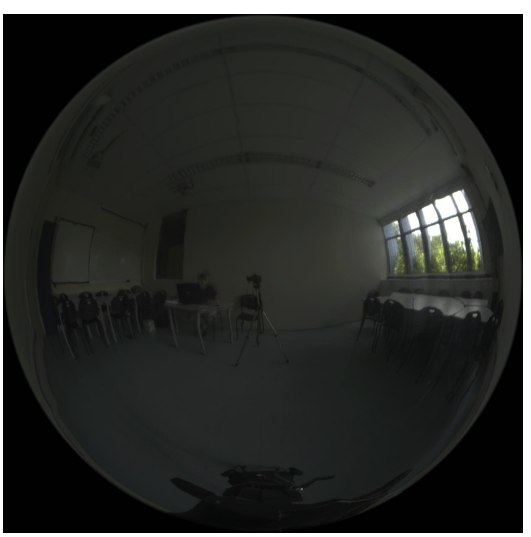

(b)

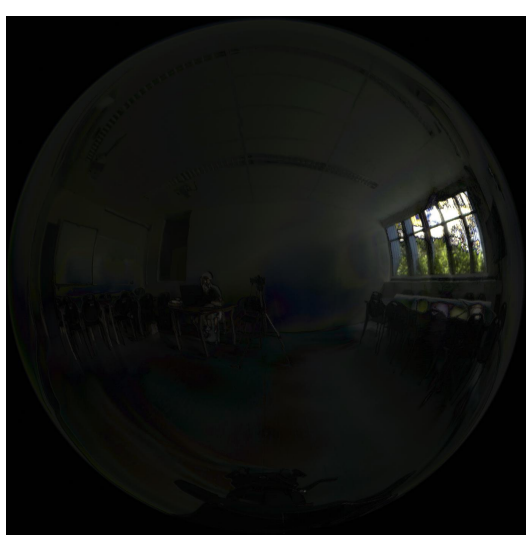

(c)

Figura 5.15: (a) Imagem de um light probe obtida às 12:22, (b) imagem gerada utilizando interpolação linear, (c) diferença.

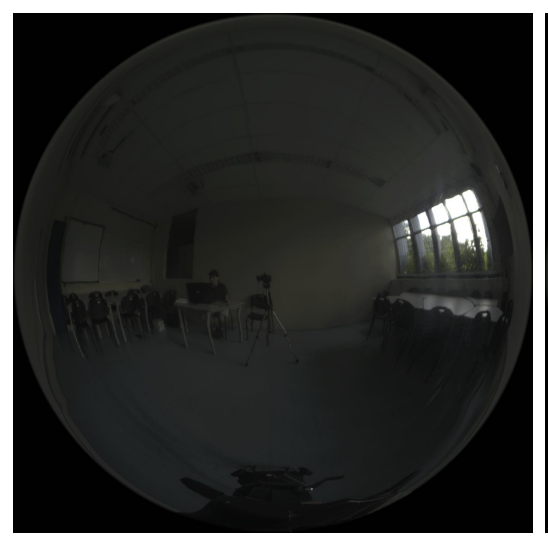

(a)

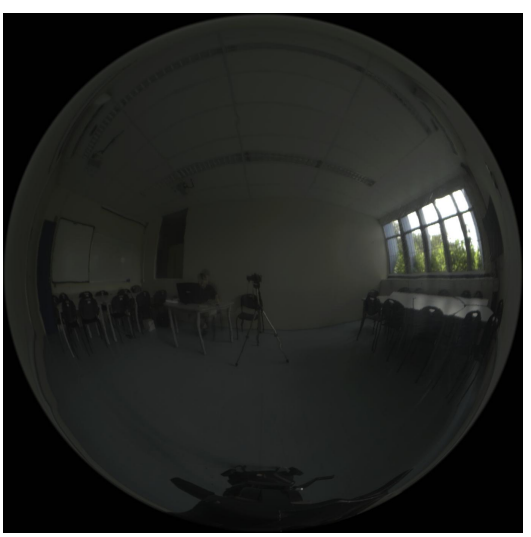

(b)

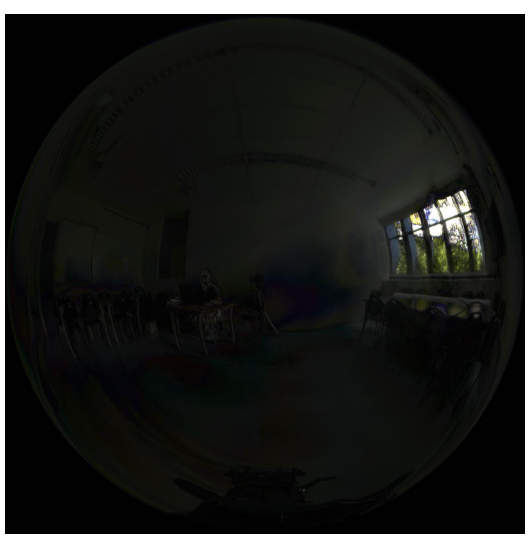

(c)

Figura 5.16: (a) Imagem de um light probe obtida às 12:22, (b) imagem gerada utilizando aproximação Bézier cúbica, (c) diferença. 


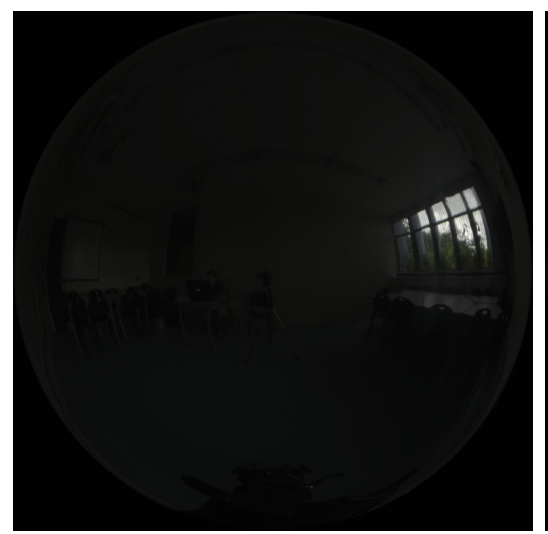

(a)

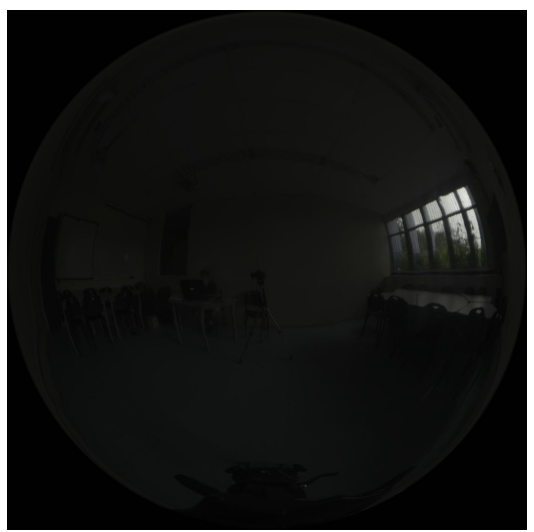

(b)

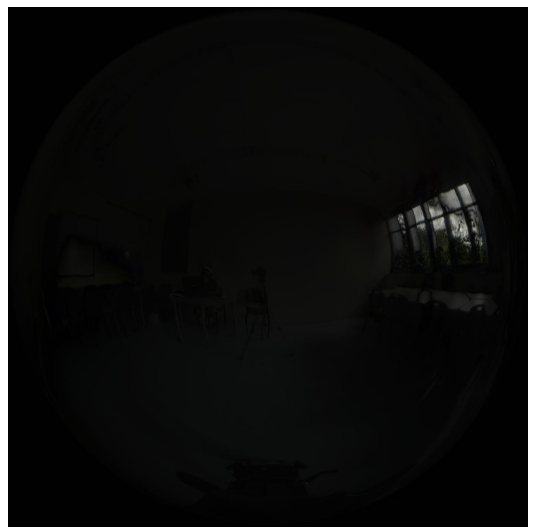

(c)

Figura 5.17: (a) Imagem de um light probe obtida às 15:53, (b) imagem gerada utilizando interpolação linear, (c) diferença.

Imagens resultantes dos experimentos com o segundo conjunto de dados podem ser vistas nas Figuras 5.18, 5.19 e 5.20.

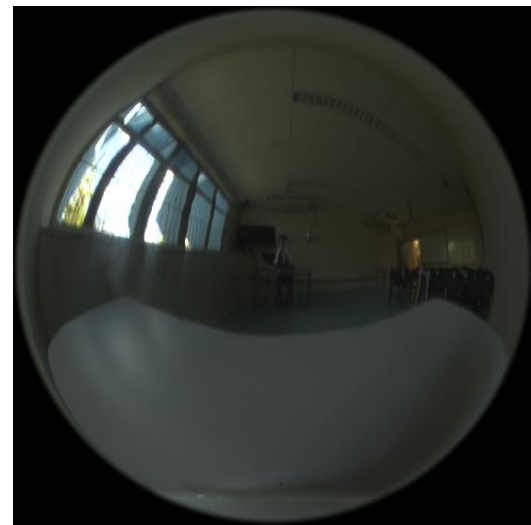

(a)

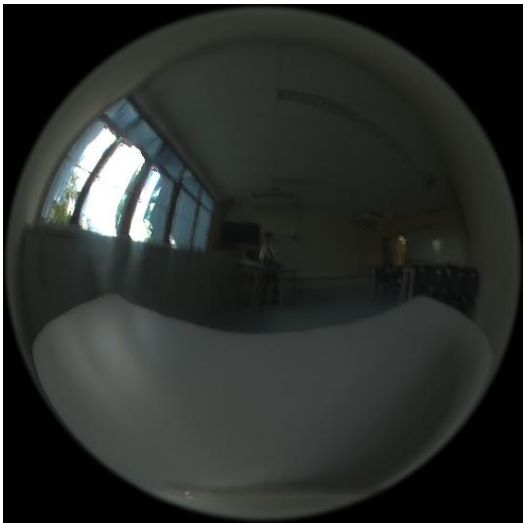

(b)

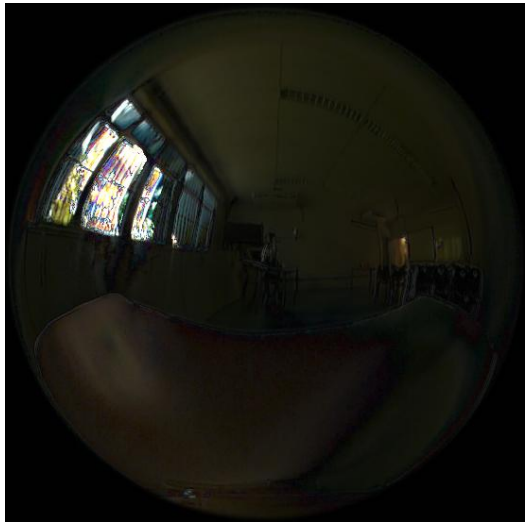

(c)

Figura 5.18: (a) Imagem de um light probe obtida às 15:38, (b) imagem gerada utilizando interpolação linear, (c) diferença.

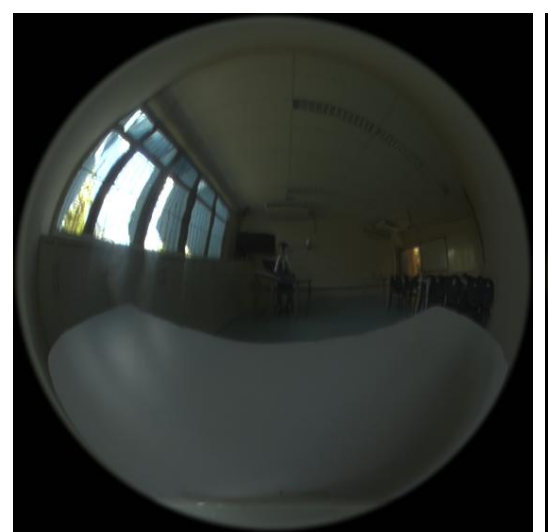

(a)

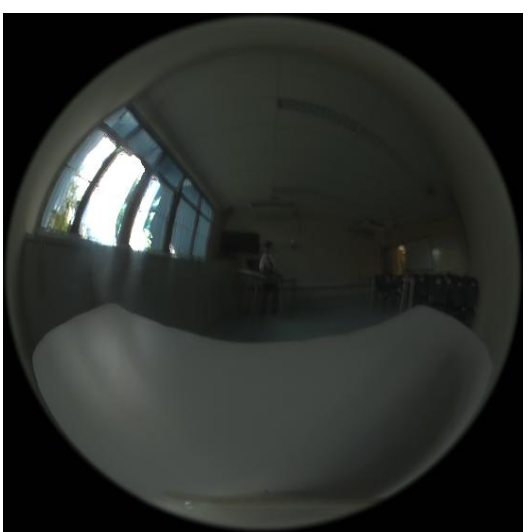

(b)

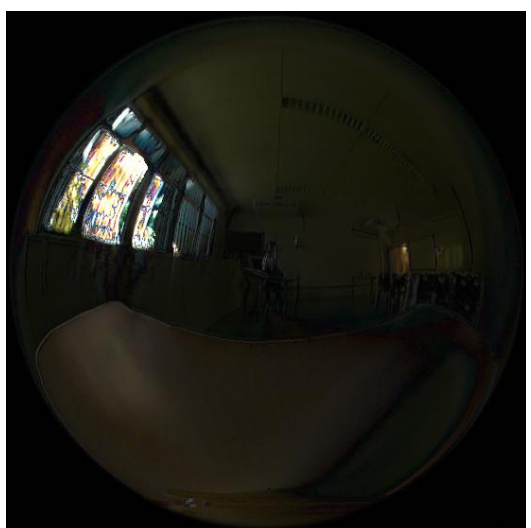

(c)

Figura 5.19: (a) Imagem de um light probe obtida às 15:38, (b) imagem gerada utilizando aproximação Bézier cúbica, (c) diferença. 


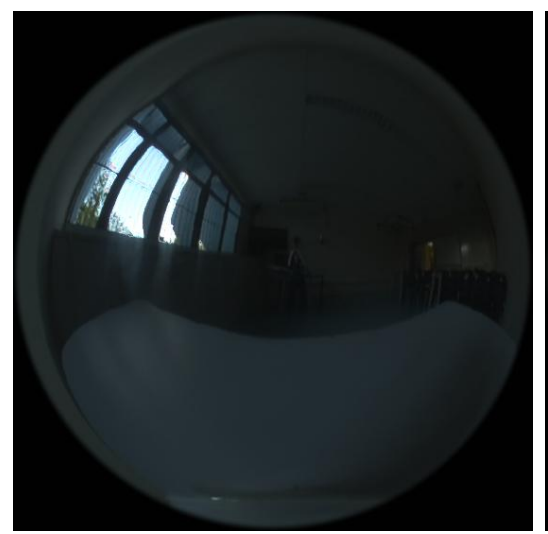

(a)

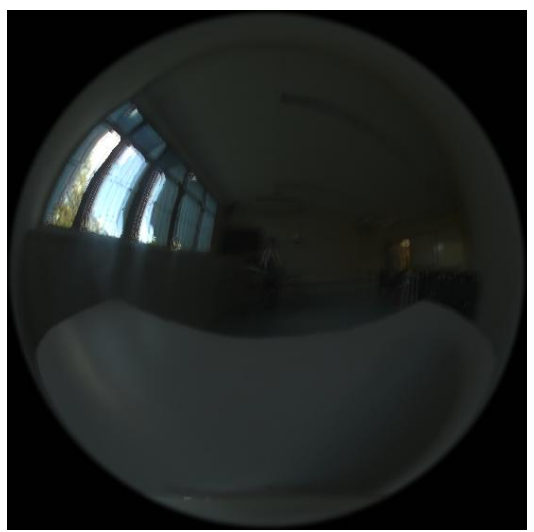

(b)

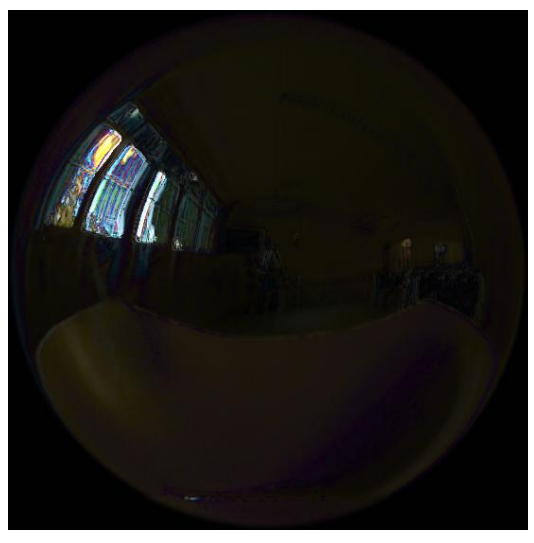

(c)

Figura 5.20: (a) Imagem de um light probe obtida às 17:40, (b) imagem gerada utilizando interpolação linear, (c) diferença.

Um ponto a ser destacado é a luminosidade nas imagens de diferença, mesmo com as imagens utilizadas nesse cálculo sendo tão similares. A causa para a elevada intensidade nas diferenças, se deu por uma combinação de fatores: movimentações da esfera, heterogeneidade de intensidades dentro da área iluminada, variações de intensidades observadas nas amostras de iluminação próximas e também há o fato de que as diferenças são calculadas com imagens no formato HDR.

Para melhor analisar os resultados, a luminosidade total das imagens também foi estimada. Essa estimativa foi calculada utilizando a distância $L^{2}$ entre a imagem em questão e uma imagem totalmente preta. Os testes, para estimação de luminosidade total, foram realizados para a interpolação linear e as aproximações Bézier cúbica e Bézier. O procedimento adotado nesse teste foi um pouco diferente do teste anterior, nesse caso não foram removidas nenhuma imagem de light probe do conjunto de dados, todas foram mantidos. As intensidades luminosas estão representadas nas Figuras 5.21 até 5.26:

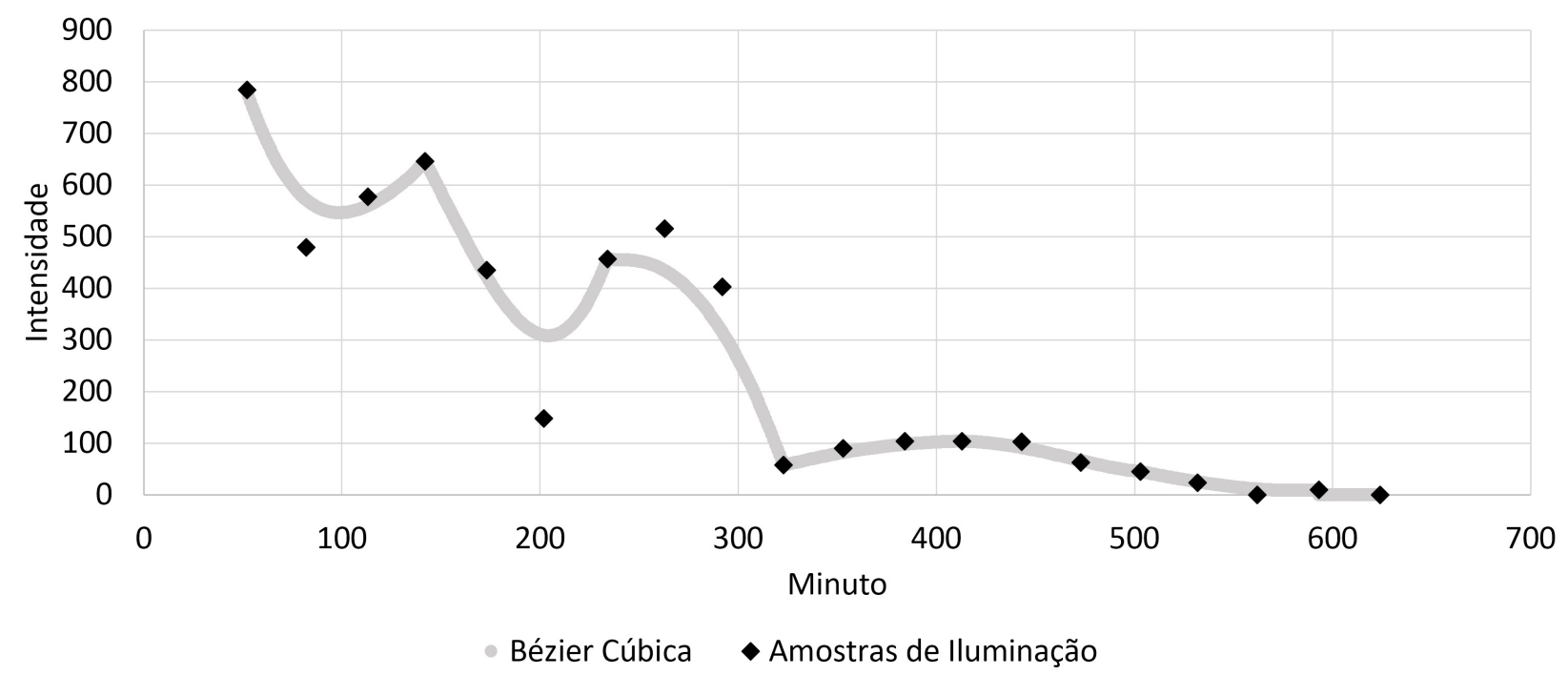

Figura 5.21: Gráfico de intensidades das imagens dos light probes originais e artificiais (Bézier Cúbica) em relação ao tempo, para a primeira série temporal. 


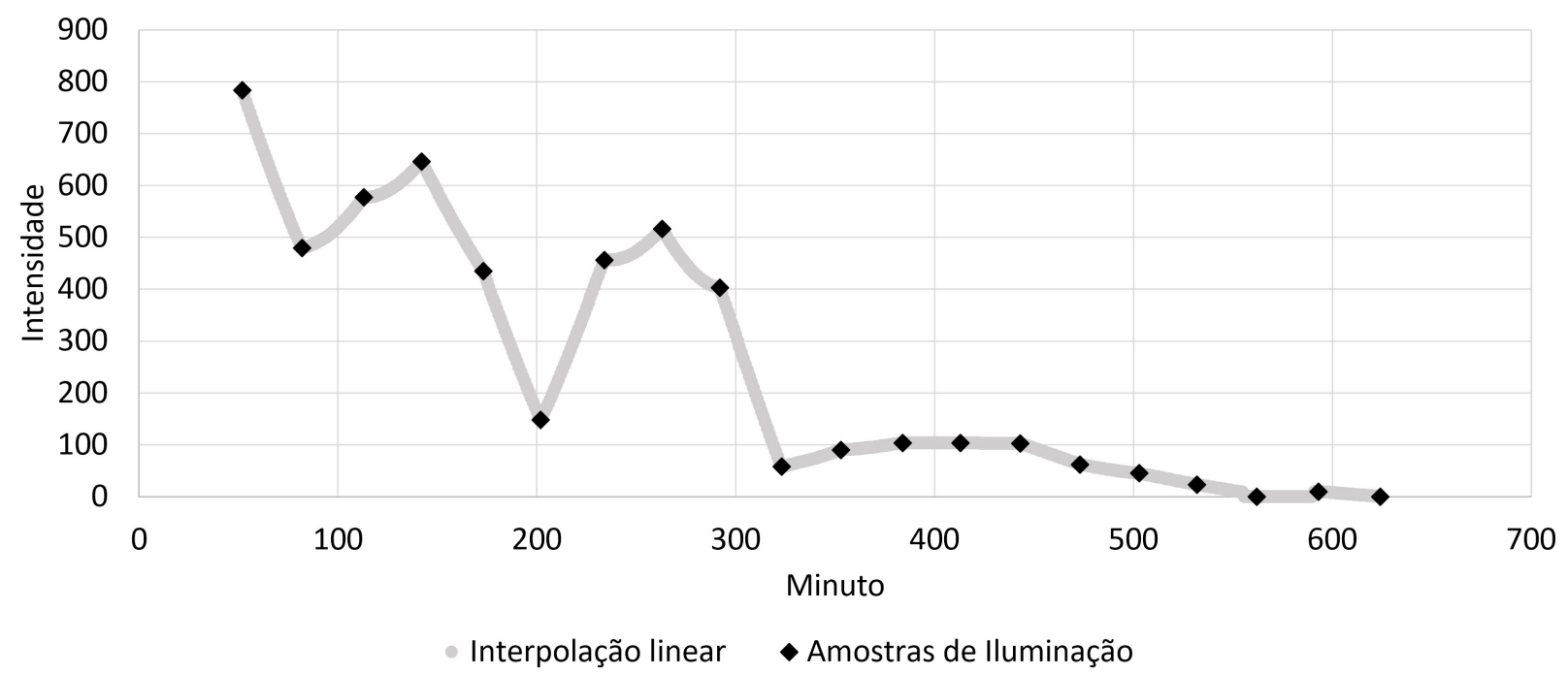

Figura 5.22: Gráfico de intensidades das imagens dos light probes originais e artificiais (Linear) em relação ao tempo, para a primeira série temporal.

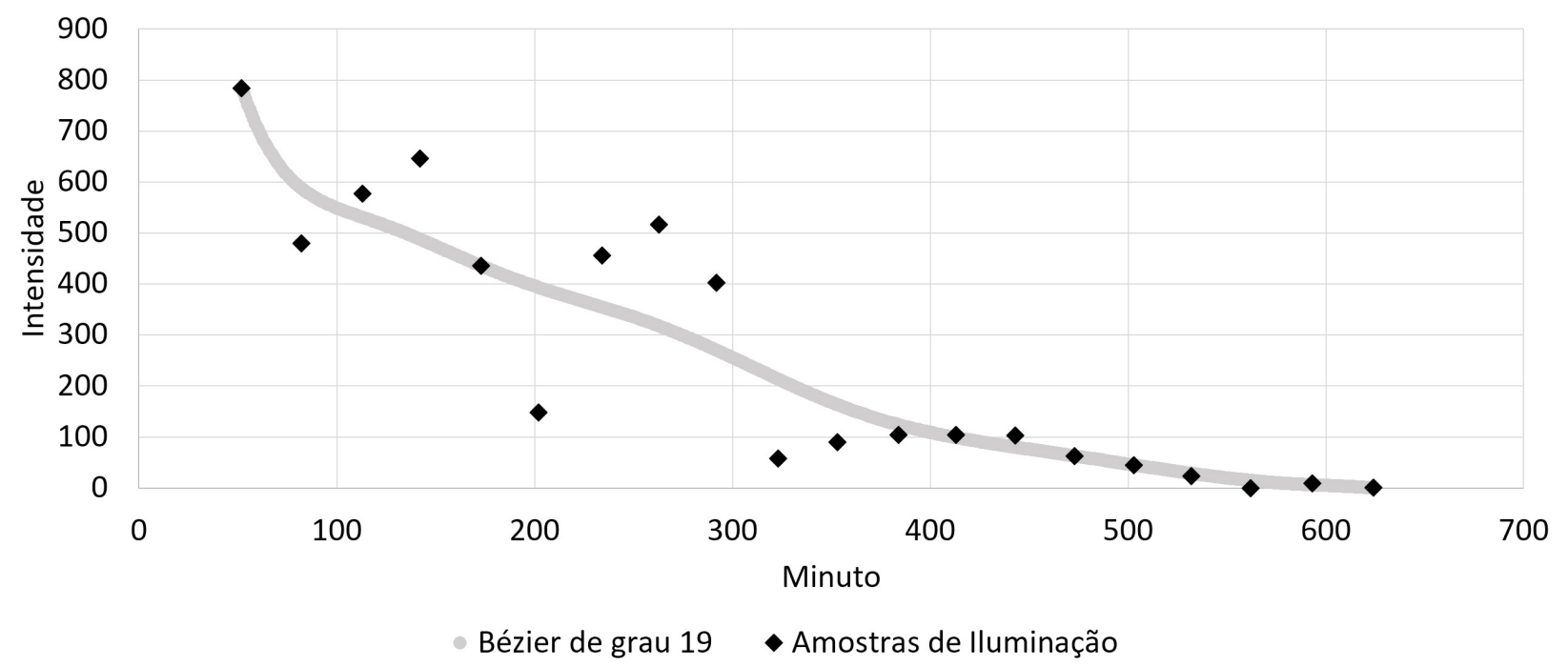

Figura 5.23: Gráfico de intensidades das imagens dos light probes originais e artificiais (Bézier) em relação ao tempo, para a primeira série temporal. 


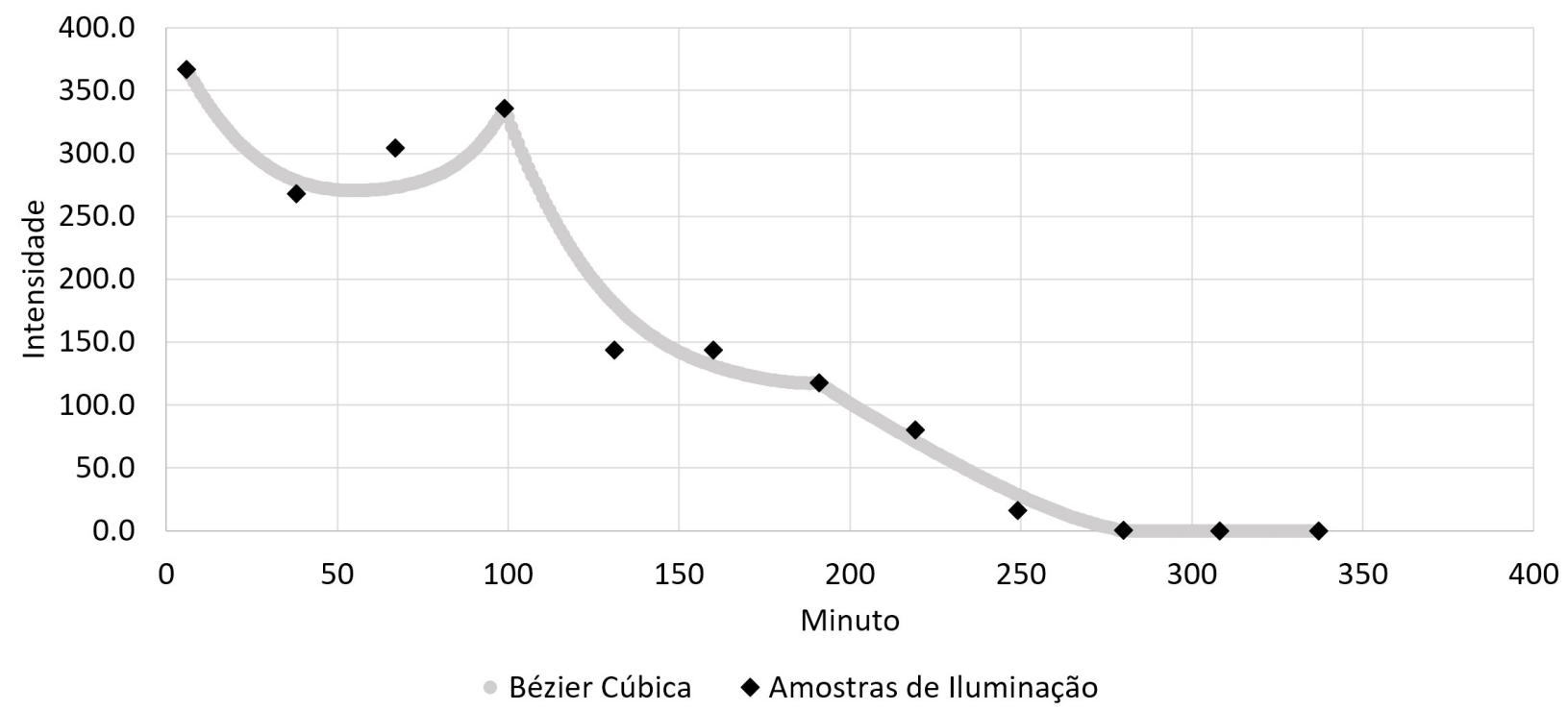

Figura 5.24: Gráfico de intensidades das imagens dos light probes originais e artificiais (Bézier Cúbica) em relação ao tempo, para a segunda série temporal.

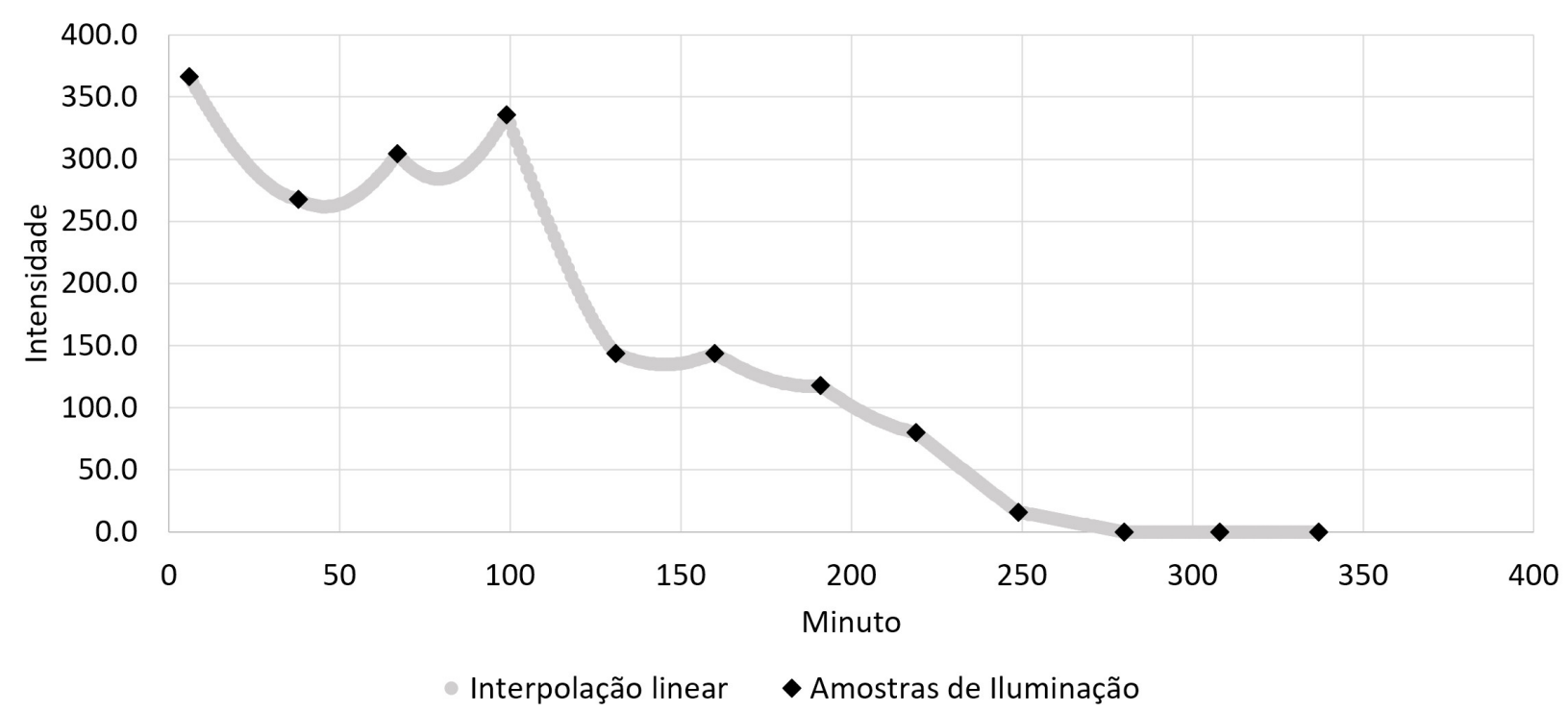

Figura 5.25: Gráfico de intensidades das imagens dos light probes originais e artificiais (Linear) em relação ao tempo, para a segunda série temporal. 


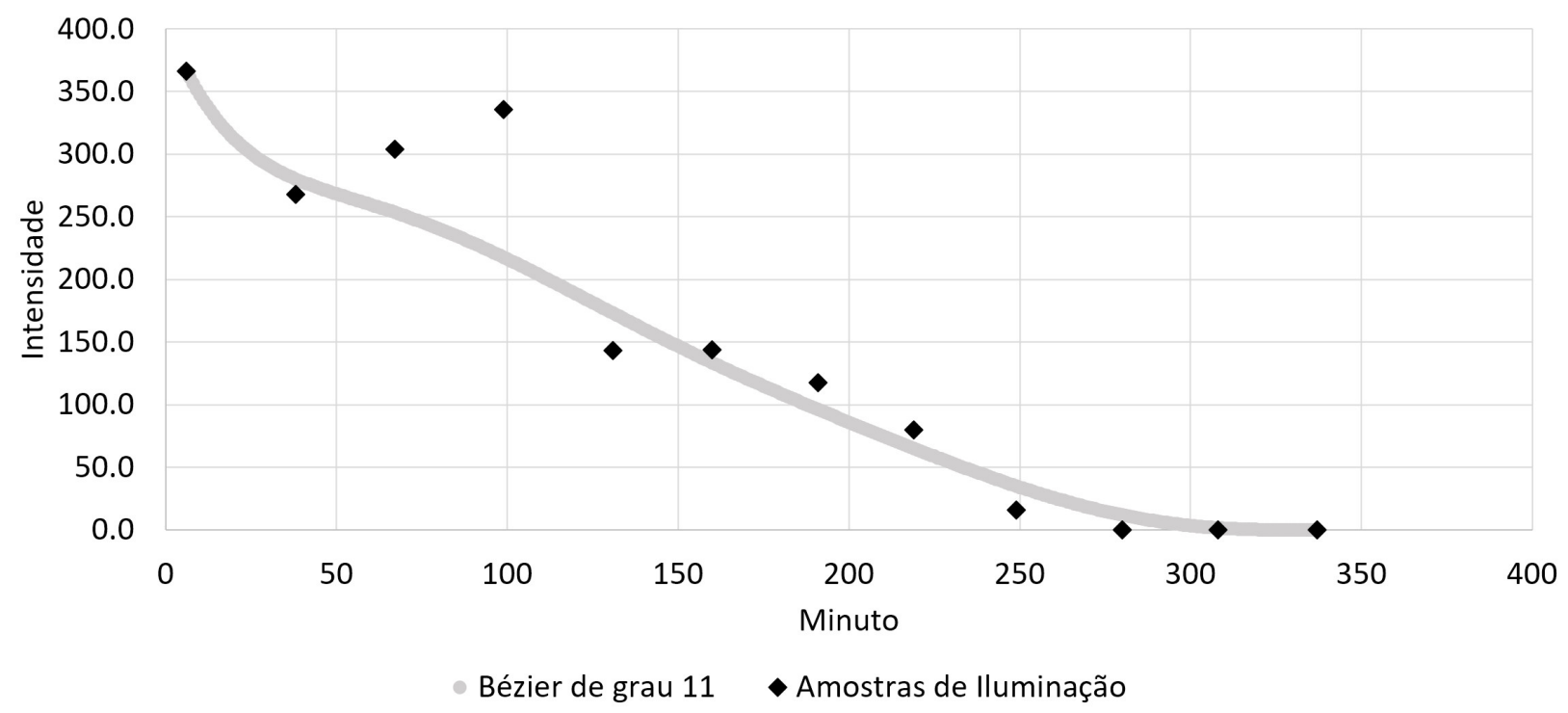

Figura 5.26: Gráfico de intensidades das imagens dos light probes originais e artificiais (Bézier) em relação ao tempo, para a segunda série temporal.

As intensidades luminosas nas imagens dos light probes originais não seguiram uma distribuição esperada, ou seja, as intensidades não necessariamente apresentaram uma queda suave ao longo do dia, houveram quedas bruscas e também aumento nas intensidades. Esse tipo de efeito pode ter sido causado pela condição climática dos dias escolhidos, com a passagem de nuvens e oclusão do Sol em determinados instantes. Esse efeito foi frequente durante o experimento, e ocorreu em ambas as capturas. Apesar de ter ocorrido nas duas aquisições, teve menor intensidade na segunda aquisição, com oscilações menores, isso explica o bom resultado da aproximação do tipo Bézier nessa aquisição.

Os gráficos das intensidades luminosas indicam que apesar das aproximações apresentarem grande suavidade, os pontos de controle não exercem tanta influência na curva, de forma que mudanças repentinas podem não ser bem representadas. Isso, porém, já não é problema em interpolações, e em especial na interpolação linear. Então, apesar do primeiro teste indicar que a Bézier cúbica apresenta resultados um pouco melhores que os resultados da interpolação linear, os gráficos de luminosidade total das imagens indicam que a interpolação linear seja superior aos outros métodos. Isso pois, se adapta mais rápido às mudanças súbitas na iluminação, que são tão frequentes e podem ser causadas por fatores como a movimentação de nuvens.

\subsection{Segundo Experimento}

Esse teste se baseia na percepção de voluntários, seu propósito é comparar imagens com e sem objetos virtuais, e determinar se voluntários conseguem distinguir os dois conjuntos. Diversas imagens, no contexto de RM, foram geradas: com objetos diferentes, em posições diferentes e em instantes diferentes, porém, sempre com iluminação proveniente de imagens de light probes artificiais, viabilizando assim a criação de questionários para validação da eficácia da metodologia.

O renderizador mental-ray ${ }^{\circledR}$ foi utilizado para produzir as imagens utilizadas nesse expe- 
rimento. Por questões de compatibilidade as imagens dos light probes foram convertidas para o formato de mapa angular, utilizando o software HDRShop ${ }^{\circledR}$. Para auxiliar na realização dos testes foi desenvolvido um plugin (Apêndice F.2) para o software Maya ${ }^{\circledR}$, a função desse plugin foi integrar o software de interpolação ao software de modelagem e renderização, facilitando o uso de IBL temporalmente variável.

O instante referente a geração de cada imagem de light probe artificial estava relacionado ao instante da aquisição da imagem do plano de fundo. Além disso, a imagem do light probe real, com instante de aquisição mais próximo ao instante de geração do mapa de iluminação artificial, foi removida do conjunto de dados. Isso evitou que a diferença de tempo entre um dado real e artificial fosse muito pequena, implicando em uma diferença aproximada mínima de cerca de 30 minutos em relação aos outros mapas de iluminação. Porém, houveram três exceções à essa regra, nesses casos a diferença de tempo entre a aquisição do plano de fundo e a imagem do light probe mais próxima foi de no mínimo 10 minutos. Nesse experimento todas as imagens de light probes foram geradas utilizando interpolação linear.

Foram utilizados alguns objetos simples para a geração das imagens finais:

- $\operatorname{canetas}($ Simões, 2015)

- latas de Coca-Cola ${ }^{\circledR}$ (Aránguez, 2015)

- bola de basquete (Fisco, 2015)

- bolas de gude (Ammusri, 2015)

Os modelos desses objetos foram obtidos a partir da internet, porém, todos sofreram alterações em seus materiais e em alguns casos a geometria também foi levemente modificada. As modificações foram feitas de modo a tornar os objetos virtuais mais parecidos com os objetos reais utilizados. O software Maya ${ }^{\circledR}$ foi utilizado para realizar as alterações.

O conjunto final de imagens foi composto por 25 imagens: 16 imagens geradas com objetos virtuais e 9 imagens sem modificações. As Figuras 5.27, 5.28 e 5.29 são exemplos de imagens que compõem esse conjunto: 


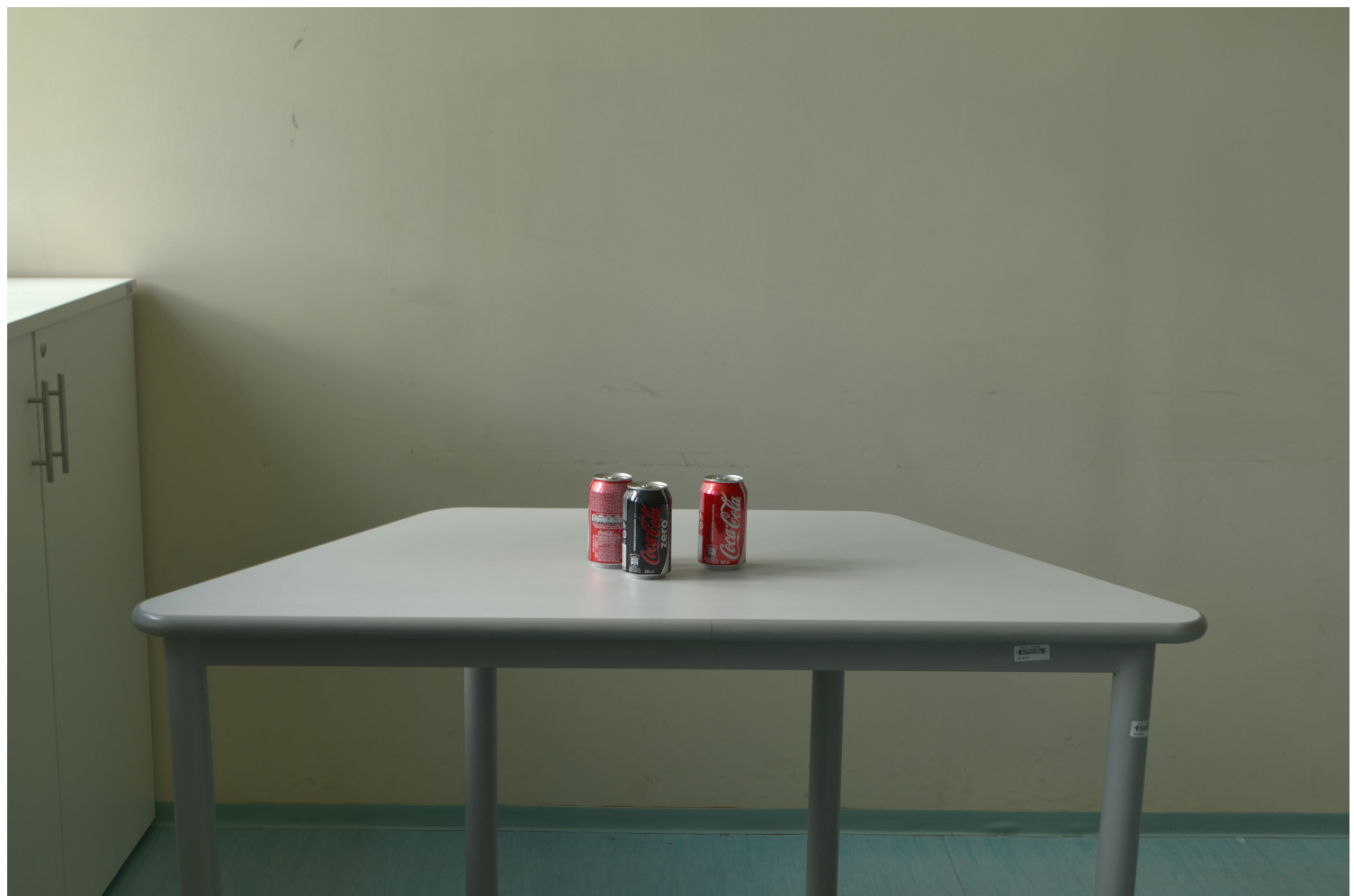

Figura 5.27: Uma das imagens (\#3) sem objetos virtuais utilizada nos testes.

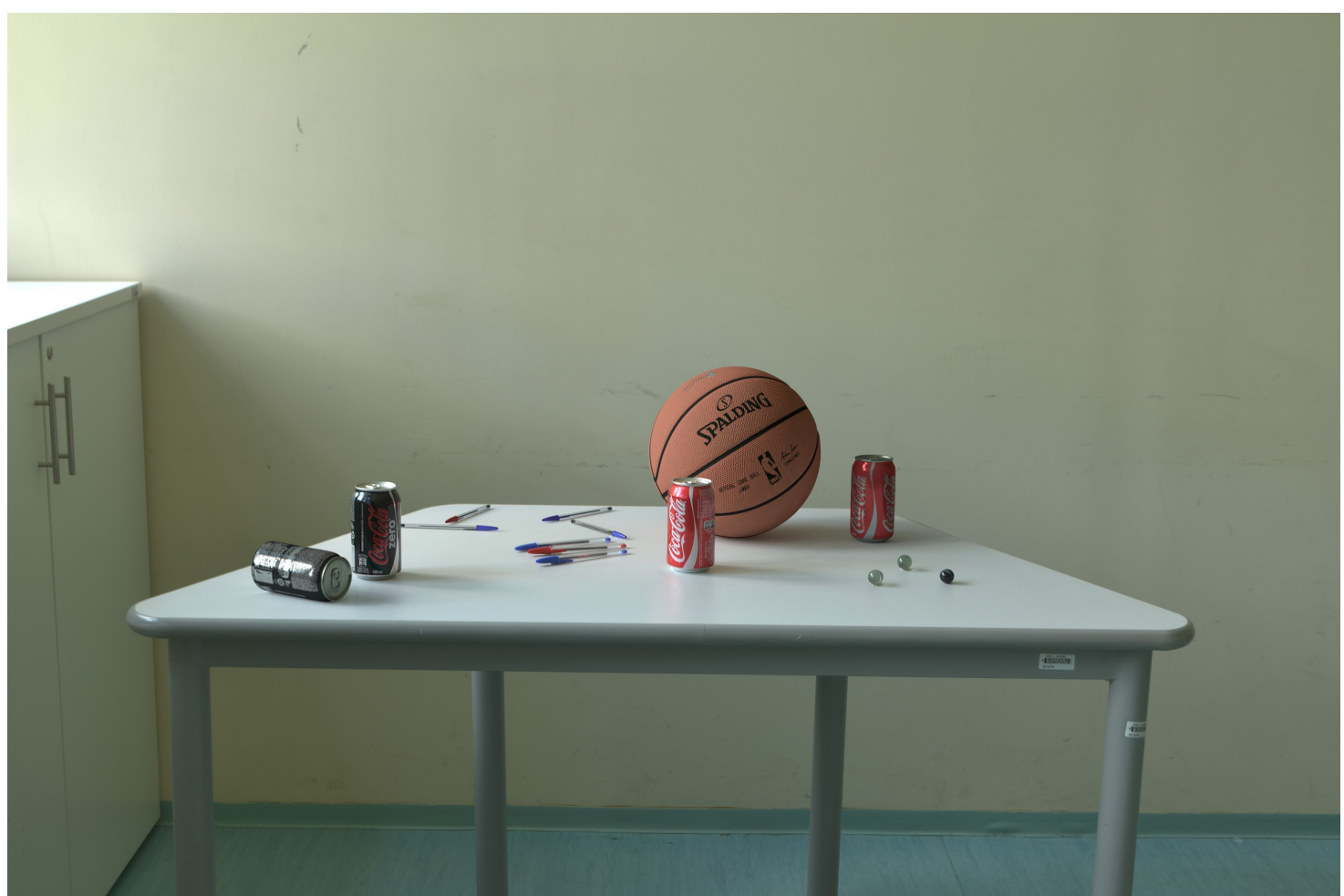

Figura 5.28: Imagem (\#11) com diversos objetos virtuais: lata de Coca-Cola ${ }^{\circledR}$ da esquerda e direita, canetas na parte de cima e bola de basquete. 


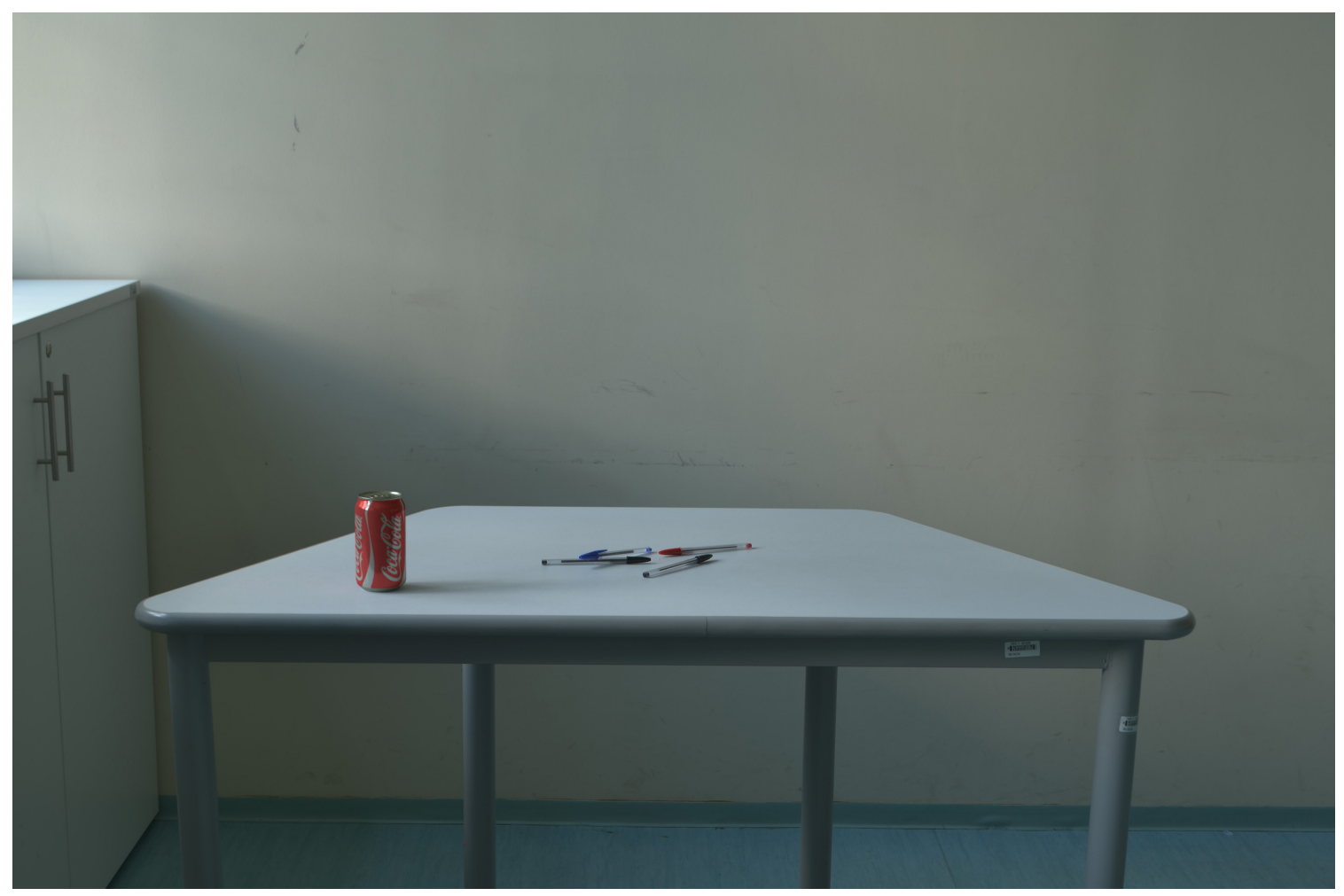

Figura 5.29: Imagem (\#15) com uma lata de Coca-Cola ${ }^{\circledR}$ virtual.

Foram gerados 6 questionários, com 20 imagens cada um. As 20 imagens que compõem cada questionário foram obtidas de maneira aleatória e sem repetição a partir do conjunto final de imagens. Cada imagem acompanha a seguinte pergunta: "A imagem contém objetos virtuais?". Além disso, os questionários também separam os candidatos que têm ou não conhecimentos em CG. Os questionários foram gerados utilizando a ferramenta Google Forms (Google, Inc., 2015). Como foram distribuídos pela internet, não houve nenhum tipo de controle sobre às condições de visualização ou sobre o tempo gasto para responder o questionário.

Os questionários foram distribuídos para 30 voluntários, sendo que 11 dos voluntários possuíam conhecimentos em CG. Os resultados compilados podem ser vistos no Apêndice $\mathrm{G}$, já o resumo pode ser visto na Tabela 5.1:

Imagens sem objetos virtuais Imagens com objetos virtuais

$\begin{array}{cll}\text { Com conhecimento em CG } & 68.49 \% & 44.22 \% \\ \text { Sem conhecimento em CG } & 52.27 \% & 60.89 \% \\ \text { Total } & 58.04 \% & 54.69 \%\end{array}$

Tabela 5.1: Porcentagem de acertos.

O grupo de pessoas com conhecimento em CG conseguiu detectar as imagens reais de maneira mais fácil, porém, sua taxa de acerto para as imagens com objetos virtuais foi menor. O grupo sem conhecimento em CG foi mais conservador e indicou mais imagens como virtuais. Porém, os resultados combinados, próximos dos $50 \%$ para os dois conjuntos 
de imagens, são um indicativo de que as imagens geradas pela solução proposta são quase indistinguíveis das imagens reais.

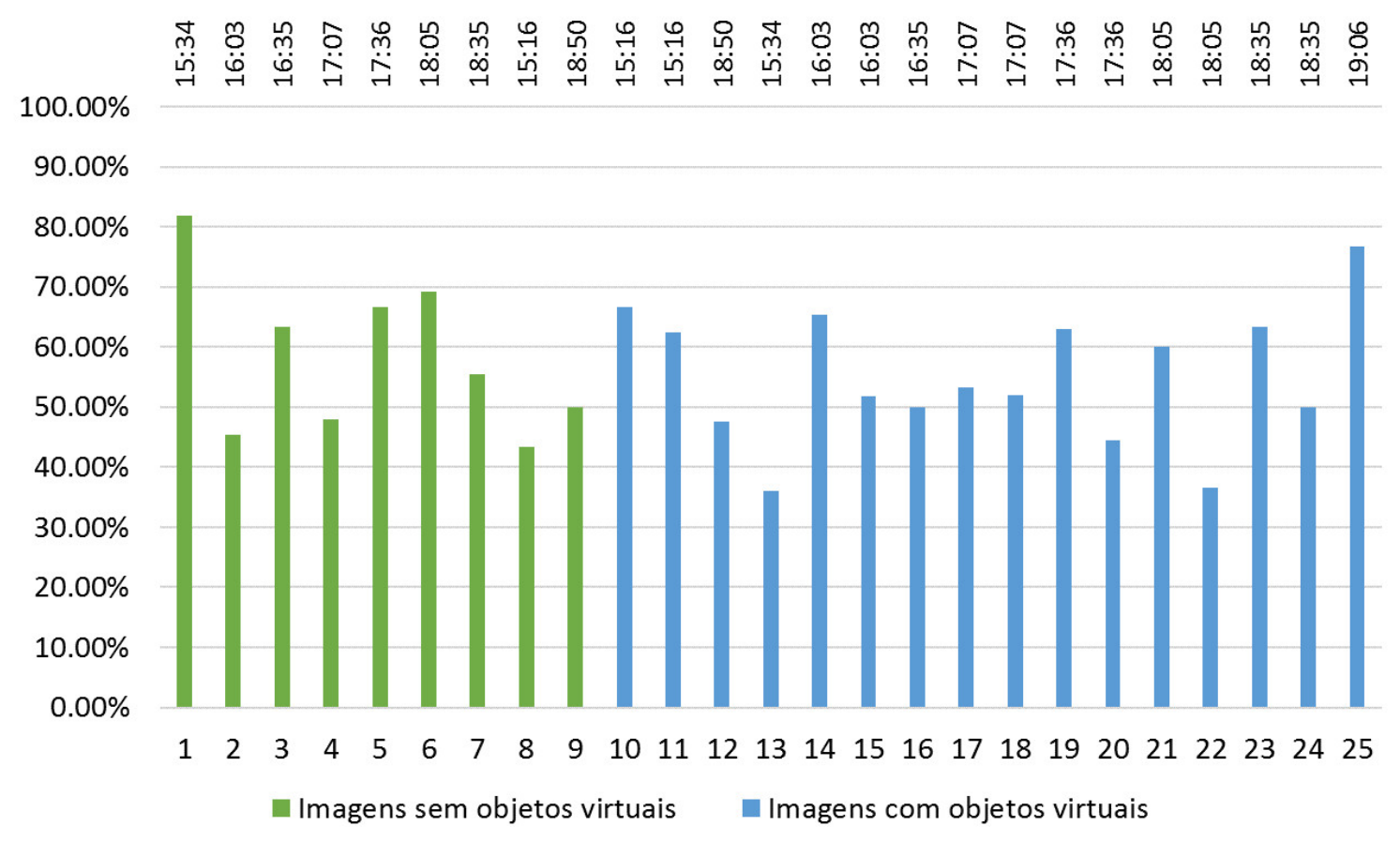

Figura 5.30: Gráfico que representa a porcentagem de acertos para cada imagem. O eixo superior indica o horário em que foi adquirida a imagem original, não modificada.

As imagens (\#10, \#11 e \#12) renderizadas a partir de mapas de iluminação artificiais, gerados com diferenças de 10 minutos em relação aos dados luminosos mais próximos, não apresentaram aceitação maior que as outras imagens, como era esperado. O grande número de objetos nessas cenas (Figura 5.31) pode ter causado desconfiança, diminuindo a aceitação dessas imagens. 


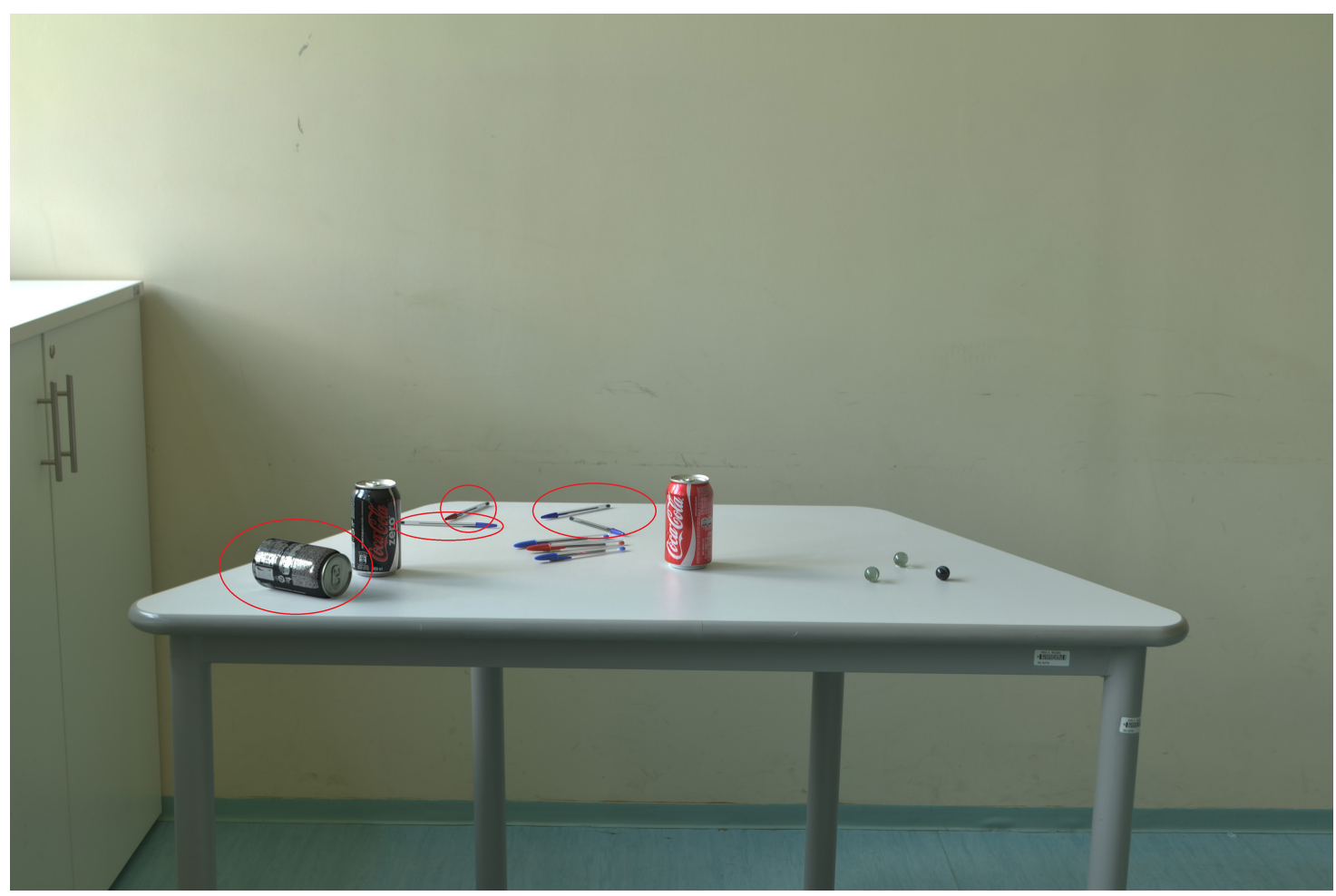

Figura 5.31: Imagem (\#10) com os objetos virtuais em destaque.

Comparando as imagens que obtiveram melhor (Figuras 5.32 e 5.33) e pior (Figura 5.34) desempenho, é possível verificar pelo menos duas diferenças significativas, o tipo de objeto utilizado em cada imagem e o horário. Apesar disso, esses fatores não determinam desempenho ruim, afinal há exemplos com boa aceitação utilizando os mesmos tipos de objetos e em horários próximos.

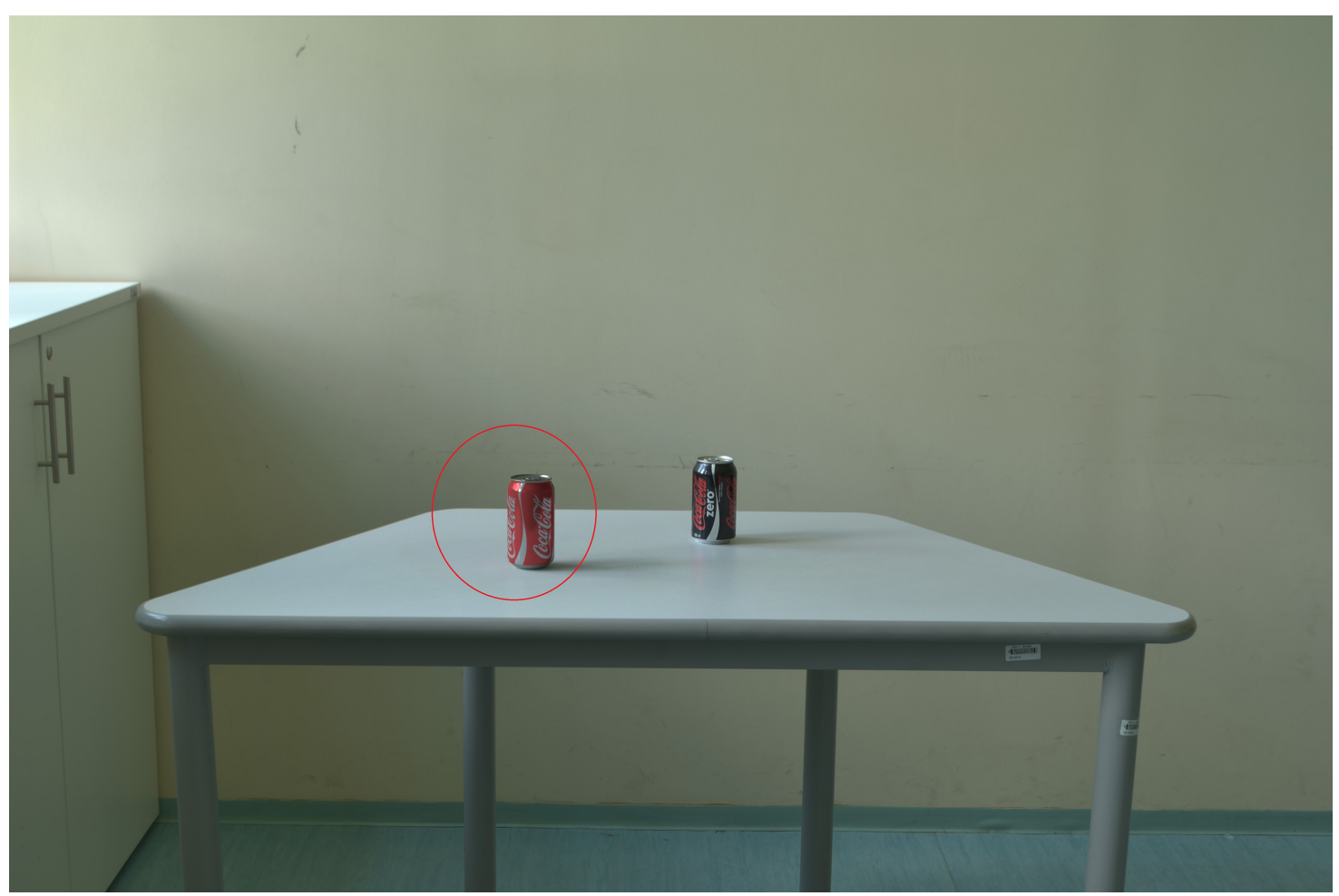

Figura 5.32: Imagem (\#13) com os objetos virtuais em destaque. 


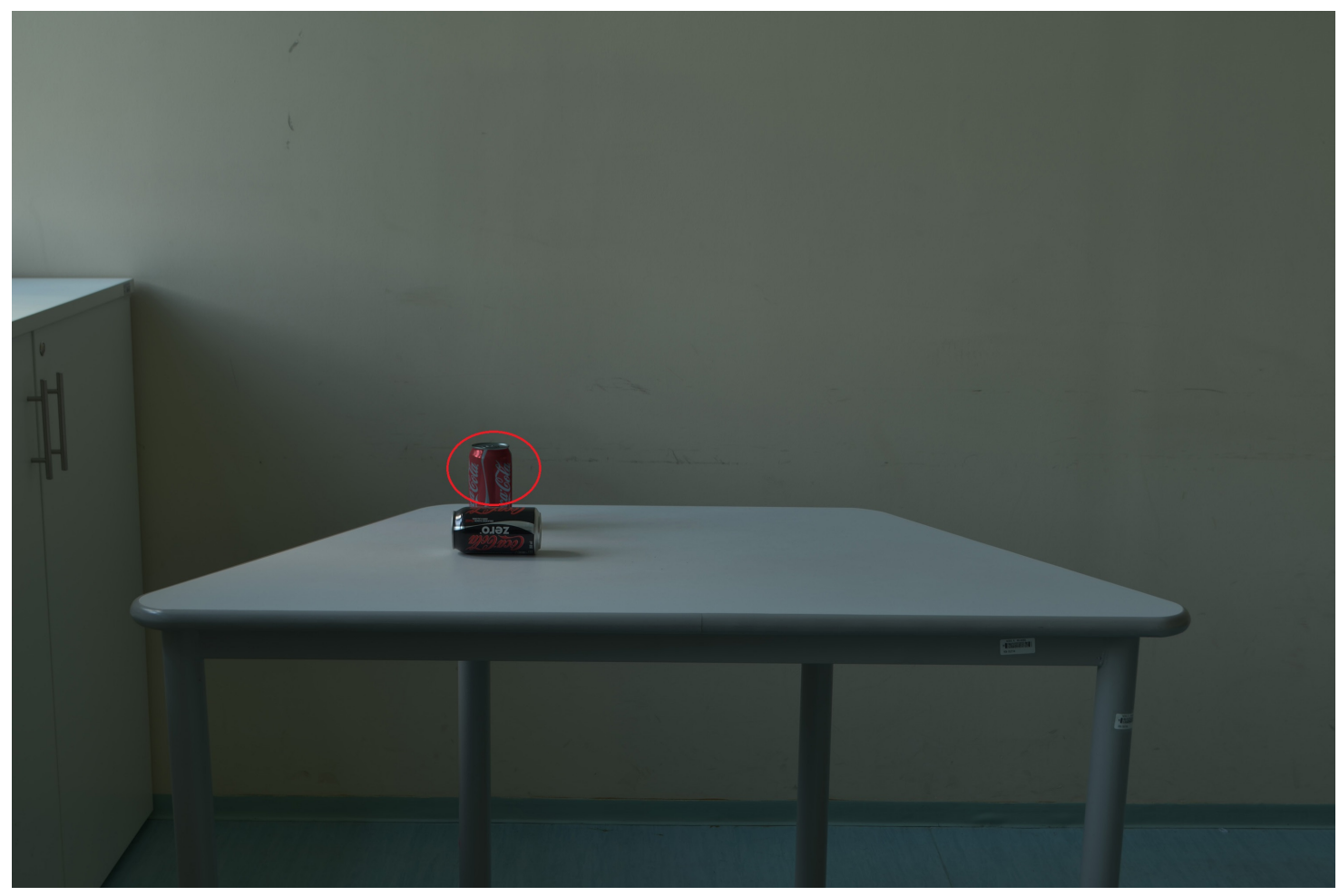

Figura 5.33: Imagem (\#22) com os objetos virtuais em destaque.

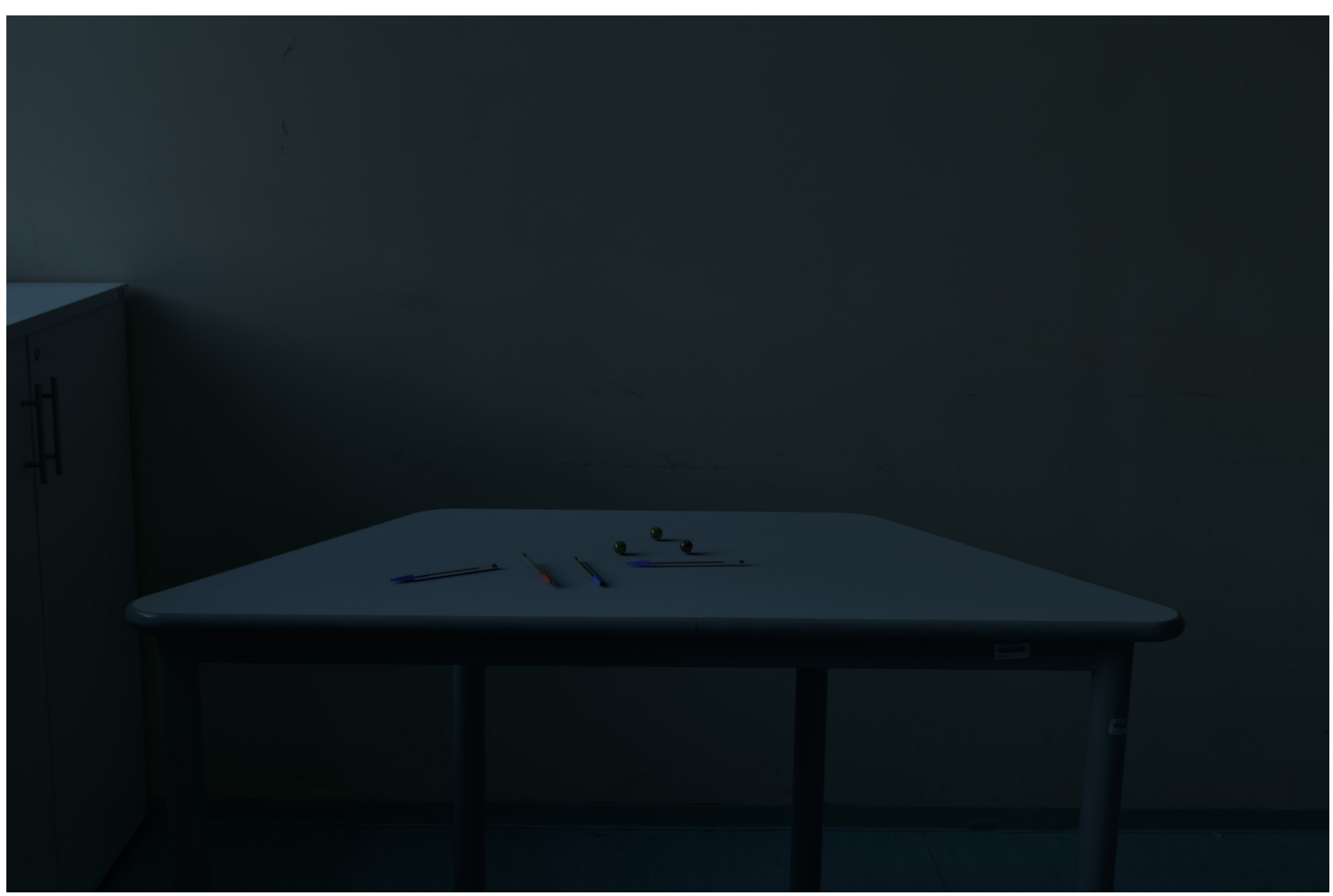

Figura 5.34: Imagem (\#25). Todos os objetos presentes nessa imagem são virtuais.

Um ponto interessante nesse experimento foram os acertos pelos motivos errados. Houveram casos em que participantes classificaram objetos reais como objetos virtuais. Um exemplo dessa ocorrência pode ser visto na Figura 5.35. 


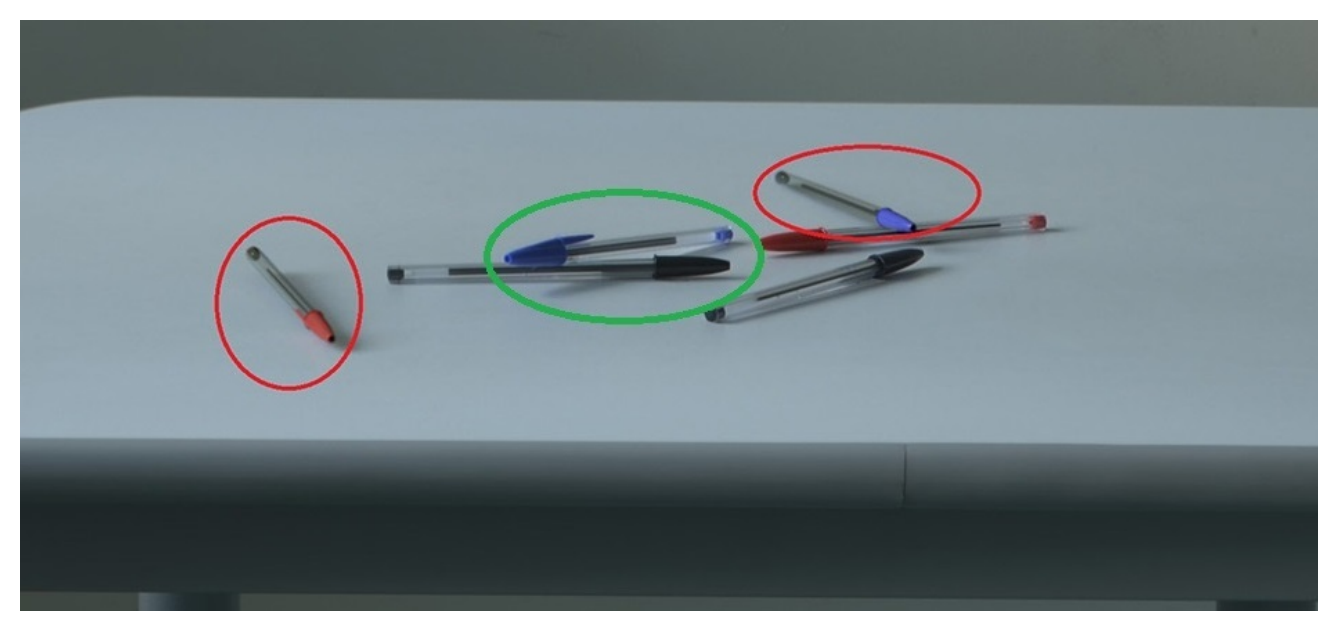

Figura 5.35: Região de interesse da imagem (\#14) que teve objetos reais indicados como virtuais. Área em vermelho representa os objetos virtuais. Ao ser questionado a respeito dessa imagem, o voluntário afirmou que continha objetos virtuais, pois a sombra da caneta central estava "errada".

Além da classificação errada pelos voluntários, outro fator que pode explicar as discrepâncias são as frequentes mudanças de luminosidade que ocorrem ao longo do dia, como foi observado durante o primeiro experimento. Discrepâncias que poderiam tornar a imagem do light probe artificial e o plano de fundo incompatíveis, aumentando a sensação de que as imagens são artificiais. Essa é uma deficiência dos método de interpolação, em especial para dias nublados, mas que poderia ser contornada aumentando a frequência de amostragem dos light probes.

Apesar de inconsistências em algumas imagens, causadas por pequenas movimentações e também pelas frequentes variações que ocorrem nas intensidades luminosas ao longo do dia, em geral, as imagens geradas apresentaram resultados satisfatórios, e, de acordo com as respostas dos voluntários, são quase indistinguíveis das imagens reais.

\section{Vídeos}

Os vídeos foram gerados por meio de keyframes interpolados linearmente. O instante de geração de cada imagem de light probe artificial, usada para iluminar os objetos virtuais, estava relacionado ao instante de geração de cada keyframe, ou seja, o mesmo instante da obtenção da imagem do plano de fundo.

Foram criados dois vídeos diferentes, em um deles as imagens de light probes foram geradas utilizando interpolações lineares, enquanto no outro foram utilizadas aproximações do tipo Bézier cúbica.

Os vídeos não foram utilizados para realização de testes, foram criados apenas com o propósito de observar o comportamento da iluminação, nos objetos virtuais, ao longo do tempo. Os vídeos podem ser obtidos pelo link: https://github.com/cfvalente/Video/

As diferenças entre os dois vídeos são sutis, porém, podem ser notadas no final do vídeo (Figura 5.36): enquanto a bola está mais escura na interpolação linear, e mais de acordo com o plano de fundo, na Bézier continua mais clara e, portanto, destoante do plano de fundo. Pelo fato dos pontos de controle não exercerem tanta influência na Bézier cúbica, a 
iluminação apresenta maior intensidade, e acaba destoante da cena. O mesmo, porém, não ocorre no caso da interpolação linear. Esse é um outro indicativo de que a escolha de um método que converge para os dados de iluminação já adquiridos é fundamental, inclusive para a renderização das cenas no contexto de RM.

Note que apesar do conjunto de imagens de light probes ter sido alinhado utilizando Photoshop ${ }^{\circledR}$, o mesmo não ocorreu com o plano de fundo, o que torna clara a movimentação durante a aquisição.

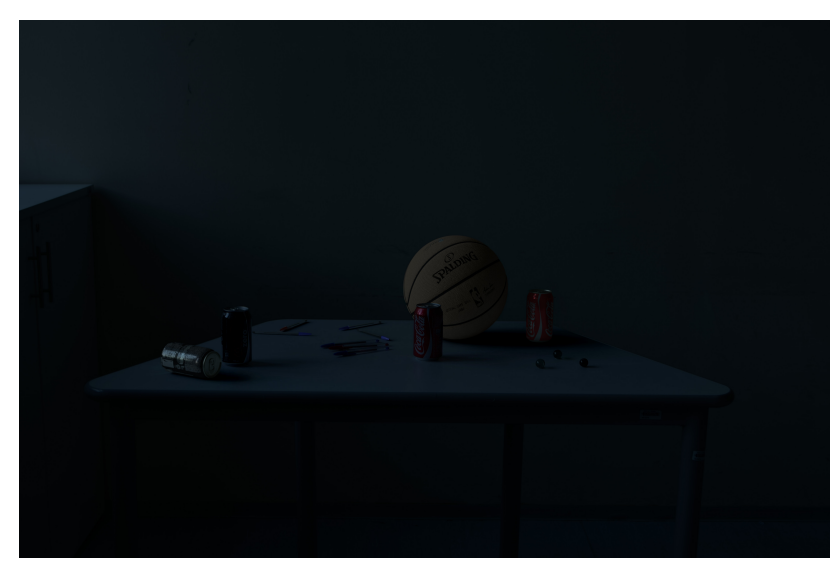

(a)

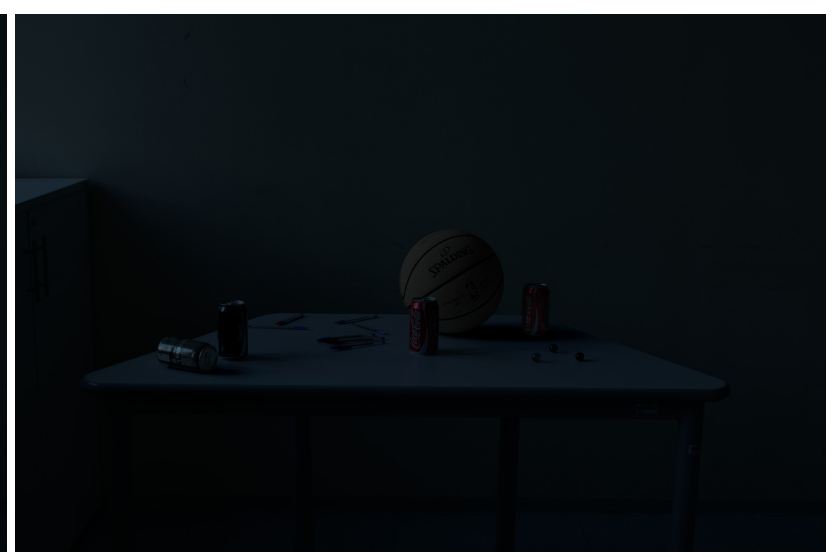

(b)

Figura 5.36: (a) keyframe do vídeo renderizado utilizando a iluminação proveniente de uma imagem de light probe gerada pela aproximação Bézier cúbica, (b) Keyframe do vídeo renderizado utilizando a iluminação proveniente de uma imagem de light probe gerada pela interpolação linear. Note que os objetos virtuais na imagem (a) estão mais claros, em especial a bola de basquete, e sua iluminação não está consistente com a iluminação do plano de fundo. 


\section{Capítulo 6}

\section{Conclusões}

IBL é uma técnica capaz de reproduzir a iluminação de uma cena real, tonalizando objetos virtuais de maneira realística. Porém, apresenta restrições, afinal, a captura da iluminação se dá para um único instante e posição. Foi apresentada uma metodologia capaz de estender IBL no domínio temporal, por meio de interpolações e aproximações de séries temporais de imagens. Diversas técnicas de interpolação e aproximação foram avaliadas para modelar o comportamento luminoso.

Das diversas funções de interpolações e aproximações avaliadas, a interpolação linear se sobressaiu, além de ser a mais eficiente e de implementação mais fácil, convergiu para a iluminação correta de maneira mais rápida. Porém, há limitações para a metodologia, oscilações na iluminação ao longo do dia podem não ser bem representadas por interpolações e, em especial, por aproximações. As imagens criadas no contexto de RM também foram validadas por voluntários, com resultados que indicam que as diferenças entre imagens com objetos virtuais, tonalizados utilizando imagens de light probes geradas por interpolações lineares, são quase indistinguíveis das imagens não modificadas.

A metodologia descrita pode ser empregada para diversas finalidades, como a visualização de projetos arquitetônicos sob condições luminosas distintas. Uma outra aplicação está relacionada ao treinamento de classificadores de objetos, que funcionem sob condições variáveis de iluminação. Classificadores, em geral, necessitam de treinamento, nesse caso, imagens realísticas poderiam ser geradas e então utilizadas durante a fase de treinamento. $\mathrm{O}$ treinamento com imagens sintéticas, utilizando condições luminosas variadas, simplificaria o processo de treinamento ao mesmo tempo que aumentaria a robustez do classificador.

Os experimentos foram concentrados em cenas internas pelo fato de que as aquisições em cenas externas se tornam mais complexas, como foi verificado durante os experimentos preliminares. Porém, IBL é uma técnica suficientemente robusta, portanto, espera-se que a aplicação da metodologia proposta em cenas externas também produza resultados satisfatórios. Apesar de terem sido utilizados apenas objetos simples durante os experimentos, objetos complexos também devem produzir resultados semelhantes, desde que modelados de maneira adequada. Uma limitação da metodologia proposta é sua execução em tempo real, para que funcionasse em tempo real, seria necessário utilizar câmeras de vídeo HDR, afinal, dados de iluminação precisariam ser obtidos a todos os instantes. Uma alternativa seria o uso de extrapolações, porém, métodos de extrapolação podem gerar valores muito ruins, o que tornaria a iluminação destoante do restante da cena. As duas alternativas vão 
de encontro com os objetivos do projeto, com a imposição do uso de equipamentos especiais ou então comprometendo a qualidade das imagens finais, inviabilizando assim a execução da metodologia em tempo real.

Com a metodologia descrita é possível utilizar IBL temporalmente variável, dispensando o uso de equipamentos especiais, para renderização de imagens realísticas. O ferramental de software desenvolvido também foi disponibilizado em forma de plugin, para facilitar o uso de IBL temporalmente variável, por desenvolvedores e designers gráficos. 


\section{Apêndice A}

\section{Interpolações}

Interpolações permitem a estimação de valores de uma função desconhecida a partir de amostras de seus valores. Funções de interpolação podem então ser utilizadas para gerar novos valores de iluminação a partir de dados obtidos de maneira esparsa em relação ao tempo (A.1).

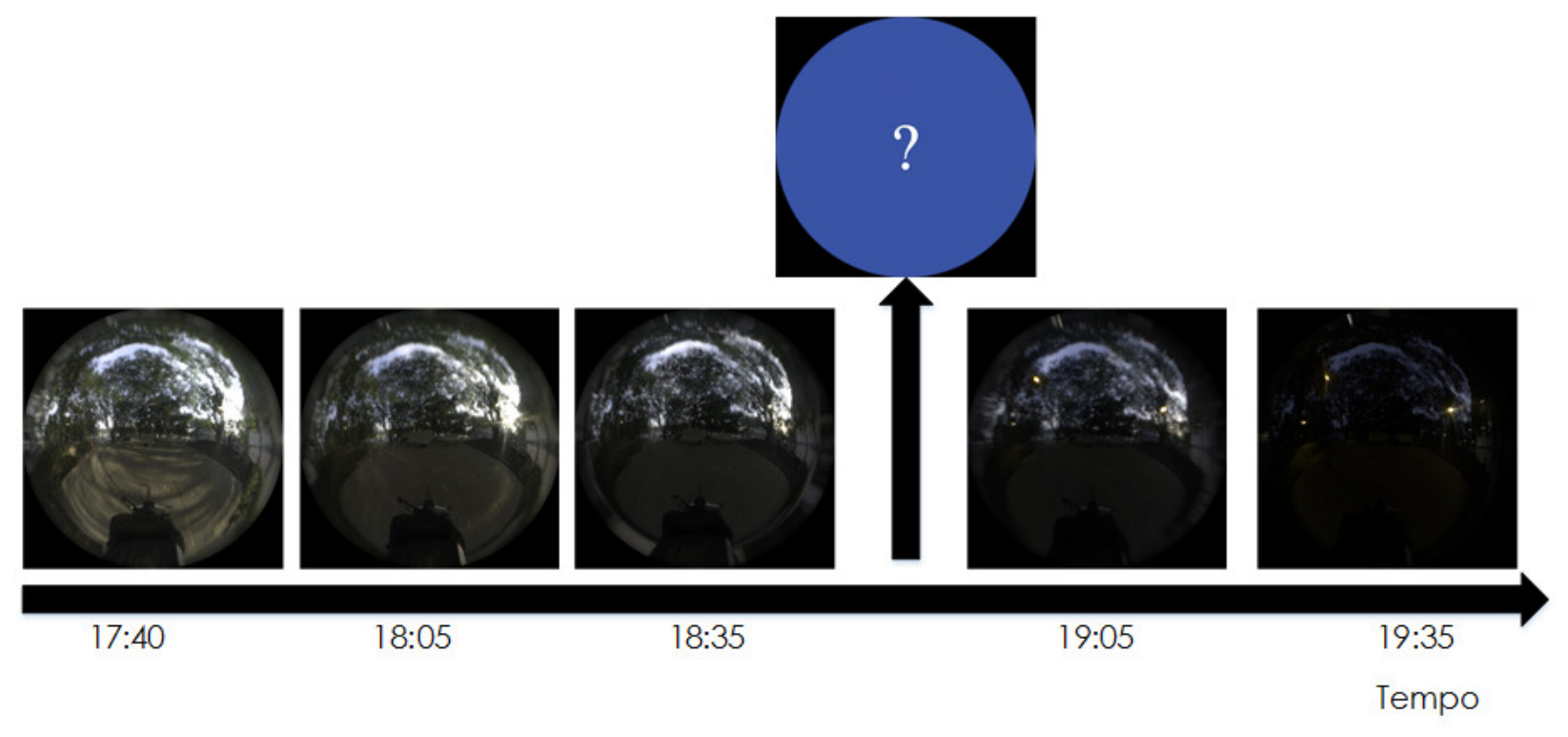

Figura A.1: Conjunto de imagens de light probes como amostras de uma função desconhecida. Funções de interpolação podem ser usadas para obter novas imagens de light probes.

Dados $n+1$ valores de uma função desconhecida $f(x)$, uma interpolação é a substituição da função $f(x)$ por uma função $g(x)$ restrita à condição de correspondência (Pozrikidis, 1998):

$$
f\left(x_{i}\right)=g\left(x_{i}\right), \quad i=0,1,2, \ldots, n
$$

Note que interpolações ocorrem quando são gerados valores intermediários, ou seja, $x \in\left[x_{0}, x_{n}\right]$. É obtida uma extrapolação caso os valores gerados não estejam no domínio de interpolação. Extrapolações em geral são evitadas, afinal, podem produzir dados pouco confiáveis. 
Interpolação podem ser constituídas por funções contínuas por partes. Uma forma de classificar essas funções é pelo conceito de continuidade paramétrica, ou seja, sua suavidade nos pontos de junção. O símbolo $C^{n}$ será utilizado para representar a continuidade paramétrica de ordem $n$. Supondo que as curvas $S$ e $R$ se encontrem em $S(p)$ e $R(q)$, então essas curvas apresentam continuidade paramétrica $n$ se (Akenine-Möller et al., 2008):

- $C^{0} \rightarrow$ Os pontos de junção das funções são os mesmos

- $C^{n} \rightarrow S^{n}(p)=R^{n}(q)$ e apresenta continuidade paramétrica $C^{n-1}$

As notações ' e " serão utilizadas para representar a primeira e a segunda derivada respectivamente.

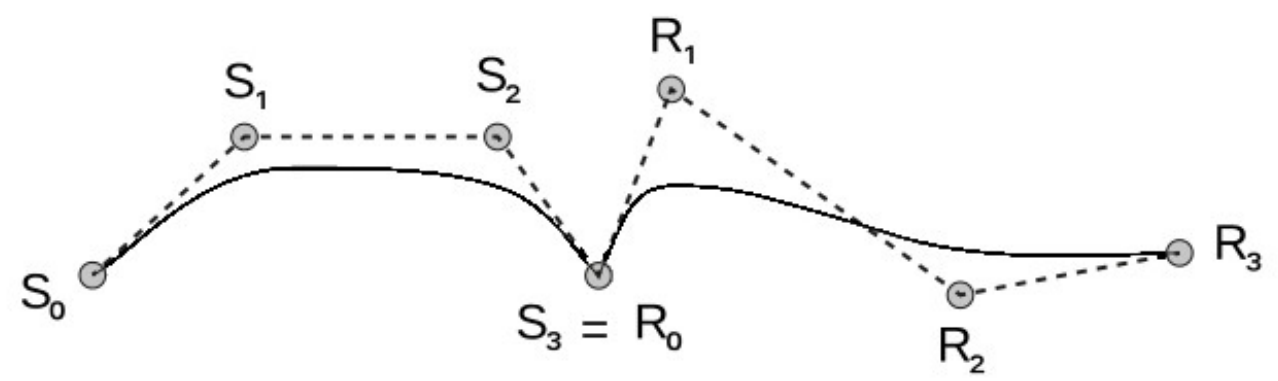

Figura A.2: Dois segmentos de curva, $S$ e $R$, com continuidade $C^{0}$. Note que apesar das curvas coincidirem em $S_{3}$ e $R_{0}$, apresentam derivadas diferentes nesse ponto, portanto, a continuidade paramétrica é $C^{0}$. (Oyster, 2014)

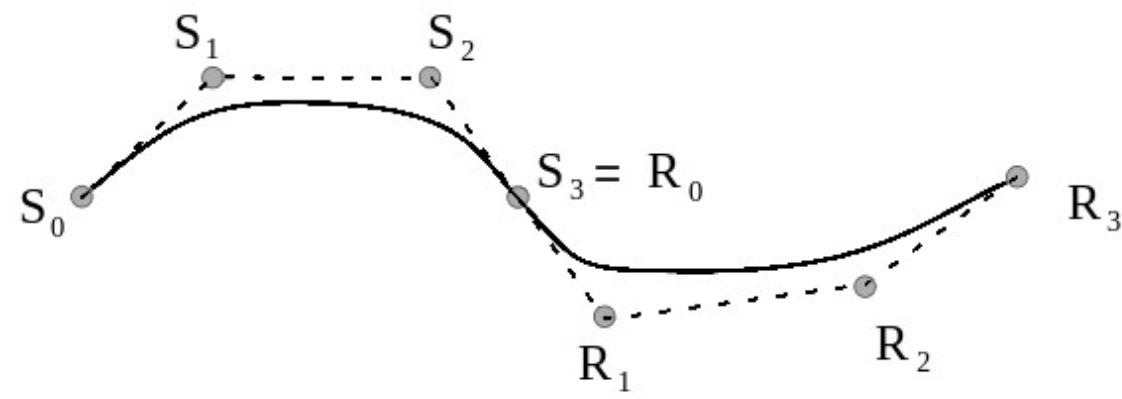

Figura A.3: Dois segmentos de curva, $S$ e $R$, com primeiras derivadas iguais no ponto de junção $\left(S_{3}=R_{0}\right)$ e com continuidade paramétrica $C^{1}$. (Fractsofphotos, 2009)

\section{Métodos de Interpolação}

Interpolação Linear (Figura A.4) é uma interpolação de baixo grau, contínua por partes, $C^{0}$, e que não necessita de dados uniformemente espaçados:

$$
y^{\text {linear }}=y_{0}+\left(y_{1}-y_{0}\right) * \frac{\left(x-x_{0}\right)}{\left(x_{1}-x_{0}\right)}
$$




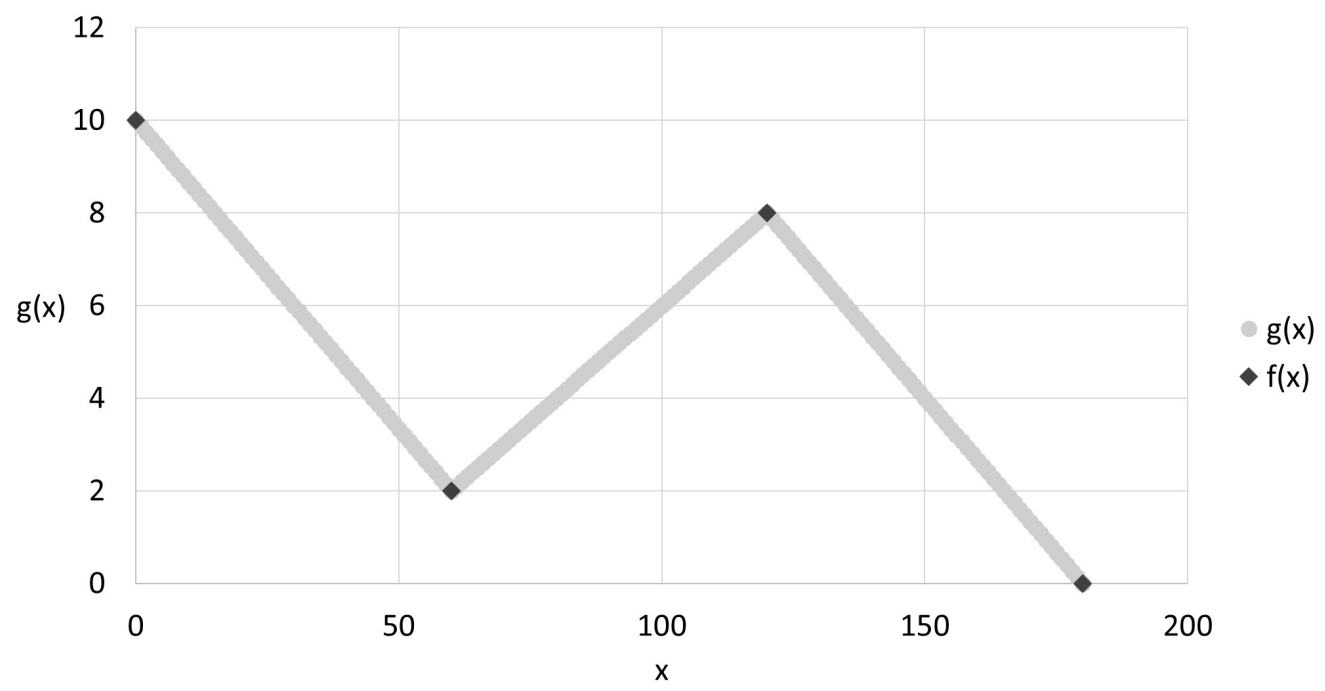

Figura A.4: Interpolação linear.

A interpolação de Lagrange (Figura A.5) é uma interpolação polinomial que gera um polinômio de ordem $N$ passando por todos os dados. Note que o polinômio gerado é único. Os dados não precisam estar uniformemente espaçados para que esse método funcione (Pozrikidis, 1998).

$$
\begin{aligned}
& y^{\text {lagrange }}=\frac{\left(x-x_{1}\right)\left(x-x_{2}\right) \ldots\left(x-x_{n}\right)}{\left(x_{0}-x_{1}\right)\left(x_{0}-x_{2}\right) \ldots\left(x_{0}-x_{n}\right)} y_{0}+\frac{\left(x-x_{0}\right)\left(x-x_{2}\right) \ldots\left(x-x_{n}\right)}{\left(x_{1}-x_{0}\right)\left(x_{1}-x_{2}\right) \ldots\left(x_{1}-x_{n}\right)} y_{1}+ \\
& +\cdots+\frac{\left(x-x_{0}\right)\left(x-x_{1}\right) \ldots\left(x-x_{n-1}\right)}{\left(x_{n}-x_{0}\right)\left(x_{n}-x_{1}\right) \ldots\left(x_{n}-x_{n-1}\right)} y_{n}
\end{aligned}
$$

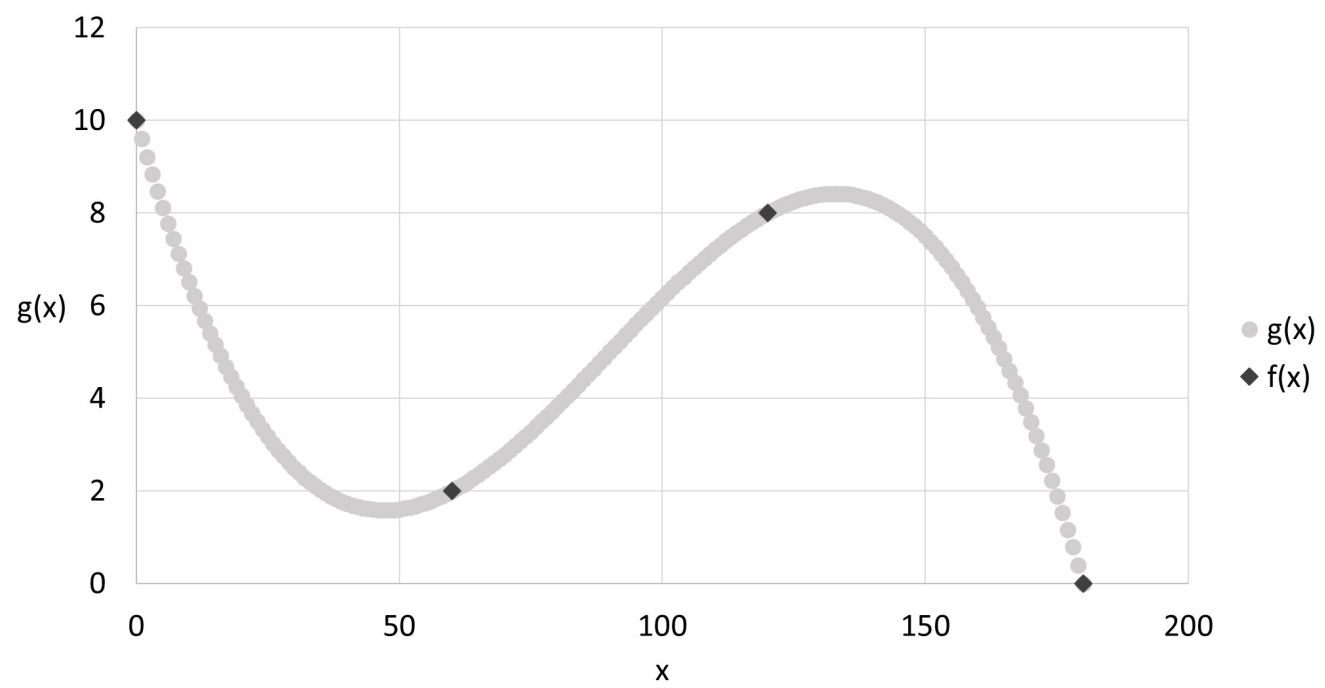

Figura A.5: Interpolação de lagrange.

Como não há pontos de junção, não há muito sentido em discutir o grau de continuidade 
paramétrica desse tipo de interpolação. Apesar de ser contínua e "suave" em toda a sua extensão, pode apresentar grandes oscilações.

Um outro método de interpolação é conhecido como Gauss's Forward Interpolation (Veerarajan e Ramachandran, 2008) (Figura A.7), esse método é construído a partir da pirâmide de diferenças centrais (Figura A.6). Supõe que o tempo de aquisição dos dados é uniforme, e é dado por $h$. É contínua por partes, $C^{0}$, sendo que o grau de cada parte é variável e dependente do número de diferenças centrais que estão disponíveis.

\begin{tabular}{cccccc}
\hline$x$ & $y$ & $\Delta y$ & $\Delta^{2} y$ & $\Delta^{3} y$ & $\Delta^{4} y$ \\
\hline$\vdots$ & $\vdots$ & & & \\
$x_{-2}$ & $y_{-2}$ & $\Delta y_{-2}$ & & \\
$x_{-1}$ & $y_{-1}$ & $\Delta y_{-1}$ & $\Delta^{2} y_{-2}$ & & \\
$x_{0}$ & $y_{0}$ & $\Delta y_{0}$ & $\Delta^{3} y_{-2}$ & $\Delta^{2} y_{-1}$ & $\Delta^{3} y_{-1}$ \\
$x_{1}$ & $y_{1}$ & $\Delta y_{+1}$ & $\Delta^{2} y_{0}$ & \\
$x_{2}$ & $y_{2}$ & &
\end{tabular}

Figura A.6: Diferenças centrais para frente.

$$
\begin{gathered}
y^{\text {gaussfi }}=y_{i}+P \Delta y_{i}+G_{2} \Delta^{2} y_{i-1}+G_{3} \Delta^{3} y_{i-1}+G_{4} \Delta^{4} y_{i-2} \ldots \\
P=\left(x-x_{i}\right) / h \\
G_{2 n}=\left(\begin{array}{c}
P+n-1 \\
2 n
\end{array}\right) \\
G_{2 n+1}=\left(\begin{array}{c}
P+n \\
2 n+1
\end{array}\right) \\
\Delta^{0} y_{i}=y_{i} \\
\Delta^{n} y_{i}=\Delta^{n-1} y_{i+1}-\Delta^{n-1} y_{i}
\end{gathered}
$$




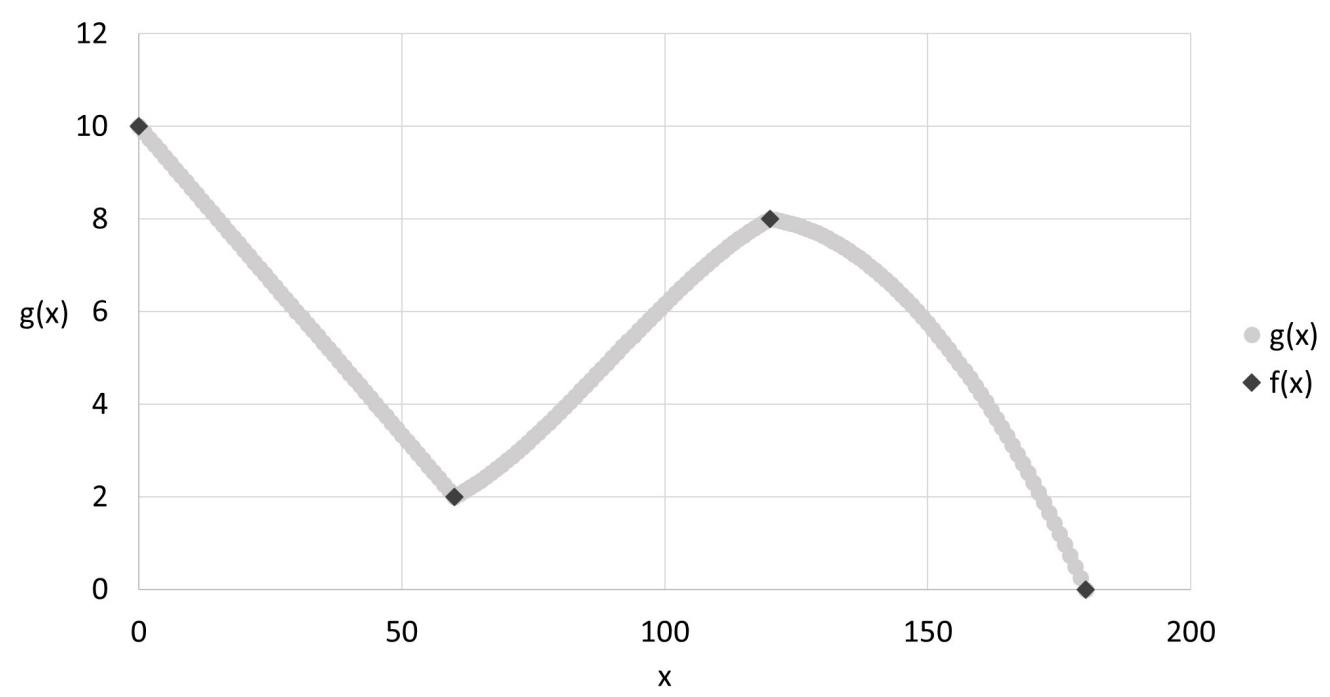

Figura A.7: Interpolação Gauss's Forward.

Gauss's Backward Interpolation (Figura A.9) é similar à Gauss's Forward Interpolation, mas utiliza as diferenças centrais para trás (Figura A.8).

\begin{tabular}{cccccc}
\hline$x$ & $y$ & $\Delta y$ & $\Delta^{2} y$ & $\Delta^{3} y$ & $\Delta^{4} y$ \\
\hline$\vdots$ & $\vdots$ & & & \\
$x_{-2}$ & $y_{-2}$ & $\Delta y_{-2}$ & & & \\
$x_{-1}$ & $y_{-1}$ & $\Delta y_{-1}$ & $\Delta^{2} y_{-2}$ & & \\
$x_{0}$ & $y_{0}$ & & $\Delta^{3} y_{-2}$ & \\
$x_{1}$ & $y_{1}$ & $\Delta y_{0}$ & $\Delta \Delta^{2}$ & $\Delta^{4} y_{-2}$ \\
$x_{2}$ & $y_{2}$ & $\Delta y_{+1}$ & $\Delta^{2} y_{0}$ & \\
$\vdots$ & $\vdots$ & & &
\end{tabular}

Figura A.8: Diferenças centrais para trás.

$$
\begin{gathered}
y^{\text {gaussbi }}=y_{i}+P \Delta y_{i-1}+G_{2} \Delta^{2} y_{i-1}+G_{3} \Delta^{3} y_{i-2}+G_{4} \Delta^{4} y_{i-2} \ldots \\
P=\left(x-x_{i}\right) / h \\
G_{2 n}=\left(\begin{array}{c}
P+n \\
2 n
\end{array}\right) \\
G_{2 n+1}=\left(\begin{array}{c}
P+n \\
2 n+1
\end{array}\right)
\end{gathered}
$$




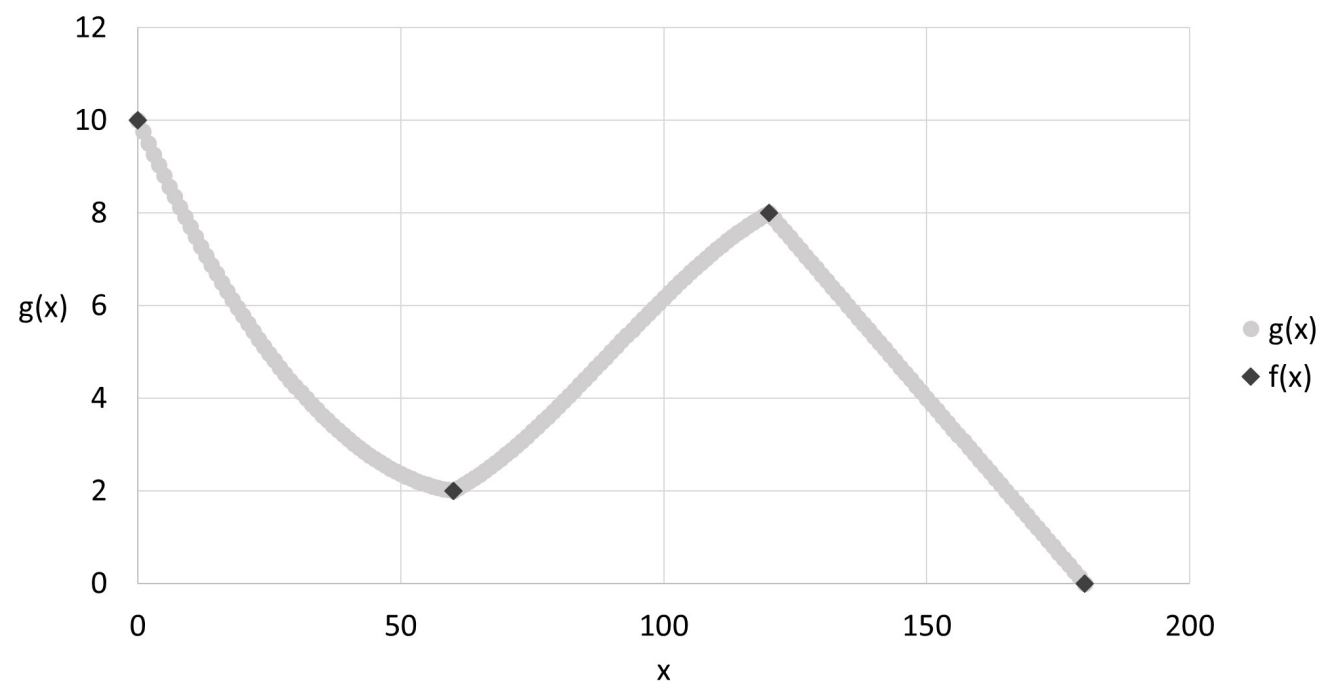

Figura A.9: Interpolação Gauss's Backward.

A interpolação de Stirling (Figura A.10) é definida como a média entre Gauss's Forward e Gauss's Backward, ou seja:

$$
y^{\text {stirling }}=\frac{y^{\text {gaussfi }}+y^{\text {gaussbi }}}{2}
$$

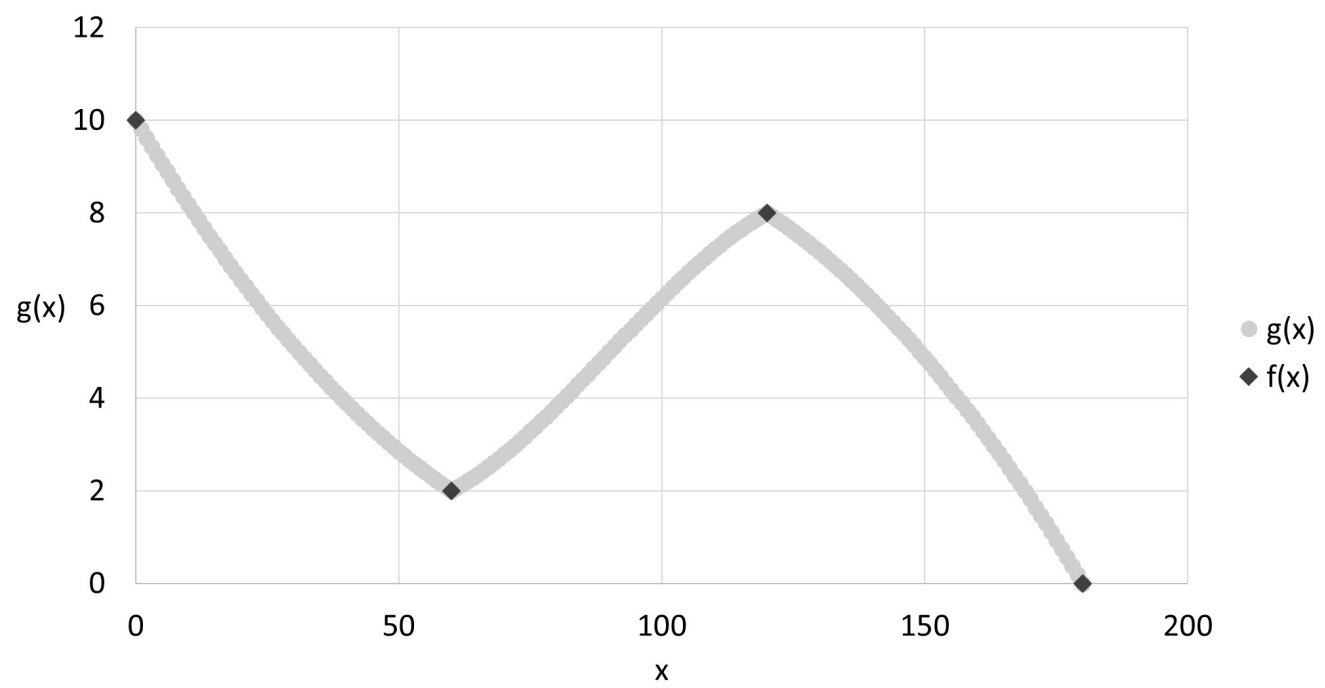

Figura A.10: Interpolação de Stirling.

A interpolação quadrática (Figura A.11) é definida por uma parábola que passa por três pontos. É uma interpolação contínua por partes e de baixo grau, pode ser escrita como:

$$
y^{\text {quad }}=\frac{\left(x-x_{1}\right)\left(x-x_{2}\right)}{\left(x_{0}-x_{1}\right)\left(x_{0}-x_{2}\right)} y_{0}+\frac{\left(x-x_{0}\right)\left(x-x_{2}\right)}{\left(x_{1}-x_{0}\right)\left(x_{1}-x_{2}\right)} y_{1}+\frac{\left(x-x_{0}\right)\left(x-x_{1}\right)}{\left(x_{2}-x_{0}\right)\left(x_{2}-x_{1}\right)} y_{n}
$$




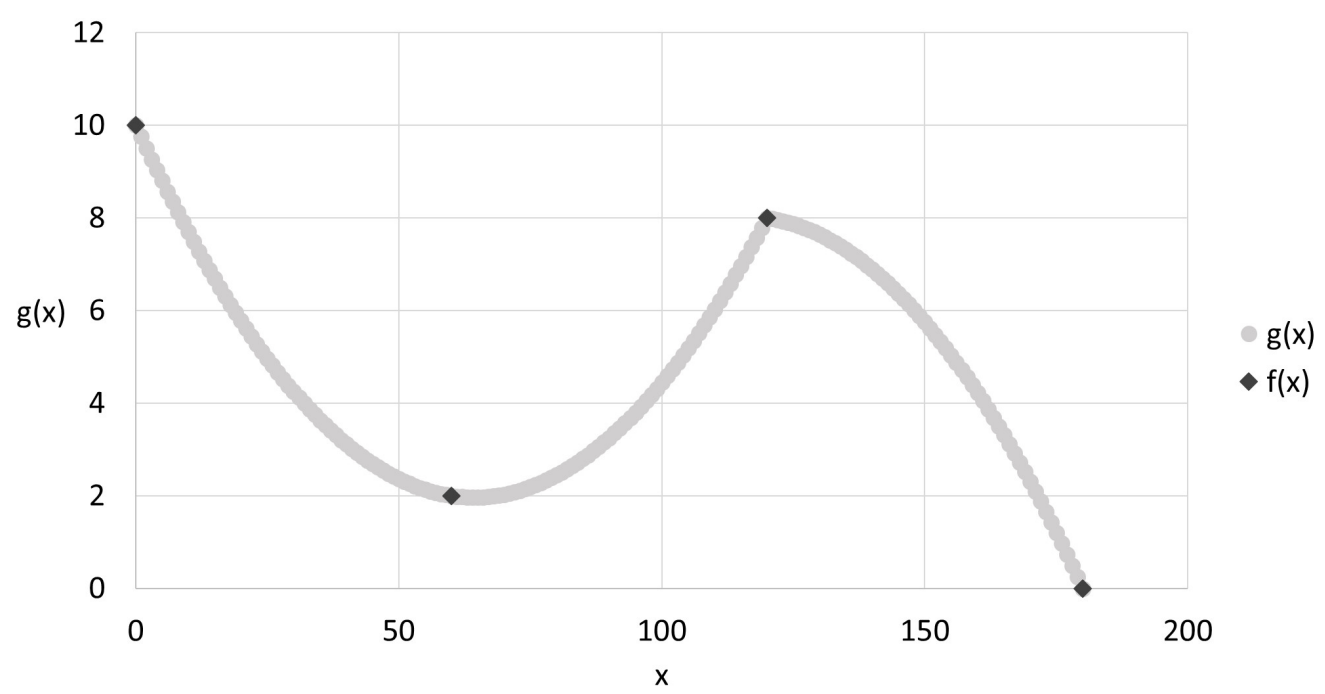

Figura A.11: Interpolação quadrática.

A interpolação quadrática é contínua, mas não necessariamente suave nos pontos de junção, ou seja, $C^{0}$.

A interpolação spline cúbica natural (Lengyel, 2012) (Figura A.12) é determinada por um conjunto de polinômios cúbicos, contínuos por partes, que mantêm continuidade e suavidade $C^{2}$ por toda curva.

Para um conjunto de $n+1$ pontos, há um conjunto de $n$ funções cúbicas $S_{i}(x)$, sendo que cada função $S_{i}(x)$ está definida no intervalo $\left[x_{i}, x_{i+1}\right]$. Para garantir a continuidade e suavidade são forçadas as seguintes propriedades:

- $S_{i}\left(x_{i+1}\right)=S_{i+1}\left(x_{i+1}\right)$

- $S_{i}^{\prime}\left(x_{i+1}\right)=S_{i+1}^{\prime}\left(x_{i+1}\right)$

- $S_{i}^{\prime \prime}\left(x_{i+1}\right)=S_{i+1}^{\prime \prime}\left(x_{i+1}\right)$

- $S_{i}\left(x_{i}\right)=y_{i}$

- $S_{i}\left(x_{i+1}\right)=y_{i+1}$

As seguintes constantes são definidas para $0 \leq i \leq n-1$ :

- $h_{i}=x_{i+1}-x_{i}$

- $k_{i}=y_{i+1}-y_{i}$

Cada $S_{i}(x)$ pode ser escrito como:

$S_{i}(x)=\frac{y_{i}^{\prime \prime}}{6 h_{i}}\left(x_{i+1}-x\right)^{3}+\frac{y_{i+1}^{\prime \prime}}{6 h_{i}}\left(x-x_{i}\right)^{3}+\left(\frac{y_{i}}{h_{i}}-\frac{y_{i}^{\prime \prime} h_{i}}{6}\right)\left(x_{i+1}-x\right)+\left(\frac{y_{i+1}}{h_{i}}-\frac{y_{i+1}^{\prime \prime} h_{i}}{6}\right)\left(x-x_{i}\right)$ 
$y_{i}^{\prime \prime}$ pode ser determinado solucionando o seguinte sistema:

$$
\begin{gathered}
{\left[\begin{array}{ccccccc}
m_{0} & h_{1} & 0 & \ldots & 0 & 0 & 0 \\
h_{1} & m_{1} & h_{2} & \ldots & 0 & 0 & 0 \\
\vdots & \vdots & \vdots & \ddots & \vdots & \vdots & \vdots \\
0 & 0 & 0 & \ldots & h_{n-3} & m_{n-3} & h_{n-2} \\
0 & 0 & 0 & \ldots & 0 & h_{n-2} & m_{n-2}
\end{array}\right]\left[\begin{array}{c}
y_{1}^{\prime \prime} \\
y_{2}^{\prime \prime} \\
\vdots \\
y_{n-2}^{\prime \prime} \\
y_{n-1}^{\prime \prime}
\end{array}\right]=\left[\begin{array}{c}
p_{0}-h_{0} y_{0}^{\prime \prime} \\
p_{1} \\
\vdots \\
p_{n-3} \\
m_{n-2}-h_{n-1} y_{n}^{\prime \prime}
\end{array}\right]} \\
p_{i}=6\left(\frac{k_{i+1}}{h_{i+1}}-\frac{k_{i}}{h_{i}}\right)
\end{gathered}
$$

Sendo que $y_{0}^{\prime \prime}$ e $y_{n}^{\prime \prime}$ podem assumir valores arbitrários. Essa interpolação é conhecida como spline cúbica natural quando essas variáveis são zeradas.

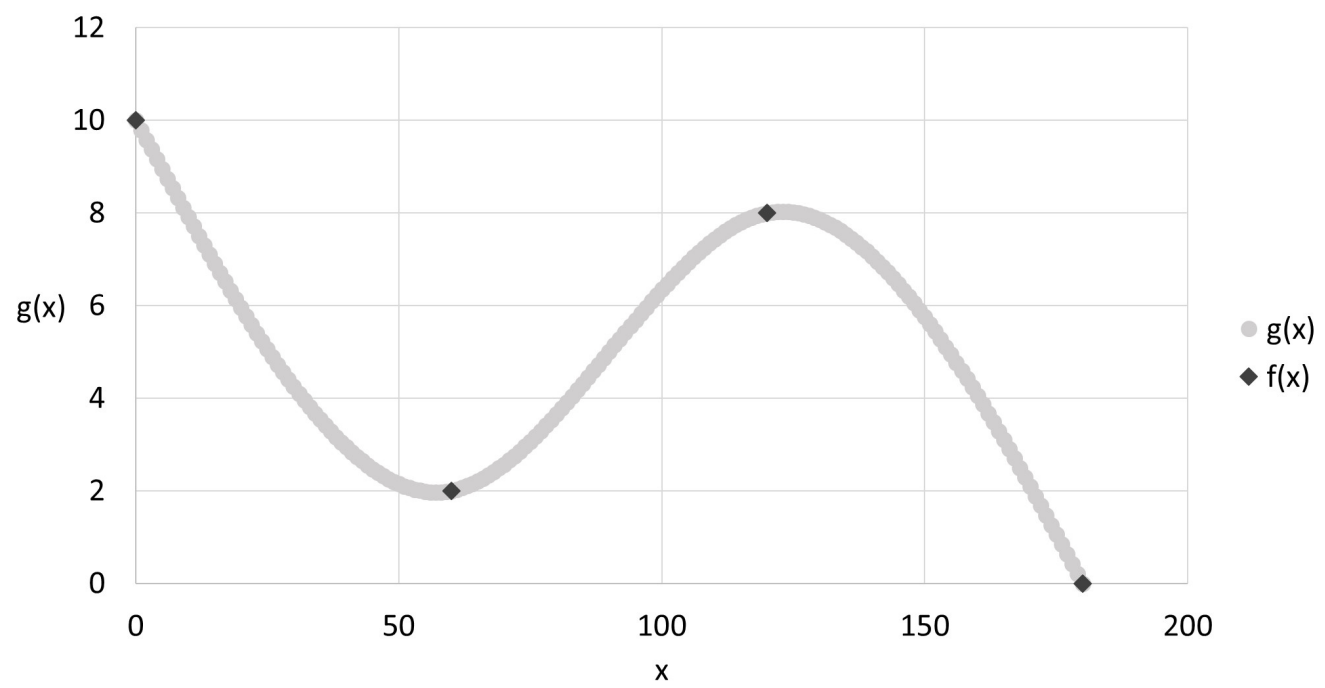

Figura A.12: Interpolação spline cúbica natural. 


\section{Apêndice B}

\section{Aproximações}

A grande diferença entre funções de aproximação e interpolação é que as funções de aproximação não necessariamente satisfazem a condição de correspondência imposta às funções de interpolação. Nem todos os graus de liberdade são usados, essa característica permite a obtenção de curvas mais suaves.

Dados valores de uma função $f(x)$, uma aproximação é uma representação de uma função $f(x)$, por meio de uma outra função $q(x)$, calculada de modo adequado (Pozrikidis, 1998).

\section{Métodos de Aproximação}

Aproximações do tipo Bézier (Akenine-Möller et al., 2008) (Figuras B.1 e B.2) são determinadas pela combinação de várias interpolações lineares, de modo a obter uma curva suave. A curva necessariamente passa pelas extremidades dos pontos de controle.

Curvas Bézier apresentam a propriedade de sempre estarem contidas no fecho convexo determinado pelos pontos de controle. Portanto, não há grandes efeitos oscilação.

Considerando $n+1$ pontos de controle, $p_{0}, p_{1}, \ldots, p_{n}$, a curva Bézier pode ser obtida por meio de uma sequência de interpolações lineares:

$$
\begin{gathered}
p(t)=p_{0}^{n}(t), t \in[0,1] \\
p_{i}^{k}(t)=p_{i}^{k-1}(t)+t\left(p_{i+1}^{k-1}(t)-p_{i}^{k-1}(t)\right) \\
k=1, \ldots, n \quad i=0, \ldots, n-k \\
p_{i}^{0}=p_{i}
\end{gathered}
$$




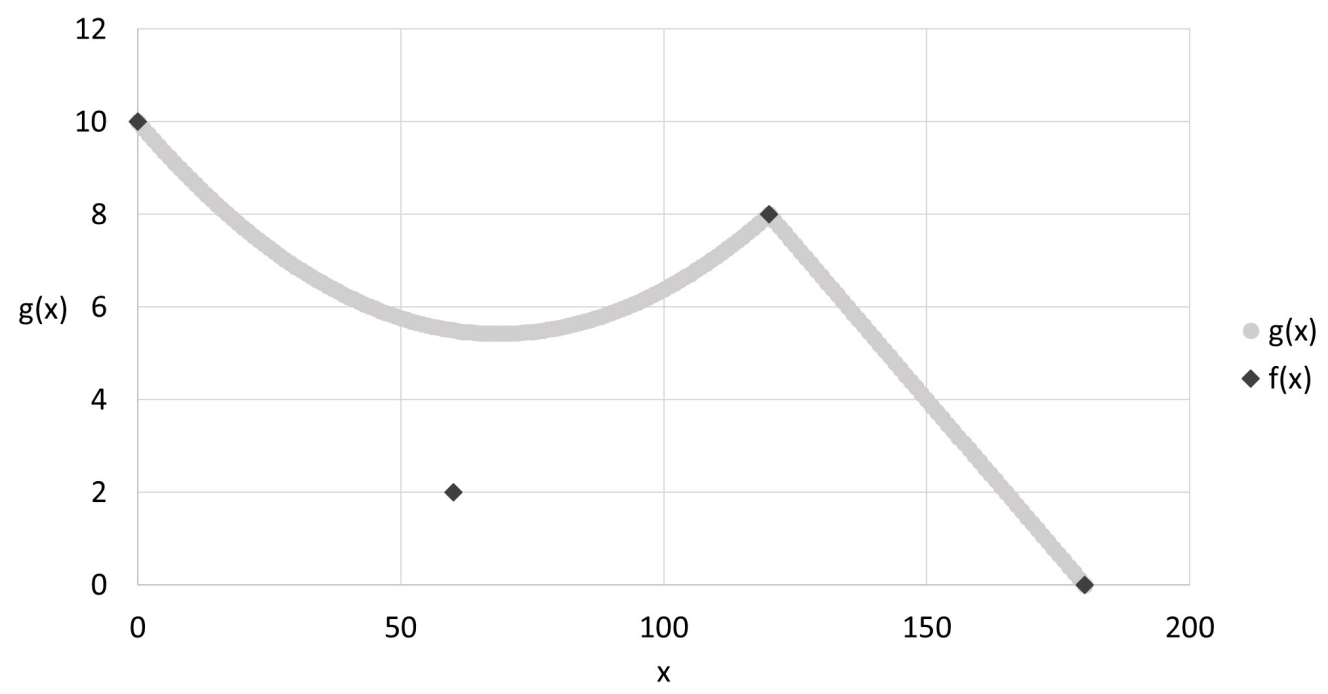

Figura B.1: Aproximação Bézier quadrática.

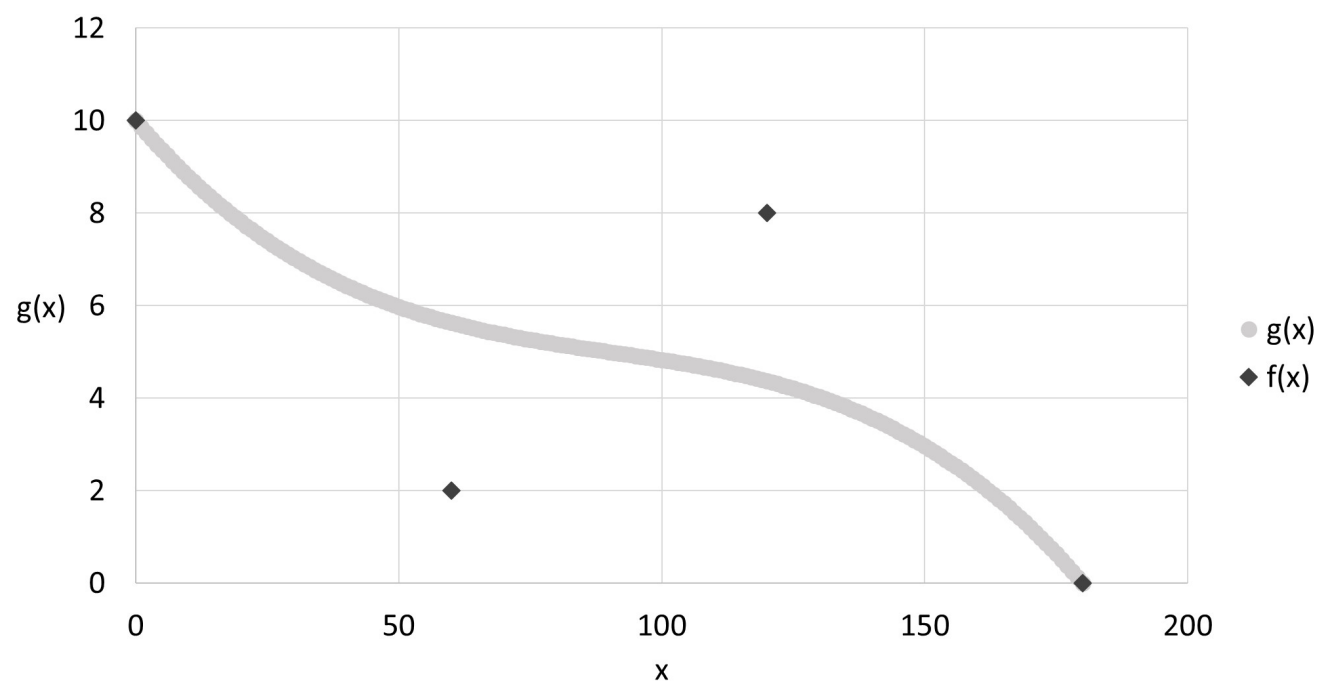

Figura B.2: Aproximação Bézier cúbica.

Não é usual utilizar todos os pontos de controle para obter uma Bézier de grau alto, isso se deve ao fato de que o peso dos pontos de controle diminui muito e o cálculo se torna computacionalmente custoso. Em geral são utilizadas curvas quadráticas ou cúbicas continuas por partes. O fato de que essas curvas sempre passam pelos pontos extremos pode ser aproveitado para proporcionar maior peso aos pontos centrais da série de dados. Porém, quando a curva é dividida, não há mais garantias em relação à suavidade, ou seja, nesse caso a continuidade paramétrica é $C^{0}$.

Outro tipo de curva aproximativa é conhecida como B-spline cúbica uniforme (Lengyel, 2012) (Figura B.3). Esse é um tipo de curva suave que apresenta continuidade paramétrica $C^{2}$. Também apresenta a propriedade de estar contida no fecho convexo determinado pelos pontos de controle.

Dados $n+1$ pontos de controle, $p_{0}, p_{1}, \ldots, p_{n}$, há $n-2$ curvas cúbicas $Q_{i}(t)$, com $1 \leq$ $i \leq n-2$. 


$$
Q_{i}(t)=\sum_{k=0}^{3} B_{k}(t) p_{i+k-1}
$$

Sendo que cada uma das funções $Q_{i}(t)$ está definida para $t \in[0,1]$.

Os pontos extremos e as intersecções das funções $Q_{i}(t)$ são chamados de nós, ou seja, os nós são dados pelos pontos: $Q_{1}(0), Q_{2}(0), Q_{3}(0), \ldots, Q_{n-2}(0), Q_{n-2}(1)$. A B-Spline é dita uniforme pois os nós são espaçados uniformemente em relação ao parâmetro $t$.

As seguintes restrições são impostas na construção de $Q_{i}(t)$ :

- $Q_{i}(1)=Q_{i+1}(0)$

- $Q_{i}^{\prime}(1)=Q_{i+1}^{\prime}(0)$

- $Q_{i}^{\prime \prime}(1)=Q_{i+1}^{\prime \prime}(0)$

- $B_{0}(0)+B_{1}(0)+B_{2}(0)+B_{3}(0)=1$

Com essas restrições:

$$
\begin{gathered}
B_{0}(t)=\frac{(1-t)^{3}}{6} \\
B_{1}(t)=\frac{4-6 t^{2}+3 t^{3}}{6} \\
B_{2}(t)=\frac{1+3 t+3 t^{2}-3 t^{3}}{6} \\
B_{3}(t)=\frac{t^{3}}{6}
\end{gathered}
$$

Em notação matricial:

$$
Q_{i}(t)=\left[\begin{array}{llll}
p_{i-1} & p_{i} & p_{i+1} & p_{i+2}
\end{array}\right]\left[\begin{array}{cccc}
1 & -3 & 3 & -1 \\
4 & 0 & -6 & 3 \\
1 & 3 & 3 & -3 \\
0 & 0 & 0 & 1
\end{array}\right]\left[\begin{array}{c}
1 \\
t \\
t^{2} \\
t^{3}
\end{array}\right]
$$

Dessa maneira os pontos iniciais e finais não são interpolados pela curva. Porém, é possível forçar a interpolação ao triplicar os pontos de controle referentes às extremidades. 


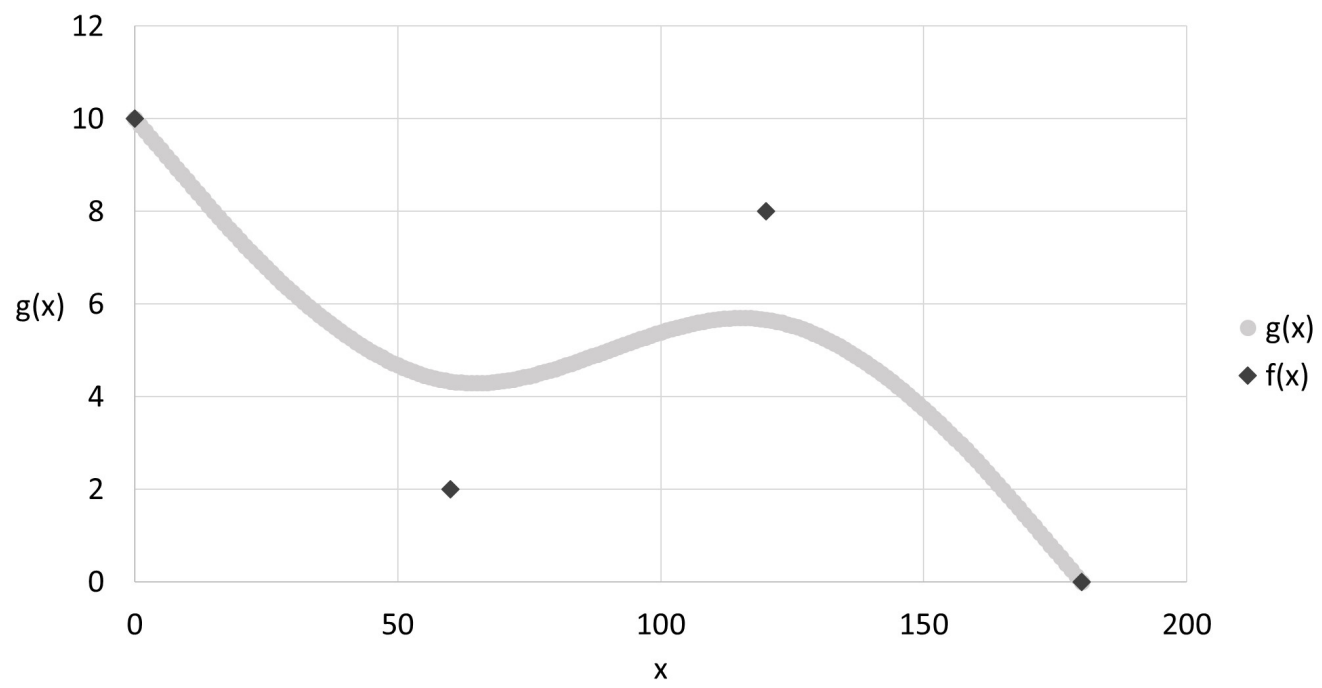

Figura B.3: Aproximação B-Spline cúbica. 


\section{Apêndice C}

\section{Curvas Paramétricas}

As aproximações apresentadas (Apêndice B) são curvas paramétricas, ou seja, é possível obter pontos dessas curvas a partir de um parâmetro $t$, definido, em geral, para um intervalo $[0,1]$. Mas isso não é o ideal, afinal, deseja-se obter uma imagem $(y)$ em função de um instante $(x)$, e não em função de um parâmetro $t$ desconhecido. Considere o seguinte exemplo numérico, de uma aproximação Bézier cúbica, para o instante 50:

- $P 1=\left(x_{1}, y_{1}\right)=(0,0)$

- $P 2=\left(x_{2}, y_{2}\right)=(98,100)$

- $P 3=\left(x_{3}, y_{3}\right)=(99,100)$

- $P 4=\left(x_{4}, y_{4}\right)=(100,100)$

Uma maneira ingênua de realizar essa operação seria definindo o parâmetro $t$ como:

$$
t=\frac{x-x_{1}}{x_{4}-x_{1}}=\frac{50-0}{100-0}=0.5
$$

Nesse caso o resultado seria o ponto $P=(86.375,87.5)$, ou seja, não é o ponto desejado.

Considere novamente uma Bézier cúbica, com pontos de controle $P_{i}, i \in\{1,2,3,4\}$ estritamente crescentes em relação à coordenadas $x$, e um instante $x$, tal que $x_{1} \leq x \leq x_{4}$. Essa aproximação é dada por:

$$
P=\left(-P_{1}+3 P_{2}-3 P_{3}+P_{4}\right) t^{3}+\left(3 P_{1}-6 P_{2}+3 P_{3}\right) t^{2}+\left(-3 P_{1}+3 P_{2}\right) t+P_{1}
$$

Como a função é contínua e estritamente crescente em $t \in[0,1]$ então existe um $t$ nesse intervalo para o qual $B z_{\text {cub }}(t)=P=(x, y)$. O parâmetro $t$ pode ser determinado resolvendo a seguinte equação cúbica:

$$
\left(-x_{1}+3 x_{2}-3 x_{3}+x_{4}\right) t^{3}+\left(3 x_{1}-6 x_{2}+3 x_{3}\right) t^{2}+\left(-3 x_{1}+3 x_{2}\right) t+\left(x_{1}-x\right)=0
$$


A variável $y$ pode então ser calculada a partir de $t$. Processos análogos podem ser aplicados para a Bézier quadrática e B-Spline cúbica.

Apesar desse problema ter sido resolvido para a Bézier quadrática, Bézier cúbica e BSpline cúbica, o mesmo não foi feito para a Bézier genérica. O grande problema nesse caso é o grau elevado que essa aproximação pode assumir. Com os dados espalhados de maneira quase uniforme esse efeito não deve ser tão acentuado como nesse exemplo, porém, note que, nesse caso, foi adotada uma simplificação. 


\section{Apêndice D}

\section{Projeção Ortográfica}

A projeção paralela ou ortográfica é um tipo de projeção em que linhas paralelas são projetadas no plano do filme de maneira ortogonal. É um modelo abstrato, e não existem câmeras reais que funcionem dessa maneira (Hughes et al., 2013).

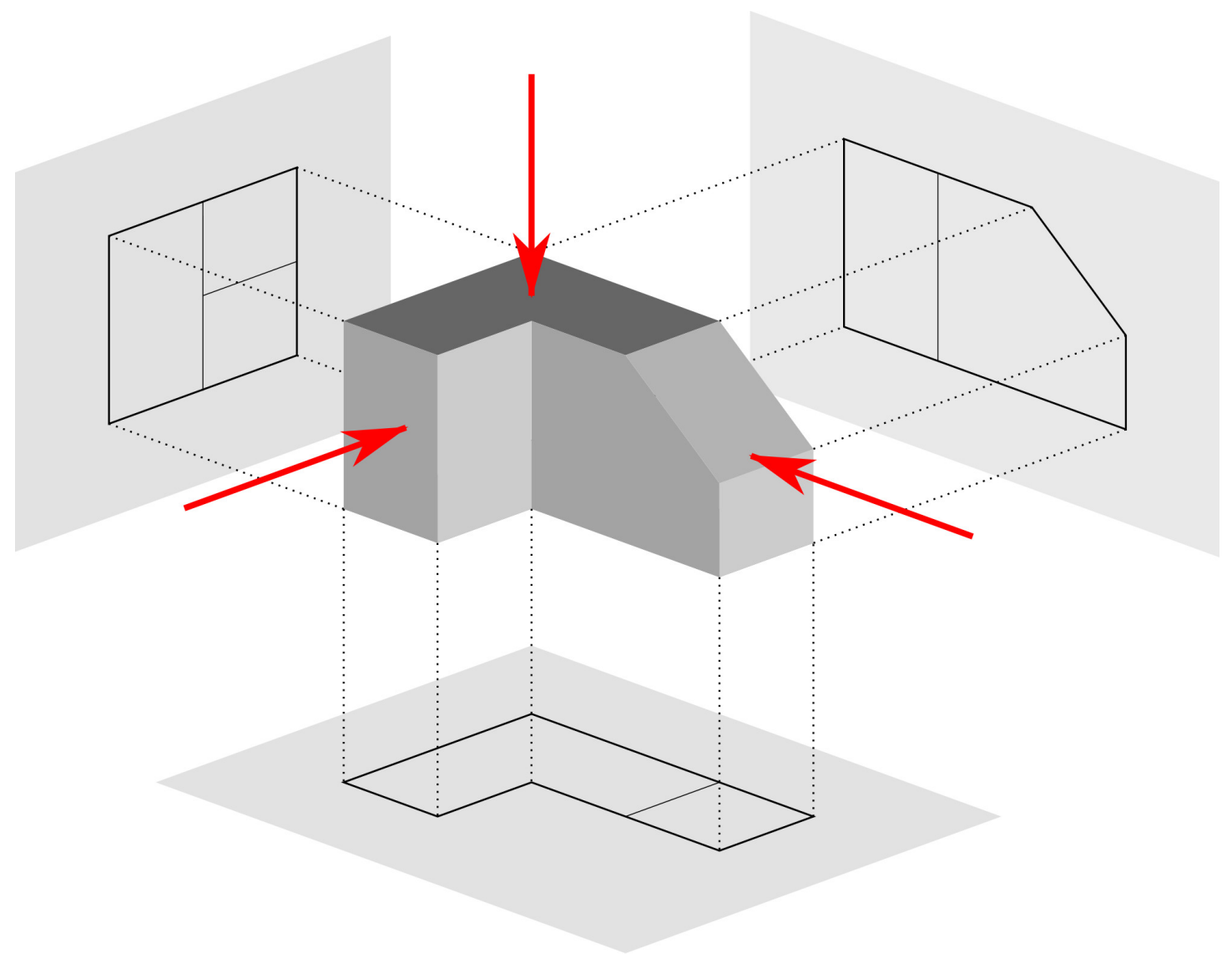

Figura D.1: Projeção ortogonal do objeto em três planos distintos. (Emok, 2008)

Esse tipo de projeção difere da projeção de perspectiva pelo fato dos raios não se encontrarem em um único ponto. Por esse motivo, não há a diminuição dos objetos com o aumento de suas distâncias para a câmera, efeito que ocorre na perspectiva. 


\section{Apêndice E}

\section{Texturas}

Texturização é o processo de modificar a aparência de uma superfície usando alguma imagem, função ou fonte de dados (Akenine-Möller et al., 2008). É útil por proporcionar maior realismo, eficiência e também praticidade ao modelar um objeto.

Texturização pode ser aplicada de diversas maneiras diferentes, um de seus usos mais básicos é a atribuição de cor à objetos, porém, há muitas outras técnicas baseadas no uso de texturas, entre elas:

- bump mapping $\quad \rightarrow$ alteração das normais, simulando efeitos de profundidade em um objeto

- displacement mapping $\rightarrow$ alteração da posição geométrica, gerando efeitos de profundidade

- alpha mapping

$\rightarrow$ fornece informações de transparência, permitindo que objetos ou parte deles se tornem translúcidos

- environment mapping $\rightarrow$ a textura contém as informações luminosas utilizadas para reflexão especular

- irradiance mapping $\rightarrow$ a textura contém as informações luminosas utilizadas para reflexão difusa

Para acessar texturas utiliza-se o sistema de coordenadas de textura, $(u, v)$. Essas coordenadas são definidas entre 0.0 até 1.0 e substituem o sistema normal de coordenadas de imagens (baseado na altura e largura, em pixels, da imagem). 


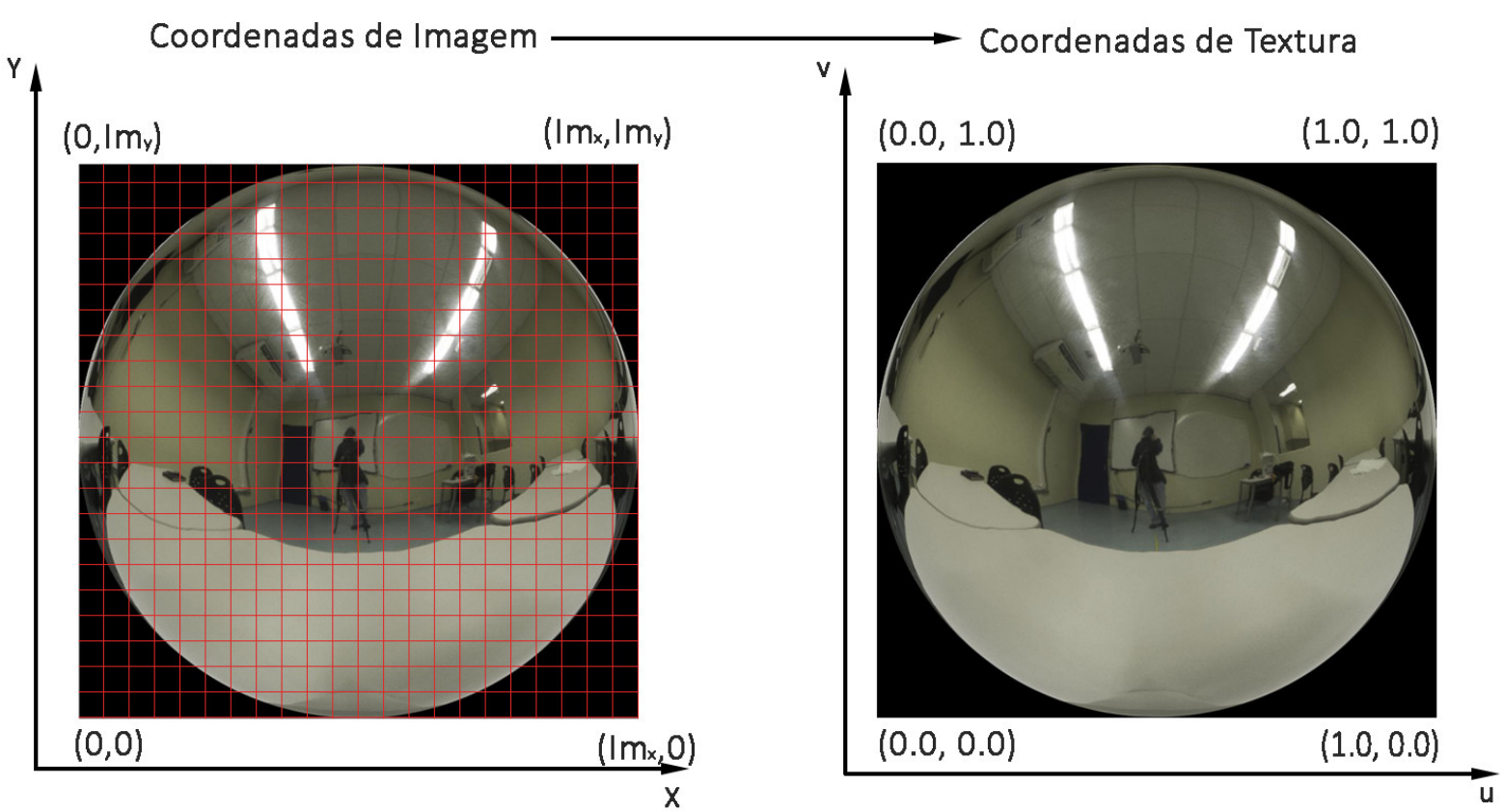

Figura E.1: Em coordenadas de imagem $\operatorname{Im}_{X}$ e $\operatorname{Im}_{Y}$ representam a largura e altura, em pixels, da imagem. Já em coordenadas de textura, a largura e a altura da imagem correspondem a valores $(u, v)$ definidos no intervalo $[0.0,1.0]$.

Em alguns casos, como a atribuição de cor a objetos, as coordenadas $(u, v)$ são definidas no instante da modelagem do objeto tridimensional. Porém, para técnicas como environment mapping ou mesmo irradiance mapping essas coordenadas devem ser determinadas em tempo de execução. No caso de environment mapping $(u, v)$ são determinados a partir do vetor de reflexão perfeita (Figura 2.5), já em irradiance mapping $(u, v)$ são determinados a partir do vetor normal do ponto em questão. 


\section{Apêndice F}

\section{Implementação}

Durante o trabalho foi desenvolvido um software capaz de interpolar e aproximar imagens no formato TIF. Com esse software também é possível determinar a distância $L^{2}$ entre duas imagens. Um plugin para o Maya ${ }^{\circledR}$ também foi desenvolvido, integrando e fornecendo uma interface gráfica ao software de interpolação, facilitando assim o uso de IBL temporalmente variável.

Tanto software para interpolação quanto o plugin para o Maya ${ }^{\circledR}$ foram testados utilizando Windows 10 e OSX 10.10. O código fonte pode ser encontrado no link:

https://github.com/cfvalente/radiance_interpolation/

\section{F.1 Software para Interpolação e Aproximação}

O software foi desenvolvido utilizando $\mathrm{C}++$, e é baseado na biblioteca para manipulação de imagens FreeImage (FreeImage, 2015).

O software é responsável por fazer a interpolação para o momento escolhido e gerar um light probe artificial. Apenas imagens HDR no formato TIF, com 32 bits por canal (3 ou 4 canais), são aceitas como entrada, a saída segue o mesmo formato. Ao executar o software, também deve ser definido um arquivo de entrada pela linha de comando. Nesse arquivo de entrada, são especificadas as operações que serão realizadas e os caminhos e instantes de obtenção de cada imagem que será processada. Será apresentada uma versão genérica, com as explicações sobre como gerar um arquivo desse tipo:

<interpolate || interpolate_loop || difference $><$ "nome da série de comparações/interpolações" $>$

- interpolate - gera uma imagem de saída para todas as interpolações definidas no instante especificado.

$<$ interpolate $><$ "nome da série de interpolações" $>$

$<\mathrm{N}$ - número de interpolações distintas utilizadas $><\mathrm{T}-$ instante da interpolação $>$

$<$ interp1 $>$

$<$ interp2 $>$

... 


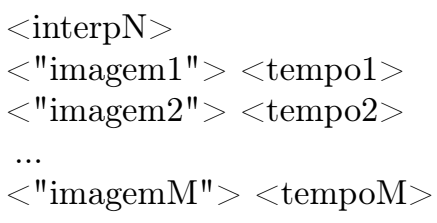

- interpolate_loop - gera uma série de imagens interpoladas com:

$$
\text { instantes }_{k}=\text { tempo } 1+k * T \text {, onde } k \in \mathbb{N} \text { e } \text { instantes }_{k} \leq \text { tempoM }_{\text {. }}
$$

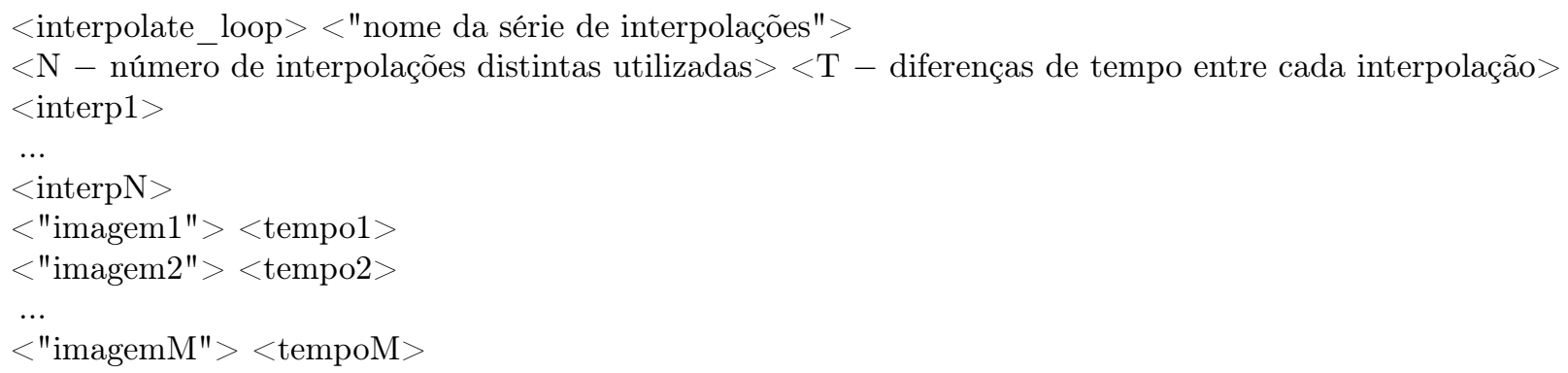

- difference - retorna o valor das diferenças $L^{1}$ e $L^{2}$ das imagens e gera uma imagem de diferença.

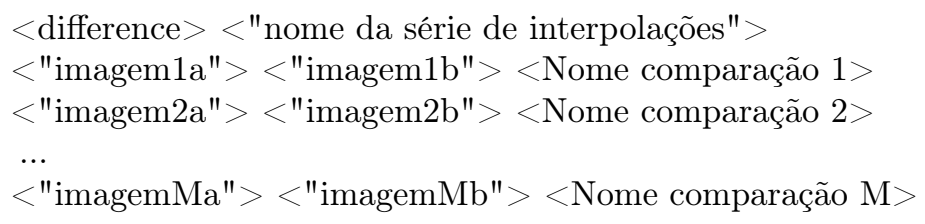

Note que as imagens e o nome da série de comparações e interpolações devem ser definidos entre aspas. Isso é feito, pois, esses "nomes" estão especificando caminhos para as imagens e o resultado da interpolação. Então para uma interpolação no instante 75 de duas imagens, "r2.tif"e "b2.tif", que forma adquiridas nos instantes 60 e 90:

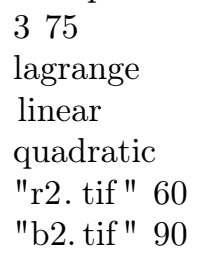

Nesse exemplo, as interpolações aplicadas são Lagrange, linear e quadrática e o resultado deve ser armazenado no diretório rb2. Há outros exemplos de arquivos de entrada que podem ser vistos junto ao código fonte.

As funções de entrada estão definidas no arquivo input.cpp. O código é suficientemente simples para inclusão de qualquer outro tipo de interpolação ou aproximação sem muitas dificuldades. Pequenas alterações devem ser feitas nas funções interpolations TypesVerifier, interpolate e também no arquivo input.h.

Foi utilizada orientação a objetos durante o desenvolvimento do software. Uma das vantagens que isso proporcionou foi a facilidade de implementar novos métodos de interpolação e aproximação, que precisam apenas estender a classe abstrata Interpolator: 
1 \#include < vector $>$

2 \#include $<$ FreeImage.h $>$

3 \#include "hdrimage.h"

4

5 class Interpolator \{

6 public:

7 Interpolator (const std :: vector $<$ int $>$ \&observations, const std::vector $<$ HdrImage $>$ \&values) : observations_(observations),

values (values) \{\}

virtual HdrImage calculateInterpolationOn(float observation) $=0$;

1 protected:

12 std :: vector $<$ int $>$ observations_;

13 std :: vector $<$ HdrImage $>$ values_;

14 ;

Há dois vetores nessa classe:

- observations $\rightarrow$ o instante em que cada imagem foi adquirida

- values $\rightarrow$ as imagens no formato HDR

A função calculateInterpolationOn é responsável por retornar uma imagem interpolada com instante observation. Um bom exemplo de como implementar uma nova interpolação e estender a classe Interpolator é dado pela interpolação linear:

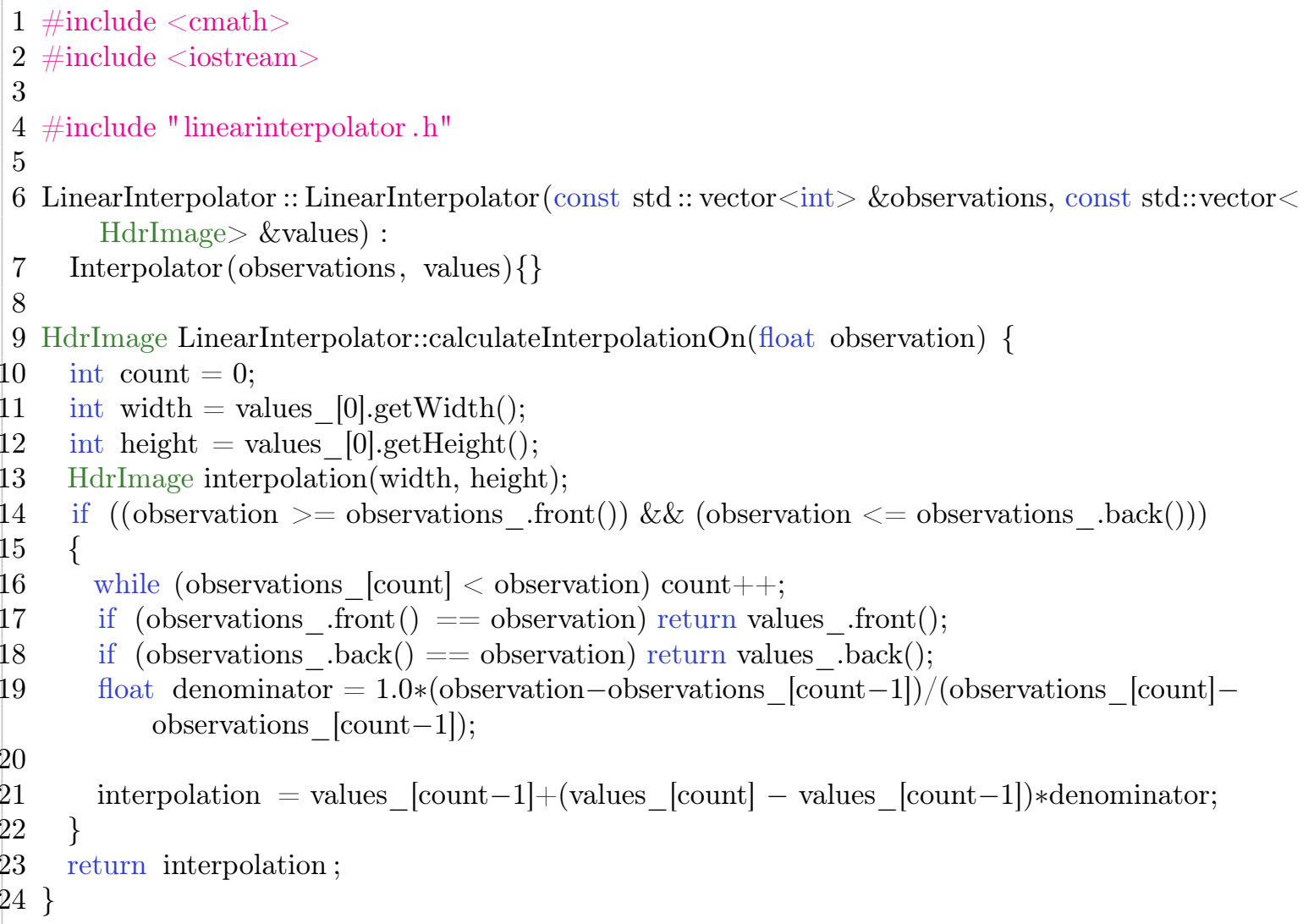

A primeira coisa que se pode notar é que a interpolação linear está estendendo a classe abstrata Interpolator, esse padrão se mantem para todas as outras interpolações e aproximações. 
1 LinearInterpolator :: LinearInterpolator (const std :: vector $<$ int $>$ \&observations, const std::vector $<$ HdrImage $>$ \&values) :

2 Interpolator(observations, values) \{\}

A função calculateInterpolationOn trabalha com o conjunto de imagens (values), instantes de aquisição (observations) e o instante de interpolação (observation) para gerar uma nova imagem. O primeiro passo dessa função é a verificação de que realmente é possível realizar uma interpolação, ou seja, se observation está dentro do intervalo definido por observations:

1 HdrImage LinearInterpolator::calculateInterpolationOn(float observation) \{

2 int count $=0$;

3 int width $=$ values_[0].getWidth () ;

4 int height $=$ values_[0].getHeight () ;

5 HdrImage interpolation(width, height);

6 if ((observation $>=$ observations_.front ()$) \& \&($ observation $<=$ observations_.back ()$))$

Em seguida são determinados os dois instantes de aquisição que estão mais próximos do instante de interpolação:

1 while (observations_[count $]<$ observation) count ++ ;

A imagem é, finalmente, gerada pela mesma equação definida na Seção (A), ou seja:

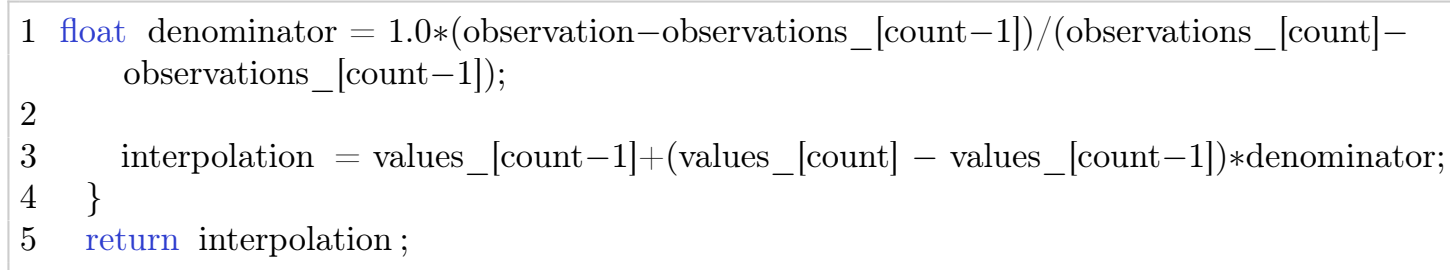

As interpolações e aproximações, em geral, funcionam dessa mesma maneira, as diferenças estão nos métodos matemáticos por trás de cada implementação. Todos os outros métodos seguem o que foi definido nos Apêndices A e B. Logo, para adicionar um novo método de interpolação basta estender a classe Interpolator, implementar o método desejado e fazer pequenas alterações nas funções de entrada.

HDRImage é uma classe de apoio, construída a partir da biblioteca FreeImage, em que estão definidas as operações para criação e manipulação de imagens HDR. Essa classe também é responsável pelo gerenciamento de memória. OpenMP (OpenMP Architecture Review Board, 2002) é utilizado para proporcionar paralelismo para muitas das funções dessa classe. As principais operações definidas por essa classe são os operadores básicos entre imagens HDR e funções auxiliares:

1 int $\operatorname{getWidth}()$;

2 int getHeight () ;

3 void saveImageAsPng(std::string filename);

4 void saveImageAsHdr(std::string filename);

5 void saveImageAsTif(std::string filename);

6 FIRGBAF getPixelAt(unsigned int $\mathrm{x}$, unsigned int $\mathrm{y}$ );

7 float calcDist (const HdrImage\& param);

8 HdrImage diffAbs(const HdrImage\& param);

9 float calcDist_L1(const HdrImage\& param);

10 float $\operatorname{hdrabs}()$; 
11 HdrImage operator-(const HdrImage\& param);

12 HdrImage operator + (const HdrImage\& param);

13 HdrImage operator*(const double\& param);

14 HdrImage operator/(const double\& param);

15 HdrImage clamp () ;

16 void setPixelAt(unsigned int $\mathrm{x}$, unsigned int $\mathrm{y}$, FIRGBAF rgb);

Há um bug na versão 3.17 da biblioteca FreeImage, que inviabiliza a manipulação de imagens HDR no formato TIF. Portanto, para utilizar essa biblioteca é necessário alterar um trecho de código do arquivo PluginTIFF.cpp, linha 1117:

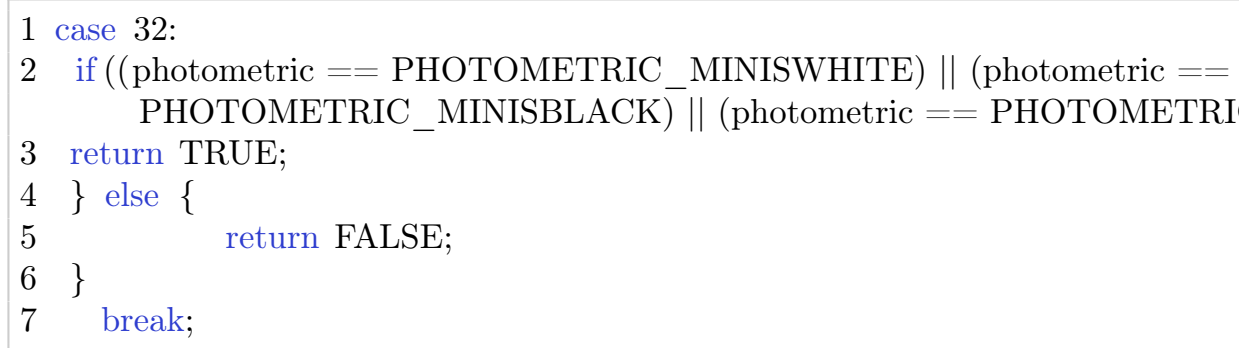

Para:

1 case 32 :

2 return TRUE;

Considerando uma série temporal com $M$ imagens, sendo que cada uma apresenta $N^{2}$ pixels, então, o custo computacional da implementação de cada método é dado por:

- Lagrange

- Linear

- Quadrática

- Gauss's Forward

- Gauss's Backward

- Stirling

- Spline cúbica natural

- Bézier

- Bézier quadrática

- Bézier cúbica

- B-Spline cúbica

$$
O\left(M^{2}+M N^{2}\right)
$$$$
O\left(M+N^{2}\right)
$$$$
O\left(M+N^{2}\right)
$$$$
O\left(M^{2} N^{2}\right)
$$$$
O\left(M^{2} N^{2}\right)
$$$$
O\left(M^{2} N^{2}\right)
$$$$
O\left(M^{2} N^{2}\right)
$$$$
O\left(M^{2} N^{2}\right)
$$

$$
O\left(M+N^{2}\right)
$$$$
O\left(M+N^{2}\right)
$$$$
O\left(M+N^{2}\right)
$$

Tabela F.1: Comparação do custo computacional dos métodos de interpolação e aproximação implementados. 


\section{F.2 Plugin Maya ${ }^{\circledR}$}

O plugin foi desenvolvido utilizando Python e a biblioteca Qt (The Qt Company, 2005) para gerenciamento da interface gráfica. Tem como função integrar o software de interpolações ao software de modelagem e renderização, facilitando o uso de IBL temporalmente variável.

Funciona nas versões 2015 e 2016 do Maya ${ }^{\circledR}$. Caso esteja trabalhando com o código fonte é necessário incluir o binário, proveniente do software de interpolação, no diretório do plugin com o nome interpolation.exe. Há ainda distribuições do plugin com os binários para Windows e OSX, que podem ser encontradas nos links:

\section{Windows https://github.com/cfvalente/rad_win/ \\ OSX https://github.com/cfvalente/rad_osx/}

Note que para utilizar a versão para Windows é necessário ter instalado Visual $\mathrm{C}++$ Redistributable for Visual Studio 2015 e Visual C ++ Redistributable for Visual Studio 2012:

https://www.microsoft.com/en-us/download/details.aspx?id=48145

https://www.microsoft.com/en-us/download/details.aspx?id=30679

Para inicializar o plugin: Windows $\rightarrow$ Settings/Preferences $\rightarrow$ Plug-in Manager, em seguida escolha a opção Browse e selecione o arquivo radplugin.py. Com isso o menu HDR Interpolation ficará disponível, nesse menu há a opção Show Menu, que vai mostrar as opções de interpolação. O plugin pode ser desabilitado no mesmo menu em que foi ativado, ou então reinicializando o Maya ${ }^{\circledR}$.

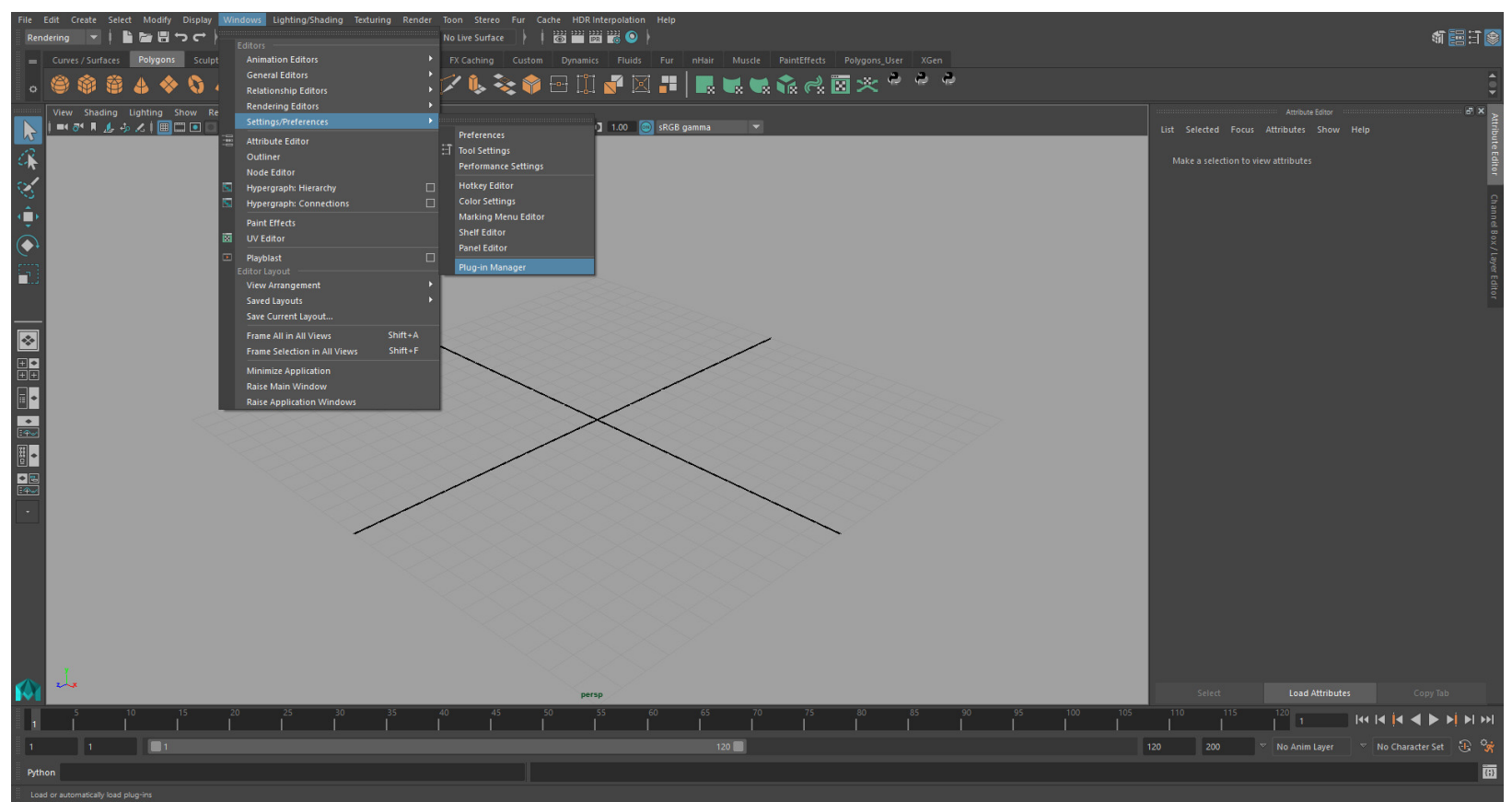

Figura F.1: Abrindo o gerenciador de plugins do Maya ${ }^{\circledR}$. 
Browse Images é usado para selecionar o conjunto de imagens que será utilizada durante a interpolação. Um instante deve ser atribuído a cada imagem, essa atribuição pode ser feita utilizando um formato Hora/Minuto, ou então, caso a opção Use Integers for time input esteja selecionada, basta utilizar inteiros para representar os instantes.

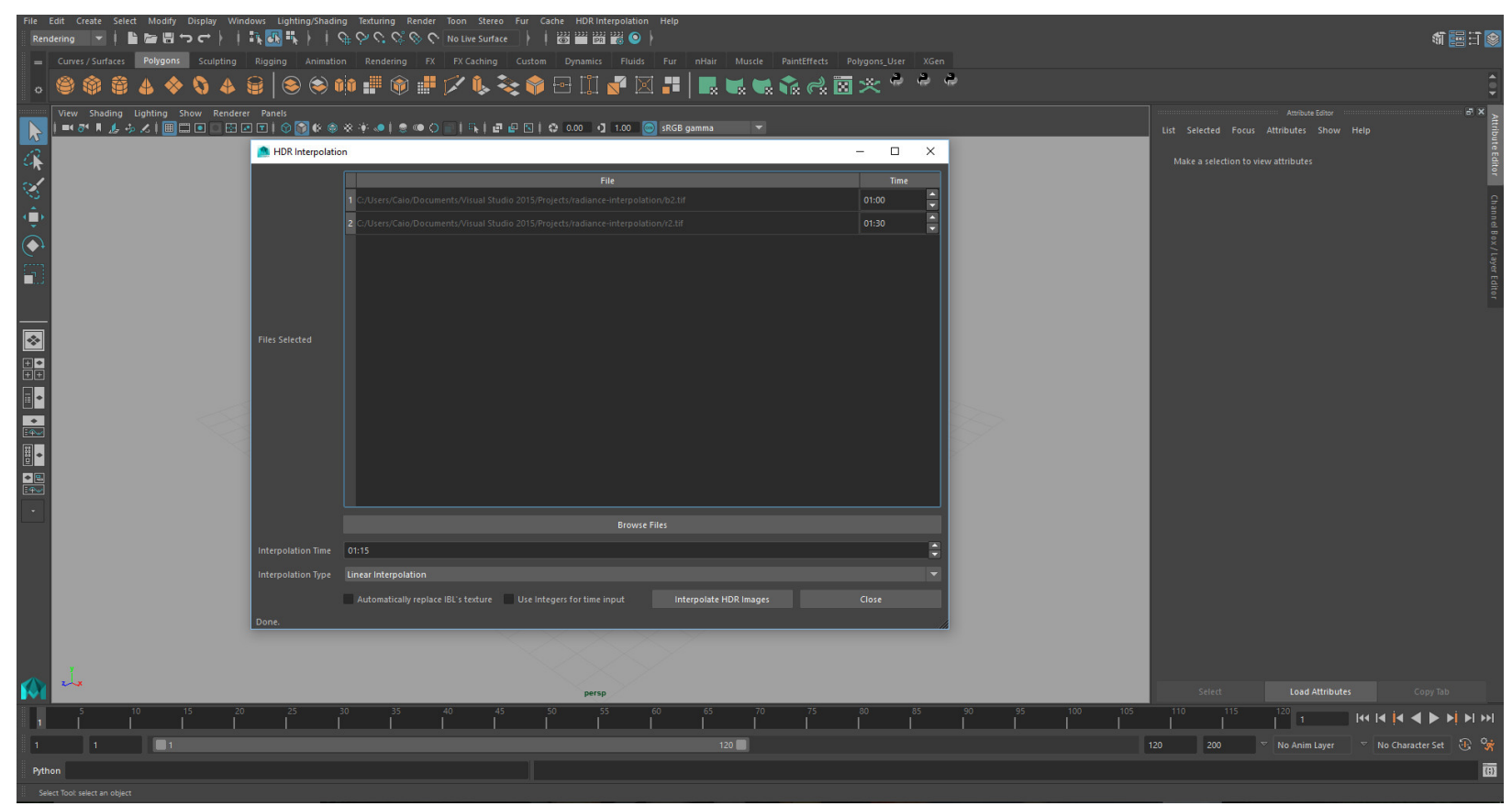

Figura F.2: Uso de formato Hora/Minuto para especificação do instante de aquisição das imagens "b2.tif"e "r2.tif".

Caso mental-ray ${ }^{\circledR}$ seja o renderizador utilizado e exista um nó do tipo IBL, então é possível atribuir automaticamente a imagem resultante da interpolação a esse nó, utilizando a opção Automatically replace IBL's texture. Se essa opção não for utilizada, a imagem resultante ficara armazenada no diretório HDR, localizado na raiz do projeto. 


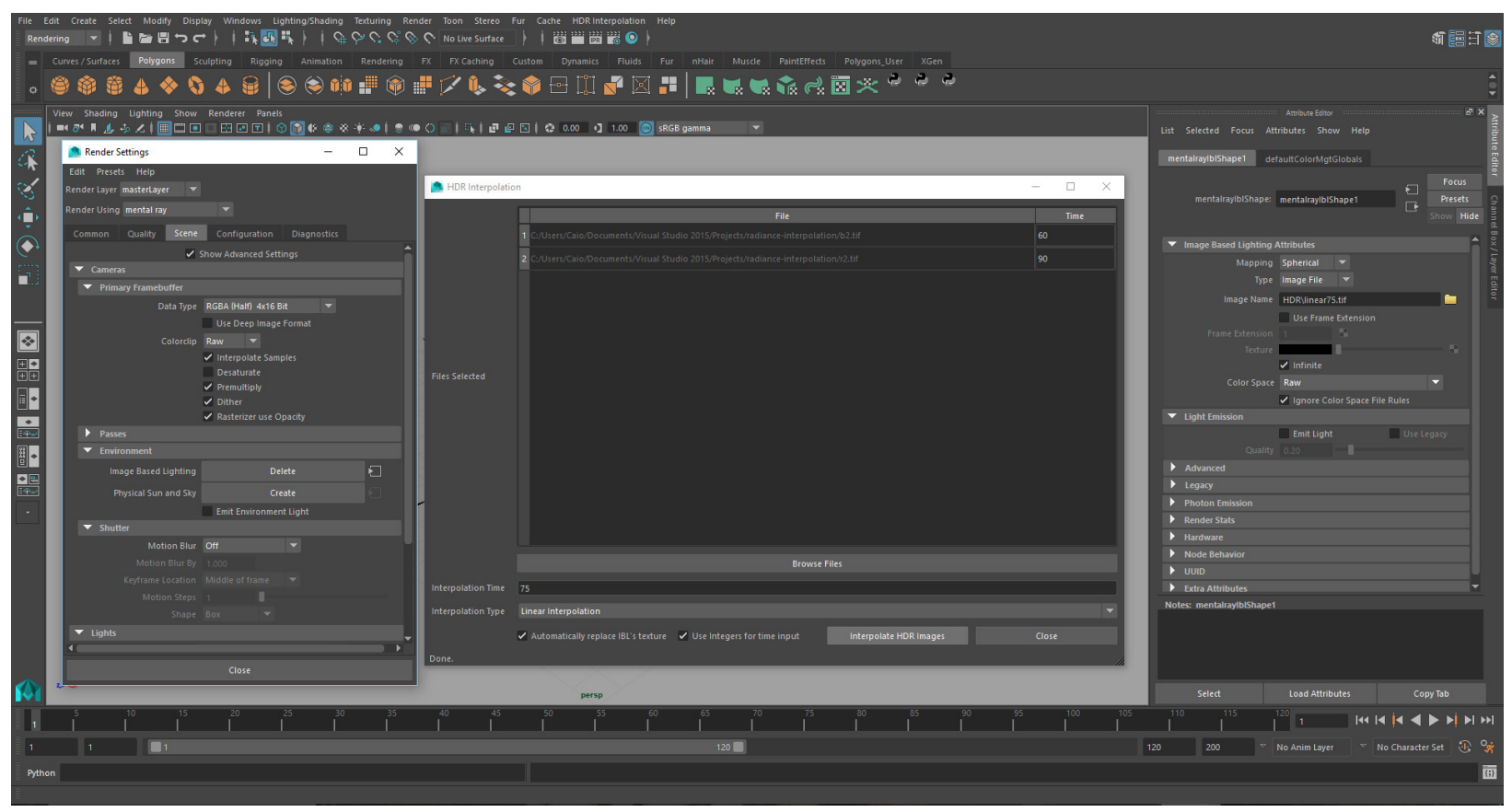

Figura F.3: Atribuição automática da imagem interpolada. Note que mental-ray ${ }^{\circledR}$ é o renderizador selecionado e existe na cena um objeto do tipo IBL.

O funcionamento do plugin é baseado na troca de mensagens e processamento de eventos. Há três arquivos principais:

- radplugin.py $\rightarrow$ responsável pelo registro e inicialização do plugin.

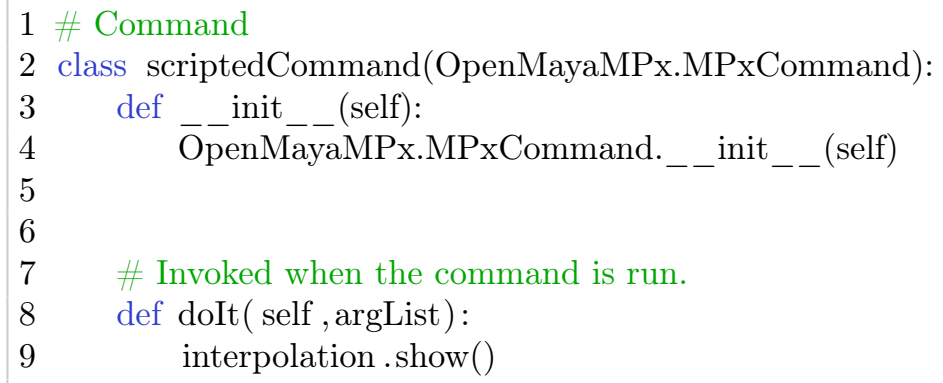

- plugingui.py $\rightarrow$ definição da interface gráfica e os eventos associados. 
files representa um vetor de strings, que armazena o caminho para todas as imagens selecionadas, TIMES é um vetor que armazena os instantes de aquisição de cada imagem, timeinput é o instante que o usuário escolheu para realizar a interpolação e _ NINTERP é o número interpolações implementadas, caso seja definida outro tipo de interpolação essa variável deve ser atualizada.

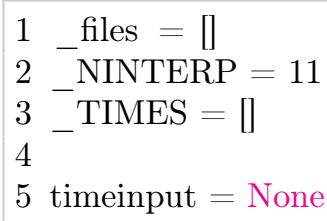

Em caso de implementação de uma nova interpolação, a função index ToInterpolationType também deverá ser modificada. Essa função relaciona o código utilizado pelo arquivo de entrada com o que está escrito na interface gráfica e o número mínimo de imagens, necessárias para que cada método funcione.

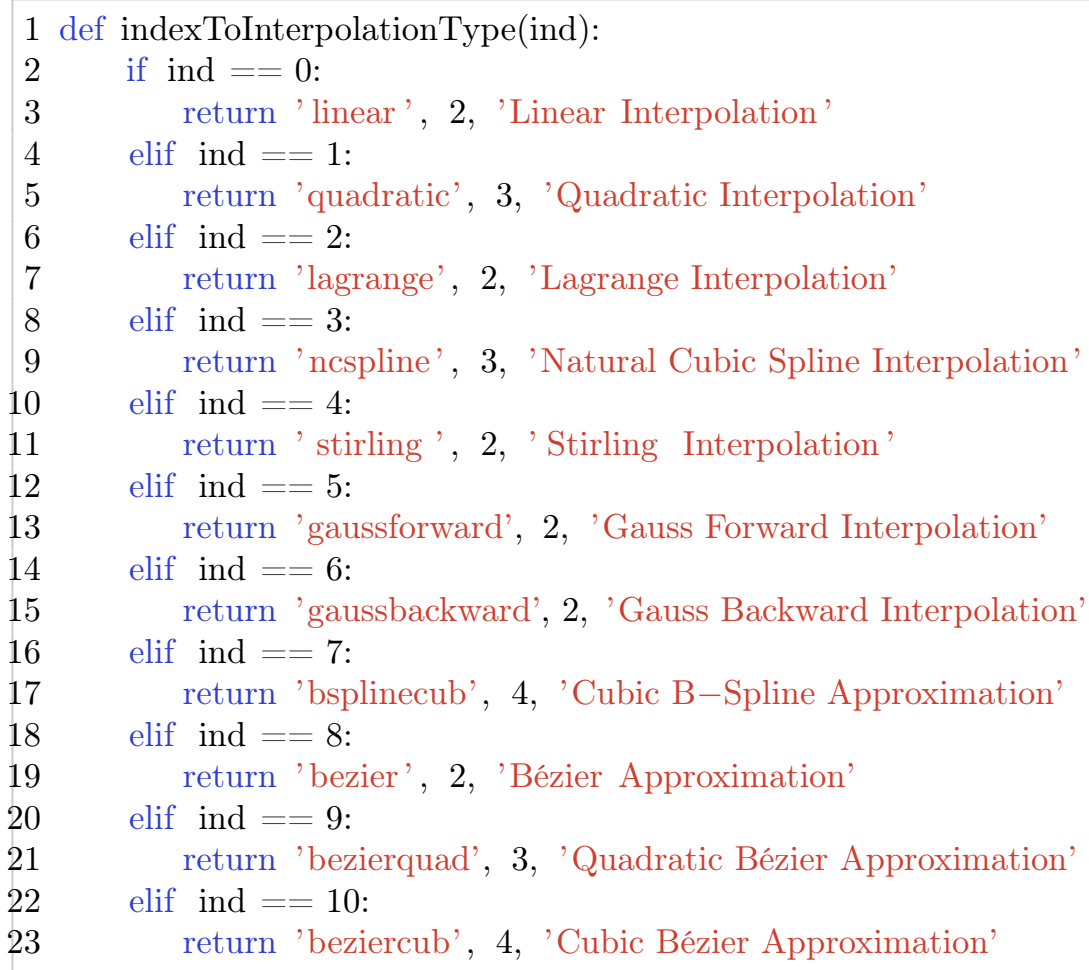

A função create_window é a parte principal do arquivo, nela está definida a interface e os eventos que devem ocorrer durante as interações com o usuário.

- interpolation.py $\rightarrow$ gerenciamento e processamento dos sinais da interface.

A função interpolate é a parte principal do plugin, essa função cria um arquivo de entrada para o software de interpolação e executa o software com o arquivo gerado. O resultado é uma imagem artificial produzida a partir das imagens e instante selecionados. Também altera a imagem utilizada pelo IBL, caso essa opção esteja ativada:

1 def interpolate( files, times, interptype, interptime, subsTexture):

2 global cont 


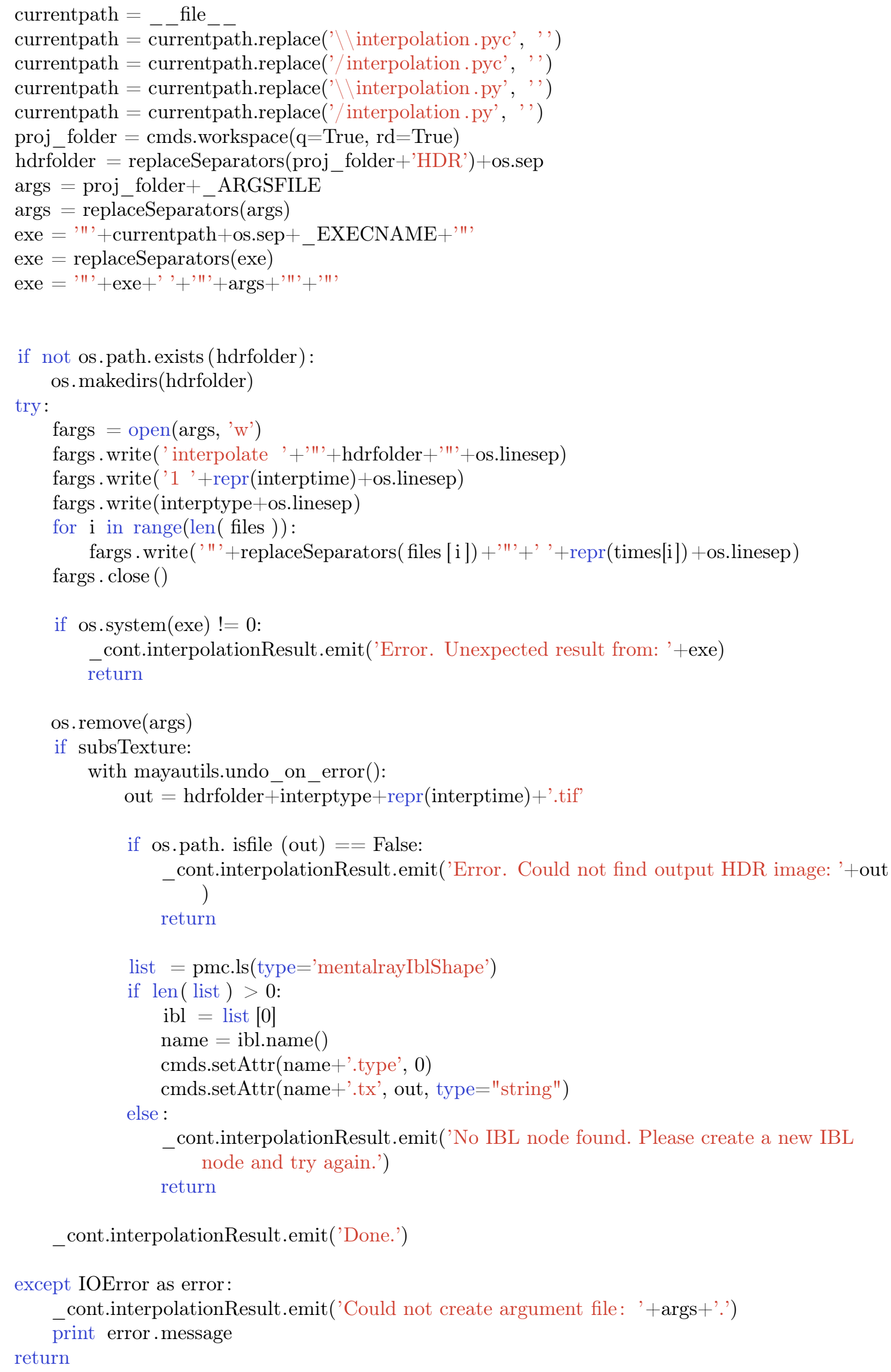




\section{Apêndice G}

\section{Dados e Resultados}

As distâncias $L^{2}$, entre os mapas de iluminação originais e artificiais, foram normalizadas em relação ao número de pixels presentes nas imagens.

\begin{tabular}{c|c|c|c|c|c|c}
\hline Instante & LAG & LIN & QUAD & FOR & BACK & STIR \\
\hline $11: 22$ & 0.65963 & 0.00013 & 0.00015 & 0.00013 & 0.00014 & 0.00013 \\
$11: 53$ & 0.02900 & 0.00013 & 0.00015 & 0.00013 & 0.00015 & 0.00014 \\
$12: 22$ & 0.01260 & 0.00013 & 0.00011 & 0.00014 & 0.00014 & 0.00014 \\
$12: 53$ & 0.00132 & 0.00007 & 0.00011 & 0.00007 & 0.00009 & 0.00008 \\
$13: 22$ & 0.00107 & 0.00016 & 0.00017 & 0.00017 & 0.00017 & 0.00017 \\
$13: 54$ & 0.00028 & 0.00012 & 0.00017 & 0.00013 & 0.00012 & 0.00013 \\
$14: 23$ & 0.00024 & 0.00014 & 0.00016 & 0.00014 & 0.00014 & 0.00014 \\
$14: 52$ & 0.00016 & 0.00012 & 0.00016 & 0.00013 & 0.00013 & 0.00013 \\
$15: 23$ & 0.00013 & 0.00010 & 0.00007 & 0.00010 & 0.00010 & 0.00010 \\
$15: 53$ & 0.00007 & 0.00002 & 0.00005 & 0.00004 & 0.00004 & 0.00004 \\
$16: 24$ & 0.00016 & 0.00001 & 0.00001 & 0.00003 & 0.00002 & 0.00003 \\
$16: 53$ & 0.00010 & 0.00001 & 0.00001 & 0.00002 & 0.00001 & 0.00002 \\
$17: 23$ & 0.00041 & 0.00001 & 0.00001 & 0.00001 & 0.00001 & 0.00001 \\
$17: 53$ & 0.00042 & 0.00001 & 0.00001 & 0.00001 & 0.00001 & 0.00001 \\
$18: 23$ & 0.00283 & 0.00001 & 0.00001 & 0.00001 & 0.00001 & 0.00001 \\
$18: 52$ & 0.00473 & 0.00000 & 0.00001 & 0.00001 & 0.00000 & 0.00001 \\
$19: 22$ & 0.06597 & 0.00001 & 0.00001 & 0.00001 & 0.00001 & 0.00001 \\
$19: 53$ & 0.28229 & 0.00000 & 0.00000 & 0.00000 & 0.00000 & 0.00000 \\
Total & 1.06141 & 0.00120 & 0.00137 & 0.00127 & 0.00130 & 0.00128
\end{tabular}

Tabela G.1: Distâncias $L^{2}$ normalizadas resultantes do primeiro experimento, com o conjunto de dados da primeira aquisição. 


\begin{tabular}{c|c|c|c|c|c}
\hline Instante & SCN & BÉZ & BÉZ QUAD & BÉZ CÚB & BSC \\
\hline $11: 22$ & 0.00015 & 0.00012 & 0.00013 & 0.00013 & 0.00013 \\
$11: 53$ & 0.00014 & 0.00013 & 0.00013 & 0.00013 & 0.00013 \\
$12: 22$ & 0.00013 & 0.00015 & 0.00014 & 0.00013 & 0.00014 \\
$12: 53$ & 0.00010 & 0.00006 & 0.00007 & 0.00006 & 0.00006 \\
$13: 22$ & 0.00014 & 0.00017 & 0.00016 & 0.00018 & 0.00017 \\
$13: 54$ & 0.00015 & 0.00011 & 0.00012 & 0.00012 & 0.00012 \\
$14: 23$ & 0.00016 & 0.00016 & 0.00014 & 0.00014 & 0.00014 \\
$14: 52$ & 0.00015 & 0.00012 & 0.00012 & 0.00012 & 0.00012 \\
$15: 23$ & 0.00011 & 0.00010 & 0.00011 & 0.00010 & 0.00010 \\
$15: 53$ & 0.00004 & 0.00006 & 0.00002 & 0.00002 & 0.00002 \\
$16: 24$ & 0.00002 & 0.00002 & 0.00001 & 0.00001 & 0.00001 \\
$16: 53$ & 0.00001 & 0.00001 & 0.00001 & 0.00001 & 0.00001 \\
$17: 23$ & 0.00001 & 0.00002 & 0.00001 & 0.00001 & 0.00001 \\
$17: 53$ & 0.00001 & 0.00001 & 0.00001 & 0.00001 & 0.00001 \\
$18: 23$ & 0.00001 & 0.00001 & 0.00001 & 0.00001 & 0.00001 \\
$18: 52$ & 0.00001 & 0.00001 & 0.00000 & 0.00001 & 0.00000 \\
$19: 22$ & 0.00001 & 0.00001 & 0.00001 & 0.00001 & 0.00001 \\
$19: 53$ & 0.00000 & 0.00000 & 0.00000 & 0.00000 & 0.00000 \\
Total & 0.00135 & 0.00125 & 0.00122 & 0.00119 & 0.00120 \\
& & & &
\end{tabular}

Tabela G.2: Distâncias $L^{2}$ normalizadas resultantes do primeiro experimento, com o conjunto de dados da primeira aquisição.

\begin{tabular}{c|c|c|c|c|c|c}
\hline Instante & LAG & LIN & QUAD & FOR & BACK & STIR \\
\hline $15: 38$ & 0.01095 & 0.00057 & 0.00076 & 0.00058 & 0.00063 & 0.00060 \\
$16: 07$ & 0.00426 & 0.00075 & 0.00076 & 0.00075 & 0.00085 & 0.00080 \\
$16: 39$ & 0.00121 & 0.00082 & 0.00084 & 0.00086 & 0.00085 & 0.00085 \\
$17: 11$ & 0.00066 & 0.00049 & 0.00079 & 0.00053 & 0.00049 & 0.00051 \\
$17: 40$ & 0.00041 & 0.00027 & 0.00032 & 0.00029 & 0.00029 & 0.00029 \\
$18: 11$ & 0.00043 & 0.00024 & 0.00031 & 0.00026 & 0.00026 & 0.00026 \\
$18: 39$ & 0.00037 & 0.00015 & 0.00014 & 0.00016 & 0.00015 & 0.00016 \\
$19: 09$ & 0.00109 & 0.00009 & 0.00014 & 0.00010 & 0.00008 & 0.00009 \\
$19: 40$ & 0.00183 & 0.00003 & 0.00002 & 0.00001 & 0.00003 & 0.00002 \\
$20: 08$ & 0.01415 & 0.00000 & 0.00000 & 0.00000 & 0.00000 & 0.00000 \\
Total & 0.03535 & 0.00340 & 0.00409 & 0.00356 & 0.00362 & 0.00358
\end{tabular}

Tabela G.3: Distâncias $L^{2}$ normalizadas resultantes do primeiro experimento, com o conjunto de dados da segunda aquisição. 


\begin{tabular}{c|c|c|c|c|c}
\hline Instante & SCN & BÉZ & BÉZ QUAD & BÉZ CÚB & BSC \\
\hline $15: 38$ & 0.00077 & 0.00051 & 0.00056 & 0.00056 & 0.00057 \\
$16: 07$ & 0.00087 & 0.00068 & 0.00076 & 0.00070 & 0.00074 \\
$16: 39$ & 0.00094 & 0.00074 & 0.00082 & 0.00079 & 0.00081 \\
$17: 11$ & 0.00066 & 0.00034 & 0.00043 & 0.00051 & 0.00047 \\
$17: 40$ & 0.00038 & 0.00023 & 0.00027 & 0.00025 & 0.00027 \\
$18: 11$ & 0.00030 & 0.00022 & 0.00023 & 0.00023 & 0.00024 \\
$18: 39$ & 0.00020 & 0.00011 & 0.00015 & 0.00015 & 0.00014 \\
$19: 09$ & 0.00011 & 0.00012 & 0.00008 & 0.00010 & 0.00009 \\
$19: 40$ & 0.00001 & 0.00009 & 0.00003 & 0.00004 & 0.00003 \\
$20: 08$ & 0.00001 & 0.00002 & 0.00000 & 0.00000 & 0.00000 \\
Total & 0.00426 & 0.00305 & 0.00334 & 0.00332 & 0.00336
\end{tabular}

Tabela G.4: Distâncias $L^{2}$ normalizadas resultantes do primeiro experimento, com o conjunto de dados da segunda aquisição.

\section{Segundo Experimento}

Como as imagens foram distribuídas de maneira aleatória em cada questionário, pode haver um número diferente de respostas para cada imagem. A parte em verde representa as imagens sem objetos virtuais, já parte em azul representa as imagens com objetos virtuais. 
Imagem Número de acertos Número de respostas \%Acertos

\begin{tabular}{cccc}
\hline 1 & 7 & 7 & $100.00 \%$ \\
2 & 3 & 4 & $75.00 \%$ \\
3 & 8 & 11 & $72.73 \%$ \\
4 & 6 & 9 & $66.67 \%$ \\
5 & 2 & 2 & $100.00 \%$ \\
6 & 7 & 11 & $63.64 \%$ \\
7 & 6 & 11 & $54.55 \%$ \\
8 & 7 & 11 & $63.64 \%$ \\
9 & 4 & 7 & $57.14 \%$ \\
Total & 50 & 73 & $68.50 \%$
\end{tabular}

$\begin{array}{cccc}10 & 2 & 4 & 50.00 \% \\ 11 & 3 & 6 & 50.00 \% \\ 12 & 1 & 9 & 11.11 \% \\ 13 & 1 & 9 & 11.11 \% \\ 14 & 8 & 11 & 72.73 \% \\ 15 & 2 & 9 & 22.22 \% \\ 16 & 2 & 4 & 50.00 \% \\ 17 & 5 & 11 & 45.45 \% \\ 18 & 4 & 9 & 44.44 \% \\ 19 & 6 & 11 & 54.55 \% \\ 20 & 6 & 11 & 54.55 \% \\ 21 & 5 & 9 & 55.56 \% \\ 22 & 4 & 11 & 36.36 \% \\ 23 & 4 & 11 & 36.36 \% \\ 24 & 4 & 11 & 36.36 \% \\ 25 & 8 & 11 & 72.73 \% \\ \text { Total } & 65 & 147 & 44.22 \%\end{array}$

Tabela G.5: Respostas dos questionários para o grupo com conhecimentos em CG. 
Imagem Número de acertos Número de respostas \%Acertos

\begin{tabular}{cccc}
\hline 1 & 11 & 15 & $73.33 \%$ \\
2 & 2 & 7 & $28.57 \%$ \\
3 & 11 & 19 & $57.89 \%$ \\
4 & 6 & 16 & $37.50 \%$ \\
5 & 6 & 10 & $60.00 \%$ \\
6 & 11 & 15 & $73.33 \%$ \\
7 & 9 & 16 & $56.25 \%$ \\
8 & 6 & 19 & $31.58 \%$ \\
9 & 7 & 15 & $46.67 \%$ \\
Total & 69 & 132 & $52.27 \%$
\end{tabular}

$\begin{array}{cccc}10 & 6 & 8 & 75.00 \% \\ 11 & 7 & 10 & 70.00 \% \\ 12 & 9 & 12 & 75.00 \% \\ 13 & 8 & 16 & 50.00 \% \\ 14 & 9 & 15 & 60.00 \% \\ 15 & 12 & 18 & 66.67 \% \\ 16 & 5 & 10 & 50.00 \% \\ 17 & 11 & 19 & 57.89 \% \\ 18 & 9 & 16 & 56.25 \% \\ 19 & 11 & 16 & 68.75 \% \\ 20 & 6 & 16 & 37.50 \% \\ 21 & 10 & 16 & 62.50 \% \\ 22 & 7 & 19 & 36.84 \% \\ 23 & 15 & 19 & 78.95 \% \\ 24 & 11 & 19 & 57.89 \% \\ 25 & 15 & 19 & 78.95 \% \\ \text { Total } & 151 & 248 & 60.89 \%\end{array}$

Tabela G.6: Respostas dos questionários para o grupo sem conhecimentos em CG. 
Imagem Número de acertos Número de respostas \%Acertos

\begin{tabular}{|c|c|c|c|}
\hline 1 & 18 & 22 & $81.82 \%$ \\
\hline 2 & 5 & 11 & $45.45 \%$ \\
\hline 3 & 19 & 30 & $63.33 \%$ \\
\hline 4 & 12 & 25 & $48.00 \%$ \\
\hline 5 & 8 & 12 & $66.67 \%$ \\
\hline 6 & 18 & 26 & $69.23 \%$ \\
\hline 7 & 15 & 27 & $55.56 \%$ \\
\hline 8 & 13 & 30 & $43.33 \%$ \\
\hline 9 & 11 & 22 & $50.00 \%$ \\
\hline Total & 119 & 205 & $58.05 \%$ \\
\hline 10 & 8 & 12 & $66.67 \%$ \\
\hline 11 & 10 & 16 & $62.50 \%$ \\
\hline 12 & 10 & 21 & $47.62 \%$ \\
\hline 13 & 9 & 25 & $36.00 \%$ \\
\hline 14 & 17 & 26 & $65.38 \%$ \\
\hline 15 & 14 & 27 & $51.85 \%$ \\
\hline 16 & 7 & 14 & $50.00 \%$ \\
\hline 17 & 16 & 30 & $53.33 \%$ \\
\hline 18 & 13 & 25 & $52.00 \%$ \\
\hline 19 & 17 & 27 & $62.96 \%$ \\
\hline 20 & 12 & 27 & $44.44 \%$ \\
\hline 21 & 15 & 25 & $60.00 \%$ \\
\hline 22 & 11 & 30 & $36.67 \%$ \\
\hline 23 & 19 & 30 & $63.33 \%$ \\
\hline 24 & 15 & 30 & $50.00 \%$ \\
\hline 25 & 23 & 30 & $76.67 \%$ \\
\hline Total & 216 & 395 & $54.68 \%$ \\
\hline
\end{tabular}

Tabela G.7: Respostas dos questionários sem distinção de grupos por conhecimento em CG. 


\section{Referências Bibliográficas}

Adobe Systems, Inc.(2015) Adobe Systems, Inc. Photoshop. 2015.1. URL http://www. photoshop.com/. Citado na pág. 13

AFLCMC/WWU(2015) Air Force Life Cycle Management Center AFLCMC/WWU. (u) raptor helmet mounted display (rhmd) system requirements document, 2015. URL https://www.fbo.gov/utils/view?id=764fa1745020b052bcf295125cbba296. Citado na pág. 2

Agusanto et al.(2003) Kusuma Agusanto, Li Li, Zhu Chuangui e Ng Wan Sing. Photorealistic rendering for augmented reality using environment illumination. Em The Second IEEE and ACM International Symposium on Mixed and Augmented Reality, páginas 208 - 216. ISBN 0-7695-2006-5. Citado na pág. 21

Akenine-Möller et al.(2008) Thomas Akenine-Möller, Eric Haines e Naty Hoffman. RealTime Rendering. CRC Press, 3 edição. ISBN 978-1-56881-424-7. Citado na pág. vii, 8, 14, 15, $57,64,71$

Ammusri(2015) Ammusri. marble. URL http://tf3dm.com/3d-model/marble-37799.html. Citado na pág. 46

Aránguez(2015) Enrique Aránguez. Coca-cola can. URL http://tf3dm.com/3d-model/ coca-cola-can-23142.html. Citado na pág. 46

Autodesk Inc.(2015) Autodesk Inc. Maya. 2015 SP6. URL http://www.autodesk.com/ products/maya/overview. Citado na pág. 29

Azuma(1997) Ronald Azuma. A survey of augmented reality. Presence: Teleoperators and Virtual Environments, 6(4):355 - 385. Citado na pág. 6, 20

Bailey(2007) Linda Bailey. A large mirror ball on the promenade. geograph.org.uk. Citado na pág. vii, 3

Blinn(1977) James F. Blinn. Models of light reflection for computer synthesized pictures. SIGGRAPH 'ry Proceedings of the 4th annual conference on Computer graphics and interactive techniques, 11(2):192-198. ISSN 0097-8930. doi: 10.1145/965141.563893. Citado na pág. 8

Castro et al.(2012) Tassio Castro, Luiz Henrique de Figueiredo e Luiz Velho. Realistic shadows on mobile augmented reality. Em 14th Symposium on Virtual and Augmented Reality (SVR), páginas 36-45. ISBN 978-0-7695-4725-1. Citado na pág. 21

Christoph Bichlmeier e Navab(2007) Sandro M. Heining Christoph Bichlmeier, Felix Wimme e Nassir Navab. Contextual anatomic mimesis hybrid in-situ visualization 
method for improving multi-sensory depth perception in medical augmented reality. Em Mixed and Augmented Reality, 200\%. ISMAR 200\%. 6th IEEE and ACM International Symposium on, páginas 129-138. doi: 10.1109/ISMAR.2007.4538837. Citado na pág. vii, 1, 2

Cohen et al.(1988) Michael F. Cohen, Shenchang Eric Chen, John R. Wallace e Donald P. Greenberg. A progressive refinement approach to fast radiosity image generation. SIGGRAPH Comput. Graph., 22(4):75-84. ISSN 0097-8930. doi: 10.1145/378456.378487. Citado na pág. 20

Debevec(2002) Paul Debevec. Tutorial: Image-based lighting. IEEE Computer Graphics and Applications, 22(2):26 - 34. ISSN 0272-1716. Citado na pág. viii, 17

Debevec(1998) Paul Debevec. Rendering synthetic objects into real scenes: bridging traditional and image-based graphics with global illumination and high dynamic range photography. páginas 189-198. ACM SIGGRAPH '98. doi: 10.1145/280814.280864. Citado na pág. viii, $3,13,14,18,19,20,21$

Debevec e Malik(1997) Paul Debevec e Jitendra Malik. Recovering high dynamic range radiance maps from photographs. páginas 369-378. ACM Press/Addison-Wesley Publishing Co. doi: 10.1145/258734.258884. Citado na pág. 11, 12, 20

Drettakis et al.(1997) George Drettakis, Luc Robert e Sylvain Bugnoux. Interactive common illumination for computer augmented reality. Em Eurographics Workshop on Rendering Techniques '97\%, páginas 45-56. Citado na pág. 20

$\operatorname{Emok}(2008)$ Emok. An illustration of the first angle projection used in engineering drawings. URL https://en.wikipedia.org/wiki/Engineering_drawing\#/media/File: First_angle_projection.svg. Citado na pág. xi, 70

Fisco(2015) Igor Fisco. NBA Spalding Basketball. URL http://tf3dm.com/3d-model/ nba-spalding-basketball-21430.html. Citado na pág. 46

Fournier et al.(1993) Alain Fournier, Atjeng S. Gunawan e Chris Romanzin. Common illumination between real and computer generated scenes. Em Graphics Interface '93, páginas 254-262. Citado na pág. 20

Fractsofphotos(2009) Fractsofphotos. Parametric continuity vector.svg. URL https://en. wikipedia.org/wiki/File:Parametric_continuity_vector.svg. Citado na pág. xi, 57

FreeImage(2015) FreeImage. Freeimage, 2015. URL http://freeimage.sourceforge.net/. Citado na pág. 73

Garrido-Jurado et al.(2014) S. Garrido-Jurado, R. Muñoz-Salinas, F.J. Madrid-Cuevas e M.J. Marín-Jiménez. Automatic generation and detection of highly reliable fiducial markers under occlusion. Pattern Recognition, 47(6):2280 - 2292. ISSN 0031-3203. Citado na pág. 29

Gibson et al.(2001) Simon Gibson, Toby Howard e Roger Hubbold. Flexible image-based photometric reconstruction using virtual light sources. Computer Graphics Forum, 20(3). Citado na pág. 22

Google, Inc.(2015) Google, Inc. Google Forms. URL https://www.google.com/forms/ about/. Citado na pág. 48 
Hajisharif et al.(2012) Saghi Hajisharif, Joel Kronander, Ehsan Miandji e Jonas Unger. Real-time image based lighting with streaming hdr-light probe sequences. Em SIGRAD 2012. Citado na pág. 23

Hanrahan et al.(1991) Pat Hanrahan, David Salzman e Larry Aupperle. A rapid hierarchical radiosity algorithm. SIGGRAPH Comput. Graph., 25(4):197-206. ISSN 0097-8930. doi: 10.1145/127719.122740. Citado na pág. 20

HDR Shop(2001) HDR Shop. HDR Shop. 1.03. URL http://www.hdrshop.com/. Citado na pág. 13

Henderson e Feiner(2007) Steve J. Henderson e Steven K. Feiner. Armar - augmented reality for maintenance and repair. Report AFRL-RH-WP-TR-2007-0112. Citado na pág. vii, 1

Hughes et al.(2013) John F. Hughes, Andries Van Dam, Morgan McGuire, David F. Sklar, James D. Foley, Steven K. Feiner e Kurt Akeley. Computer Graphics Principles and Practice. Addison-Wesley Professional, 3 edition edição. ISBN ISBN-13: 978-0321399526. Citado na pág. 7,70

Jacobs e Loscos(2006) Katrien Jacobs e Céline Loscos. Classification of illumination methods for mixed reality. Computer Graphics Forum, 25(1):29 - 51. ISSN 01677055. Citado na pág. 2, 5, 7, 23, 29

Jurohi(2006) Jurohi. BSDF: BRDF + BTDF. URL https://en.wikipedia.org/wiki/ Bidirectional_scattering_distribution_function\#/media/File:BSDF05_800.png. Citado na pág. vii, 8

Kajiya(1986) James T. Kajiya. The rendering equation. Em SIGGRAPH '86 Proceedings of the 13th annual conference on Computer graphics and interactive techniques, páginas 143-150. ISBN 0-89791-196-2. Citado na pág. 7

Kanbara e Yokoya(2002) Masayuki Kanbara e Naokazu Yokoya. Geometric and photometric registration for real-time augmented reality. Em ISMAR '02 Proceedings of the 1st International Symposium on Mixed and Augmented Reality, página 279-280. ISBN 0-7695-1781-1. Citado na pág. 21

Kato e Billinghurst(1999) Hirokazu Kato e Mark Billinghurst. Marker tracking and hmd calibration for a video-based augmented reality conferencing system. Em Proceedings 2nd IEEE and ACM International Workshop on Augmented Reality (IWAR'99), páginas 85 94. IEEE. ISBN 0-7695-0359-4. Citado na pág. 7

Kautz et al.(2002) Jan Kautz, Peter-Pike Sloan e John Snyder. Fast, arbitrary brdf shading for low-frequency lighting using spherical harmonics. Em Eurographics Rendering Workshop. Citado na pág. 23

Knecht et al.(2010) Martin Knecht, Christoph Traxler, Oliver Mattausch, Werner Purgathofer e Michael Wimmer. Differential instant radiosity for mixed reality. Em Proceedings of the 2010 IEEE International Symposium on Mixed and Augmented Reality (ISMAR 2010), páginas 99-107. Citado na pág. 22

Knecht et al.(2012) Martin Knecht, Christoph Traxler, Oliver Mattausch e Michael Wimmera. Reciprocal shading for mixed reality. Computers and Graphics, 36(7):846-856. Citado na pág. viii, 22,23 
Kolivand e Sunar(2013) Hoshang Kolivand e Mohd Shahrizal Sunar. Covering photorealistic properties of outdoor components with the effects of sky color in mixed reality. Multimedia Tools and Applications, 72(3):2143-2162. ISSN 1573-7721. doi: 10.1007/s11042-013-1494-9. Citado na pág. 22

Kolivand e Sunar(2014) Hoshang Kolivand e Mohd Shahrizal Sunar. Realistic real-time outdoor rendering in augmented reality. PLoS ONE, 9(9):e108334. doi: 10.1371/journal. pone.0108334. Citado na pág. 22

Land e McCann(1971) Edwin H. Land e John J. McCann. Lightness and retinex theory. Journal of the Optical Society of America, 61(1):1-11. doi: 10.1364/JOSA.61.000001. Citado na pág. 22

Lengyel(2012) Eric Lengyel. Mathematics for 3D Game Programming and Computer Graphics. Course Technology PTR, 3 edição. ISBN 978-1-4354-5886-4. Citado na pág. 62, 65

Madsen e Lal(2010) Claus B. Madsen e Brajesh B. Lal. Probeless Illumination Estimation for Outdoor Augmented Reality. Soha Maad, http://www.intechopen.com/books/howtoreference/augmented-reality/probelessillumination-estimation-for-outdoor-augmented-reality. ISBN ISBN: 978-953-7619-69-5. Citado na pág. 21

Madsen e Lal(2011) Claus B. Madsen e Brajesh B. Lal. Outdoor illumination estimation in image sequences for augmented reality. Em GRAPP 2011 - Proceedings of the International Conference on Computer Graphics Theory and Applications, Vilamoura, Algarve, Portugal, March 5-7, 2011, páginas 129-139. Citado na pág. viii, 21, 22

Milgram e Kishino(1994) Paul Milgram e Fumio Kishino. A taxonomy of mixed reality visual displays. IEICE Transactions on Information Systems, E77-D(12). Citado na pág. vii, 6

Mitsunaga e Nayar(1999) T. Mitsunaga e S.K. Nayar. Radiometric self calibration. Em Computer Vision and Pattern Recognition, 1999. IEEE Computer Society Conference on., volume 1, página 380 Vol. 1. doi: 10.1109/CVPR.1999.786966. Citado na pág. 13

Nakamae et al.(1986) Eihachiro Nakamae, Koichi Harada, Takao Ishizaki e Tomoyuki Nishita. A montage method: the overlaying of the computer generated images onto a background photograph. Em SIGGRAPH '86 Proceedings of the 13th annual conference on Computer graphics and interactive techniques, páginas 207-214. ISBN 0-89791-196-2. Citado na pág. 20

Neverova et al.(2012) Natalia Neverova, Damien Muselet e Alain Trémeau. Lighting estimation in indoor environments from low-quality images. Em ECCV'12 Proceedings of the 12th international conference on Computer Vision, volume 2, páginas 380-389. ISBN 978-3-642-33868-7. doi: 10.1007/978-3-642-33868-7_38. Citado na pág. 22

$\mathrm{Ng}$ et al.() Ren Ng, Ravi Ramamoorthi e Pat Hanrahan. All-frequency shadows using non-linear wavelet lighting approximation. Em ACM SIGGRAPH 2003 Papers, páginas 376-381. ISBN 1-58113-709-5. Citado na pág. 27

Nvidia(2015) Nvidia. mental-ray. plugin for Maya 2016 Service Pack 4. URL http: //www.nvidia.com/object/mental-ray-standalone.html. Citado na pág. 29 
OpenMP Architecture Review Board(2002) OpenMP Architecture Review Board. OpenMP application program interface version 2.0. URL http://openmp.org/wp/. Citado na pág. 76

Oyster(2014) Fred the Oyster. Parametric continuity c0.svg. URL https://en.wikipedia. org/wiki/File:Parametric_continuity_C0.svg. Citado na pág. xi, 57

Perez et al.(1993) Richard Perez, Robert Seals e Joseph Michalsky. All-weather model for sky luminance distribution - preliminary configuration and validation. Solar Energy, 50 (3):235 - 245. Citado na pág. 22, 24

Pharr e Humphreys(2010) Matt Pharr e Greg Humphreys. Physically Based Rendering. Morgan Kaufmann, 2 edição. ISBN ISBN-13: 978-0123750792. Citado na pág. 9

Phong(1975) Bui Tuong Phong. Illumination for computer generated pictures. Communications of $A C M, 18(6): 311-317$. ISSN 0001-0782. doi: 10.1145/360825.360839. Citado na pág. 8

Pozrikidis(1998) Costas Pozrikidis. Numerical Computation in Science and Engineering. 1 edição. ISBN 0195112539. Citado na pág. 56, 58, 64

Ramamoorthi e Hanrahan(2001) Ravi Ramamoorthi e Pat Hanrahan. An efficient representation for irradiance environment maps. Em SIGGRAPH '01 Proceedings of the 28th annual conference on Computer graphics and interactive techniques, páginas 497-500. ISBN 1-58113-374-X. Citado na pág. 23

Reinhard et al.(2010) Erik Reinhard, Sumanta Pattanaik, Greg Ward, Paul Debevec, Wolfgang Heidrich e Karol Myszkowski. High Dynamic Range Imaging Acquisition, Display And Image-Based Lighting. Morgan Kaufmann, 2 edição. ISBN 978-0-12-374914-7. Citado na pág. $11,15,16$

Robertatac(2011) Robertatac. Hgu55p with scorpion and clear day visor, 2011. URL https://en.wikipedia.org/wiki/File:HGU55P_with_Scorpion_and_Clear_ Day_Visor_5.jpg. Citado na pág. vii, 2

Salgado(2010) ESO/José Francisco Salgado. Imagine being a fly vlt.jpg. URL http://en. wikipedia.org/wiki/File:Imagine_being_a_fly_VLT.jpg. Citado na pág. vii, 14

Sato et al.(1999) Imari Sato, Yoichi Sato e Katsushi Ikeuchi. Acquiring a radiance distribution to superimpose virtual objects onto a real scene. IEEE Transactions on Visualization and Computer Graphics, 5:1-12. Citado na pág. 2, 21

Shen e Cai(2009) Hui-Liang Shen e Qing-Yuan Cai. Simple and efficient method for specularity removal in an image. Applied Optics, 48(14):2711-2719. doi: 10.1364/AO.48. 002711. Citado na pág. 22

Simões(2015) Felipe Simões. Pen. URL http://tf3dm.com/3d-model/pen-27304.html. Citado na pág. 46

Smith(2006) Brad Smith. Phong. URL http://en.wikipedia.org/wiki/File:Phong _ components_version_4.png. Citado na pág. vii, 9

SpheronVR(2016) SpheronVR. Spherocam hdr. URL https://www.spheron.com/ products/cgi-reality-based-visualization.html. Citado na pág. 12 
Supan et al.(2006) Peter Supan, Ines Stuppacher e Michael Haller. Image based shadowing in real-time augmented reality. International Journal of Virtual Reality, 5(3):1-7. Citado na pág. 21

Tanski(2004a) Grzegorz Tanski. Global illumination illustration. URL http://en. wikipedia.org/wiki/File:Global_illumination.JPG. Citado na pág. vii, 9

Tanski(2004b) Grzegorz Tanski. Local illumination illustration. URL http://en.wikipedia. org/wiki/File:Local_illumination.JPG. Citado na pág. vii, 9

The Qt Company(2005) The Qt Company. Qt version 4.0. URL qt.io. Citado na pág. 78

Unger et al.(2013) Jonas Unger, Joel Kronander, Per Larsson, Stefan Gustavson e Anders Ynnerman. Temporally and spatially varying image based lighting using hdr-video. Em EUSIPCO, páginas 1-5. IEEE. Citado na pág. 22

Veerarajan e Ramachandran(2008) T. Veerarajan e T. Ramachandran. Numerical Methods with Programs in C. McGraw-Hill. ISBN 978-0077263744. Citado na pág. 59

Wandell(1995) B.A. Wandell. Foundations of Vision. Sinauer Associates. ISBN 9780878938537. Citado na pág. xiii, 11 